\title{
The catalytic stability of some selected bifunctional nanoporous-based catalysts in the hydroisomerisation of $\mathbf{n}-\mathbf{C} 7$ and the effect of post-synthesis modification techniques
}

\author{
Faisal M. Alotaibi • Raed H. Abudawood • \\ Hamid A. Al-Megren • Mohammed C. Al-Kinany • \\ Essam H. Jamea • Arthur A. Garforth
}

Received: 5 February 2014/ Accepted: 20 March 2014/Published online: 4 April 2014

(c) The Author(s) 2014. This article is published with open access at Springerlink.com

\begin{abstract}
In this work, some commercial and in-house nanoporous-based catalysts, such as USY, beta and mordenite zeolites, and mesoporous aluminosilicate molecular sieves such as MCM-48 and SBA-15, loaded with metals and acting as mono- and bimetallic bifunctional catalysts, were used for hydroisomerisation experiments in a fixedbed reactor at pressures between 1 and 15 bar and at feed space time ranging from 2.57 to $10.26 \mathrm{~h}^{-1}$ (35.14-140.6 kg s mol ${ }^{-1}$ ) to hydroisomerise $n$-heptane over a temperature range of $210-270{ }^{\circ} \mathrm{C}$. The effect of post-synthesis treatments of micro- and mesoporous catalysts was examined, regarding their activity, selectivity and stability, such as acid and steam dealumination techniques, acid leaching via a chelating agent, bimetal loading techniques, different platinum loading methods, and composite or hybrid catalyst generation. Results show that pore architecture is the most important factor affecting coke formation and deactivation in zeolite catalysts. It was found that those catalysts with high $\mathrm{Si} / \mathrm{Al}$ ratios and those
\end{abstract}

F. M. Alotaibi $(\bowtie) \cdot$ H. A. Al-Megren · M. C. Al-Kinany Petrochemicals Research Institute, King Abdulaziz City for Science and Technology (KACST), P.O.Box 6086,

Riyadh 11442, Saudi Arabia

e-mail: fmsalotaibi@kacst.edu.sa

R. H. Abudawood

Research and Development Center, Saudi Aramco, Dhahran 31311, Saudi Arabia

E. H. Jamea

SABIC Technology Center, Saudi Basic Industries Corporation, Riyadh 11551, Saudi Arabia

A. A. Garforth

School of Chemical Engineering and Analytical Science,

The University of Manchester, Manchester M13 9PL, UK which had been acid-leached or steamed showed better activity, higher selectivity towards isomeric products and better time stability. Moreover, the balance between the number of metal sites and the number of acid sites played an important role in determining the activity, selectivity and stability of the bifunctional catalysts. Higher metal loading improves catalytic stability, due to a better balance and closeness of the catalytic functions. Moreover, the bimetallic catalyst improves the formation of smaller metal particles and better dispersion, which may affect selectivity and stability.

Keywords The time-on-stream stability · Alkanes' hydroisomerisation - Catalyst deactivation - Zeolites · Bifunctional catalysts - Nanoporous catalysts $\cdot$ Bimetallic catalysts

\section{Introduction}

Tailoring catalysts to optimise their chemical, physical and mechanical features is the most widely used method of limiting a reduction in catalytic activity. With relatively slow coke formation, the fine tuning of the strength and density of acid sites in zeolites is essential to achieve a sufficiently high activity for the desired reaction. Furthermore, limitations to the diffusion of reactant, product and coke precursor molecules can be reduced by the creation of mesoporosity within zeolite crystals to produce nano-sized crystals, which will slow down coke formation. Appropriate selection of operating conditions is a crucial factor in promoting desorption of the desired products and thus limiting deactivation of the catalyst [1].

Despite the inevitable loss of catalytic activity (catalyst deactivation) in most industrial processes, there are many

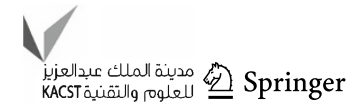


ways to minimise this process and thus extend the lifetime of a catalyst. As the old saying goes, "an ounce of prevention is worth a pound of cure" [2]. The zeolite pore architecture has been found to play an important role for both the deactivation rate as a result of coking and also the composition of the carbonaceous deposits, such that zeolites with relatively large supercage pore systems, such as $\mathrm{Y}$ zeolites, are inherently favourable to coking reactions, which in turn leads to faster deactivation. In contrast, beta zeolite exhibits much better coking resistance, even though both zeolites have three-dimensional systems of channels [3].

The Pt/H-MOR catalyst is the most widely recognised example of a zeolitic isomerisation catalyst. It was first developed to isomerise smaller alkanes such as $n$-pentane and $n$-hexane for the Shell Hysomer process and can bring about a high isomer yield [4]. However, due to the strong tendency of middle paraffin isomerisation (C7-C9 carbon chain length) to undergo cracking, no hydroisomerisation process has yet been used industrially [5]. Strongly acidic zeolites such as H-mordenite have weaknesses as isomerisation catalysts due to the rapidity of their deactivation, particularly by olefinic carbonaceous species. There is therefore a great incentive for academic and industrial researchers to discover and develop new catalysts that are active, selective and able to resist deactivation $[6,7]$. There have been detailed descriptions in the literature of how post-synthesis treatments by steam and acid of several zeolites can reduce the concentration of lattice aluminium and improve thermal/hydrothermal stability and catalytic performance whilst retaining the zeolite crystal structure. It must also be noted that mesopores form as a result of the dealumination of $\mathrm{H}$-mordenite, significantly diminishing the coke's deactivating effect $[8,9]$.

The vast majority of microporous zeolites have pore diameters below $15 \AA$, leading to very high mass transfer limitations; hence, the intracrystalline diffusion of species inside the pores of zeolites is severely limited, which affects their catalytic activity and significantly reduces their product selectivity, because the increased residence time of the products in the zeolite pores favours undesired reactions such as over-cracking. Because of this limitation, there has been much work to find creative ways to eliminate the mass transfer problem. Moreover, the formation of mesopores can favour the formation of more branched or bulkier products. Evidently, generating a network of mesopores in zeolites crystals would offer numerous advantages for a great number of reactions [10]. Mesoporous aluminosilicate molecular sieves, such as SBA-15 and MCM-48, which have high surface area, large pore diameters and narrow pore size distribution and which possess uniform hexagonal and cubic one- and three-dimensional pore systems, respectively, are thus supposedly more resistant to pore blocking, which allows faster diffusion of reactants. However, they have been shown to be inferior to microporous zeolites in their acid strength and despite their larger pore diameters, which make them more able to deal with bulky molecules, they do not show higher activity than zeolites, e.g. in heavy oil cracking and the catalytic conversion of large molecules in vacuum gas oil and distillation residues. Thus, many significant improvements in both the hydrothermal stability and acidity of mesostructured aluminosilicates have been recently reported [11-13].

In this work, the time-on-stream (TOS) behaviour and deactivation rates of some commercial USY, beta and mordenite zeolites and mesoporous aluminosilicate molecular sieves such as Al-MCM-48 and Al-SBA-15 that have been loaded with platinum metal, with a wide range of $\mathrm{Si} / \mathrm{Al}$ ratios, pore sizes and acidity characteristics, are evaluated in the hydroisomerisation of $\mathrm{n}-\mathrm{C} 7$ when reaction conditions such as temperature, pressure and contact time are varied. n-C7 was used as a representative model compound for naphtha. A number of post-synthetic methods have been adopted to improve the catalytic properties of zeolites, such as acidity, porosity and thermal and hydrothermal stability, as these modifications are hard to achieve directly during zeolite synthesis. The main methods are ion exchange, dealumination by acid leaching or acid chelating, and stabilising through hydrothermal treatment (steaming), mono- and bimetallic effects.

\section{Experimental}

\section{Catalyst preparation}

Some commercial USY, beta, mordenite, and mesoporous aluminosilicates samples were provided by different suppliers [14-20], as shown in Table 1. These zeolite supports were designed and modified by various post-synthesis techniques so that they could be used for multiple purposes; for instance, high alkane hydroconversions like cracking, isomerisation and alkylation. They were supplied in powder form without binder materials. The in-house mordenite zeolite sample was synthesised with different properties from those of the commercial mordenite samples, then post-synthesis modified by acid and steam dealumination techniques under different treatment conditions.

USY-A, USY-C, 320HOA and 350HOA samples were subjected to post-synthetic modification by treating with AHFS to remove any EFAL. Three series of bifunctional catalysts supported on 350HOA USY were also prepared: monometallic types containing only platinum or nickel were prepared by the ion-exchange method, while the method used for bimetallic ones containing both platinum and nickel was simultaneous competitive ion exchange. 
Table 1 List of catalyst supports investigated in the TOS study

\begin{tabular}{|c|c|c|c|c|}
\hline & $\begin{array}{l}\text { Zeolite } \\
\text { trade } \\
\text { name }\end{array}$ & Zeolite type & $\begin{array}{l}\text { Post-synthesis } \\
\text { modification }\end{array}$ & Supplier \\
\hline 1 & USY-A & USY & Mildly steamed & Crosfield \\
\hline 2 & USY-C & USY & Severely steamed & Crosfield \\
\hline 3 & $320 \mathrm{HOA}$ & USY & $\begin{array}{l}\text { Moderately } \\
\text { steamed }\end{array}$ & $\begin{array}{l}\text { Tosoh } \\
\text { corporation }\end{array}$ \\
\hline 4 & $350 \mathrm{HOA}$ & USY & $\begin{array}{l}\text { Moderately } \\
\text { steamed and } \\
\text { acid } \\
\text { leached }\end{array}$ & $\begin{array}{l}\text { Tosoh } \\
\text { corporation }\end{array}$ \\
\hline 5 & CP814E & BEA & As synthesised & $\begin{array}{l}\text { Zeolyst } \\
\text { international }\end{array}$ \\
\hline 6 & Al-MCM-48 & $\begin{array}{l}\text { Mesoporous } \\
\text { aluminosilicates }\end{array}$ & $\begin{array}{l}\text { Aluminated by } \\
\text { grafting }\end{array}$ & Claytec \\
\hline 7 & Al-SBA-15 & $\begin{array}{l}\text { Mesoporous } \\
\text { aluminosilicates }\end{array}$ & $\begin{array}{l}\text { Aluminated by } \\
\text { grafting }\end{array}$ & Claytec \\
\hline
\end{tabular}

Finally, two series of dealuminated mordenite catalysts were prepared by acid leaching under different conditions and by applying the steaming dealumination technique at different temperatures to the in-house synthesised mordenite in its ammonium form.

\section{Hydrothermal synthesis of mordenite zeolite}

The recipe for mordenite zeolite was obtained from a verified synthesis handbook [21]. Gel calculations to determine the required weights of each reactant were performed using the synthesis molar gel composition of $6 \mathrm{Na}_{2} \mathrm{O}: \mathrm{Al}_{2} \mathrm{O}_{3}: 30$ $\mathrm{SiO}_{2}: 780 \mathrm{H}_{2} \mathrm{O}$. Therefore, calculated weights of deionised water and sodium hydroxide ( $99 \mathrm{wt} \% \mathrm{NaOH})$ from Merck and sodium aluminate $\left(50.9 \mathrm{wt} \% \quad \mathrm{Al}_{2} \mathrm{O}_{3}+31.2 \mathrm{wt} \%\right.$ $\mathrm{Na}_{2} \mathrm{O}+17.9$ wt $\% \mathrm{H}_{2} \mathrm{O}$ ) from Sigma-Aldrich were mixed in a plastic bottle until they were completely dissolved. The required amount of Ludox AS-40 colloidal silica (40 wt $\%$ silica +60 wt $\%$ water) from Sigma-Aldrich was then added to the solution and all were stirred using a magnetic stirrer for $12 \mathrm{~h}$, after which the mixture was poured into a Teflon-lined stainless-steel autoclave and heated in an oven at $180{ }^{\circ} \mathrm{C}$ for crystallisation. After $24 \mathrm{~h}$ crystallisation time, the mixture was taken out of the oven, decanted and centrifuged several times while washing with deionised water after each centrifugation until the $\mathrm{pH}$ of the decanted solution dropped below 9. Finally, the samples were dried at $110{ }^{\circ} \mathrm{C}$ overnight until they were ready for characterisation. The optimum mordenite phase with the highest purity and crystallinity was optimised against some synthesis parameters while keeping the composition ratio of $\mathrm{Na}_{2} \mathrm{O}-\mathrm{Al}_{2} \mathrm{O}_{3}-$ $\mathrm{SiO}_{2}-\mathrm{H}_{2} \mathrm{O}$ constant at the above molar gel composition. Three factors were optimised: the ageing time of the synthesis gel, the crystallisation time and the crystallisation temperature. It was found that the optimum synthesis conditions were an ageing time of $12 \mathrm{~h}$, crystallisation time of $24 \mathrm{~h}$ and crystallisation temperature of $180{ }^{\circ} \mathrm{C}$. This procedure was repeated more than 10 times and reproducible results were obtained, in terms both of the yields, crystallinity, bulk and framework $\mathrm{Si} / \mathrm{Al}$ ratio and of the crystal morphology and size.

Post-synthesis modification techniques

\section{Ion exchange}

The procedure of ion exchange is carried out simply by immersing zeolite in a solution of the salt of the targeted cation at room temperature or a higher temperature if the exchange rate is to be improved [22], since the Brønsted acid site is generated after the modification of the parent zeolite in its sodium form by first exchanging the sodium ion with ammonium, then calcining the zeolite in the ammonium form at high temperatures to transform it into the hydrogen form. One gram of the parent commercial zeolites in their sodium form-320HOA and CBV10Aand in-house as-synthesised mordenite zeolite were dissolved in $100 \mathrm{ml}$ of $0.5 \mathrm{M}$ ammonium nitrate, (99 wt\% purity, Sigma-Aldrich) and heated at $80{ }^{\circ} \mathrm{C}$ under reflux conditions and constant stirring for $1 \mathrm{~h}$. This process was performed three times (multiple ion exchange) assuming a complete uptake of ammonium in the catalysts. The mixtures obtained were centrifuged, washed with deionised water until $\mathrm{pH}$ was 7 , then dried at $100{ }^{\circ} \mathrm{C}$ overnight. After three ion exchanges, residual $\mathrm{Na}$ was determined by inductively coupled plasma (ICP) elemental analysis to be below $0.05 \mathrm{wt} \%$.

\section{Acid leaching}

The treatment of zeolites by acid leaching leads to dealumination, which generally improves their efficiency in processes that result in rapid catalyst deactivation through coking, such as cracking. Acid leaching results in an increase in the $\mathrm{Si} / \mathrm{Al}$ ratio through the removal of tetrahedral aluminium atoms from the framework and the subsequent introduction of mesopores into the structure, thus enhancing the thermal stability of the zeolite. It has the advantage of not forming EFAL inside the zeolite structure, as happens when $\mathrm{Al}$ is removed by steaming [23-26]. Acid attack was carried out by heating a suspension of in-house as-synthesised mordenite in its ammonium form $\left(\mathrm{NH}_{4}-\right.$ MOR) in nitric acid or hydrochloric acid (BDH Chemicals) under reflux conditions and constant stirring under the acid leaching conditions listed in Table 2. The suspension was then filtered, washed with distilled water and dried at $110{ }^{\circ} \mathrm{C}$ overnight until it was ready for characterisation. 
Table 2 Conditions of acid leaching by mineral acids

\begin{tabular}{|c|c|c|c|c|c|c|}
\hline Condition & $\begin{array}{l}\mathrm{NH}_{4}^{-} \\
\mathrm{MOR} \\
(\mathrm{wt})\end{array}$ & $\begin{array}{l}\text { Acid } \\
\text { type }\end{array}$ & $\begin{array}{l}\text { Acid } \\
\text { conc. } \\
\text { (molar) }\end{array}$ & $\begin{array}{l}\text { Acid, } \\
\text { vol. } \\
\text { (ml) }\end{array}$ & $\begin{array}{l}\text { Leaching } \\
\text { time (h) }\end{array}$ & $\begin{array}{l}\text { Temp } \\
\left({ }^{\circ} \mathrm{C}\right)\end{array}$ \\
\hline 1 & 1 & $\mathrm{HCl}$ & 6 & 50 & 12 & 25 \\
\hline 2 & 1 & $\mathrm{HCl}$ & 6 & 50 & 24 & 25 \\
\hline 3 & 1 & $\mathrm{HCl}$ & 6 & 100 & 24 & 25 \\
\hline 4 & 1 & $\mathrm{HCl}$ & $\begin{array}{l}12.1 \\
\quad(\text { conc })\end{array}$ & 100 & 24 & 120 \\
\hline 5 & 1 & $\mathrm{HNO}_{3}$ & 10 & 100 & 16 & 25 \\
\hline 6 & 1 & $\mathrm{HNO}_{3}$ & 6 & 50 & 24 & 25 \\
\hline 7 & 1 & $\mathrm{HNO}_{3}$ & $\begin{array}{l}15.8 \\
(\text { conc })\end{array}$ & 100 & 24 & 25 \\
\hline 8 & 1 & $\mathrm{HNO}_{3}$ & $\begin{array}{l}15.8 \\
\quad(\text { conc })\end{array}$ & 50 & 24 & 25 \\
\hline 9 & 1 & $\mathrm{HNO}_{3}$ & $\begin{array}{l}15.8 \\
\quad(\text { conc })\end{array}$ & 100 & 24 & 120 \\
\hline 10 & 1 & $\mathrm{HNO}_{3}$ & 6 & 100 & 24 & 120 \\
\hline 11 & 1 & $\mathrm{HNO}_{3}$ & 6 & 100 & 48 & 120 \\
\hline 12 & 2 & $\mathrm{HNO}_{3}$ & 10 & 100 & 24 & 120 \\
\hline 13 & 1 & $\mathrm{HNO}_{3}$ & 10 & 100 & 16.5 & 120 \\
\hline 14 & 1 & $\mathrm{HNO}_{3}$ & 10 & 100 & 48 & 120 \\
\hline 15 & 1 & $\mathrm{HNO}_{3}$ & 10 & 100 & 87 & 120 \\
\hline 16 & 1 & $\mathrm{HNO}_{3}$ & 10 & 100 & 168 & 120 \\
\hline
\end{tabular}

Table 3 Conditions of acid leaching by AHFS

\begin{tabular}{llllll}
\hline Sample & $\begin{array}{l}\text { AHFS, } \\
\text { wt }(\mathrm{g})\end{array}$ & $\begin{array}{l}\text { 320USY, } \\
\text { wt }(\mathrm{g})\end{array}$ & $\begin{array}{l}\text { Mixing } \\
\text { time }(\mathrm{h})\end{array}$ & $\begin{array}{l}\text { Temp } \\
\left({ }^{\circ} \mathrm{C}\right)\end{array}$ & $\begin{array}{l}\text { Mixture } \\
\text { volume }(\mathrm{ml})\end{array}$ \\
\hline
\end{tabular}

Optimising the mixture volume

$\begin{array}{lllllr}\text { F1 } & 0.6 & 2 & 1 & 25 & 25 \\ \text { F2 } & 0.6 & 2 & 1 & 25 & 50 \\ \text { F3 } & 0.6 & 2 & 1 & 25 & 75 \\ \text { F4 } & 0.6 & 2 & 1 & 25 & 100\end{array}$

Optimising the mixing time

$\begin{array}{lllcll}\text { F2 } & 0.6 & 2 & 1 & 25 & 50 \\ \text { F5 } & 0.6 & 2 & 3.5 & 25 & 50 \\ \text { F6 } & 0.6 & 2 & 7 & 25 & 50 \\ \text { F7 } & 0.6 & 2 & 14 & 25 & 50\end{array}$

Optimising the AHFS weight

$\begin{array}{llllll}\text { F8 } & 0.3 & 2 & 1 & 25 & 50 \\ \text { F2 } & 0.6 & 2 & 1 & 25 & 50 \\ \text { F9 } & 1.2 & 2 & 1 & 25 & 50\end{array}$

Optimising the mixture temperature

\begin{tabular}{llllrl} 
F2 & 0.6 & 2 & 1 & 25 & 50 \\
F10 & 0.6 & 2 & 1 & 50 & 50 \\
F11 & 0.6 & 2 & 1 & 75 & 50 \\
F12 & 0.6 & 2 & 1 & 100 & 50 \\
\hline
\end{tabular}

AHFS solution was used to remove EFAL from the USY samples: USY-A, USA-C, 320HOA and 350HOA. The $320 \mathrm{HOA}$ sample containing $2 \mathrm{wt} \%$ sodium with the ammonium form as the starting material was fine tuned using AHFS as a chelating compound to provide the best conditions to remove only the EFAL whilst maintaining the aluminium framework and original zeolite crystallinity. Thus, four main factors were considered when optimising the chemical treatments: the AHFS and USY mixture volume, the treatment duration time, the zeolite-to-AHFS weight ratio and the temperature of chemical treatment, as shown in Table 3. The zeolite-to-AHFS mass ratio was optimised in the range of 1.67-6.67. For AHFS treatments, $2 \mathrm{~g}$ of the steamed zeolite USY samples was placed in AHFS (99.999\% trace metals basis, Sigma-Aldrich) solution and the suspension was heated to the required temperature and stirred whilst being heated with refluxing. The suspension was filtered, washed by warm deionised water to remove any residual fluoride species until $\mathrm{pH}$ was 7 , and then dried at $100{ }^{\circ} \mathrm{C}$ overnight. The solid obtained was subjected to three ion exchanges in ammonium nitrate solution in order to eliminate sodium and any residual fluoride species.

\section{Steaming}

Steaming or hydrothermal treatment dealumination involves calcining zeolites in the ammonium (or hydrogen) form, in the presence of steam at high temperatures. This results in the removal of aluminium atoms from the zeolite framework and their replacement by silicon atoms, thus increasing the $\mathrm{Si} / \mathrm{Al}$ ratio of the framework. However, the aluminium atoms which have been removed remain in the zeolite as EFAL species, which can lead to enhanced acidity through the formation of Lewis acid sites [23]. The formation of EFAL species occurs through the migration of aluminium from the framework into the outer surface of crystals and is rate-controlled, which means that it can be accelerated or slowed down by changing the steaming temperature [27]. The in-house as-synthesised $\mathrm{NH}_{4}-\mathrm{MOR}$ was dealuminated by steaming at 500,600 and $700{ }^{\circ} \mathrm{C}$ for $12 \mathrm{~h}$ at each steaming temperature, using a fixed-bed laboratory microreactor. Deionised water was fed to the reactor using a high-performance liquid chromatography (HPLC) pump at a controlled flow rate of $0.125 \mathrm{ml} \mathrm{min}^{-1}$. Nitrogen carrier gas (BOC, oxygen free) was dried by passage through a bed of molecular sieves and fed into the reactor at a controlled flow rate of $187.5 \mathrm{ml} \mathrm{min}{ }^{-1}$ using a mass flow controller. The catalyst $(1 \mathrm{~g}$, bed particle size of 40 and 60 mesh) was located in the reactor between two beds of glass wool in the centre of the heated stable zone of the furnace. In a typical experiment, the $\mathrm{NH}_{4}$-MOR was heated from ambient temperature to the required reactor temperature of $500{ }^{\circ} \mathrm{C}$ at a rate of $3{ }^{\circ} \mathrm{C} \mathrm{min}{ }^{-1}$ in a flow of air $\left(50 \mathrm{ml} \mathrm{min}^{-1}\right)$ at ambient pressure for $2 \mathrm{~h}$. When these conditions had stabilised, the water was introduced to the 
reactor. At the end of the required time period $(12 \mathrm{~h}$ for steaming), the water feed was stopped and the catalyst was then cooled in a stream of dry nitrogen.

\section{Metal loading}

Metals from group VIII, such as platinum and nickel, are commonly loaded onto the zeolites used in commercial refining processes as bifunctional catalysts, having both a hydrogenation/dehydrogenation function provided by the metal and an acidic function provided by the zeolite acid sites [28, 29]. A common method for preparing bifunctional catalysts is a multi-step process consisting mainly of the deposition of a metal precursor compound over the support surface, either by impregnation, ion exchange or mechanical mixing; the drying and calcination of the catalysts; and the transformation of the precursor compound into the active metallic phase by reduction. It is well established that the metal dispersion and thus the metal/ acid ratio depend markedly on the way the metal is introduced [30]. The catalysts listed in Table 1 were loaded with $1 \mathrm{wt} \%$ platinum via the ion-exchange technique using an amino complex of platinum, and were fully described in a previous work [29-31]. The CP814E catalyst was loaded with $1 \mathrm{wt} \%$ platinum by wet impregnation using tetraammine platinum (II) chloride, at room temperature with excess solution under constant stirring overnight, followed by evaporation at $70{ }^{\circ} \mathrm{C}$ and drying at $110{ }^{\circ} \mathrm{C}$. A series of monometallic and bimetallic bifunctional catalysts was formed by loading 350HOA USY with different amounts of platinum, nickel and platinum-nickel by competitive ion exchange. The first series comprised monometallic bifunctional catalysts containing $0.5,1,1.5$ and $2 \mathrm{wt} \%$ of platinum, the second was a series of monometallic bifunctional catalysts containing $0.5,1,1.5,2,10$ and 20 wt\% of nickel and the third series was of bimetallic bifunctional catalysts containing $1 \mathrm{wt} \%$ of platinum and $0.25,0.5,0.75$ and $1 \mathrm{wt} \%$ of nickel. The monometallic catalysts were prepared using the ion-exchange method, while the method used for the bimetallic catalysts was simultaneous competitive ion exchange, which means that the platinum and nickel precursors, $\mathrm{Pt}\left(\mathrm{NH}_{3}\right)_{4} \mathrm{Cl}_{2} \mathrm{H}_{2} \mathrm{O}$ and $\mathrm{Ni}\left(\mathrm{NO}_{3}\right)_{2} 6 \mathrm{H}_{2} \mathrm{O}$ (Fischer Chemical, $98 \%$ purity), respectively, were mixed with the zeolite at the liquid-to-solid ratio of $50(1 \mathrm{~g}$ of zeolite to $50 \mathrm{ml}$ of the metal complex solution), using ammonium hydroxide solution to adjust the $\mathrm{pH}$ of the suspension obtained at $>9$.

Composite catalysts

Two composite bifunctional catalysts consisting of beta and USA zeolites were prepared as follows: (1) the $1 \mathrm{wt} \% \mathrm{Pt} /$ CP814E and $1 \mathrm{wt} \% \mathrm{Pt} / \mathrm{USY}-\mathrm{C}$ catalysts were mixed physically at a mass ratio of $1: 1$; (2) CP814E and USY-C in their ammonium forms were mixed at a mass ratio of $1: 1$ and were loaded by $1 \mathrm{wt} \% \mathrm{Pt}$ using the ion-exchange method.

\section{Catalyst characterisation}

Characterisation techniques used were ICP optical emission spectroscopy (ICP-OES), X-ray diffraction (XRD), ${ }^{27} \mathrm{Al}$ and ${ }^{29} \mathrm{Si}$ MAS-solid-state NMR, pyridine adsorption Fourier transform infrared spectroscopy, ammonia temperature programmed desorption $\left(\mathrm{NH}_{3}-\mathrm{TPD}\right)$, scanning electron microscopy and energy dispersive $\mathrm{X}$-ray analysis (SEM), transmission electron microscopy (TEM), X-ray photoelectron spectroscopy (XPS), hydrogen chemisorption of platinum, BET surface area analysis by nitrogen adsorption, and thermogravimetric analysis (TGA).

Catalyst loading and testing

It was fully described in a previous work [31].

\section{Results and discussion}

\section{Deactivation behaviour of 320HOA USY zeolite}

320HOA USY zeolite was supplied by Tosoh Corporation in the form of a white powder with particle sizes between 6 and $10 \mu \mathrm{m}$ [15]. Figures 1 and 2 show the XRD pattern and SEM microgram of $320 \mathrm{HOA}$ USY, respectively, and Table 4 shows the in-house characterisation of 320HOA USY using various techniques.

USY zeolite structure was confirmed from the XRD pattern for a fresh sample with $2 \mathrm{wt} \%$ sodium content as supplied, 320HOA USY has a lower crystallinity but a

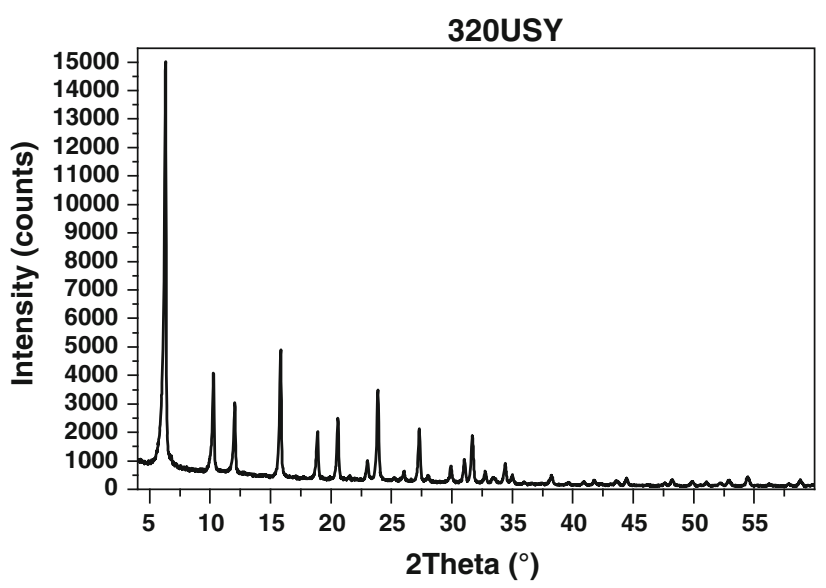

Fig. 1 XRD pattern of 320HOA USY

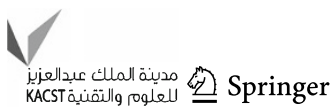




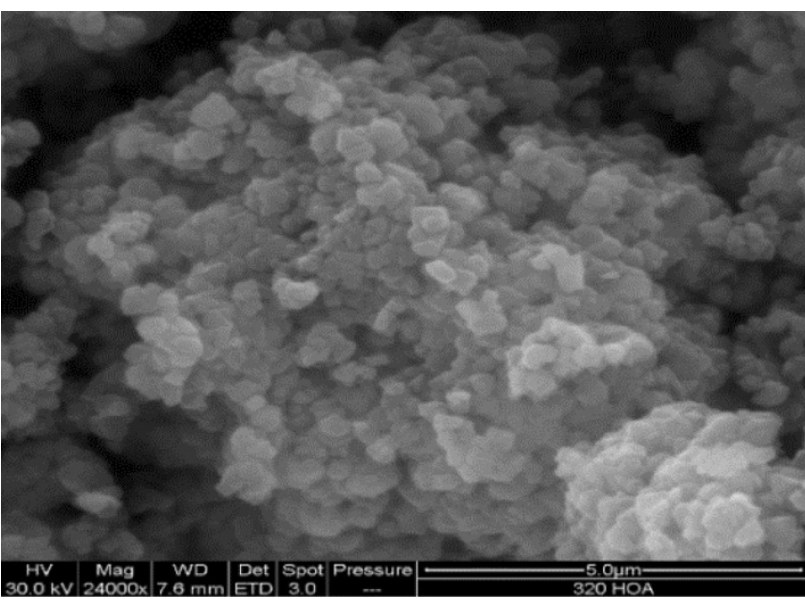

Fig. 2 SEM micrograph of 320HOA USY

higher unit cell size compared with CBV712 USY and CBV720 USY as explained in the previous work [31]. This can be related to the fact that $320 \mathrm{HOA}$ USY was produced via less steaming dealumination process and that no acid leaching was applied afterwards, which can be confirmed by the lower bulk $\mathrm{Si} / \mathrm{Al}$ molar ratio. As a result, a reduced amount of unit cell size shrinking occurred. The rounded edged cubic crystallites, ranging in size between 1 and $3 \mu \mathrm{m}$, are combined with an amorphous phase which normally surrounds the zeolite Y crystals after the dealumination process, as is confirmed by the SEM images shown in Fig. 2. The ${ }^{27} \mathrm{Al}$ solid-state NMR for this USY catalyst, as shown in Fig. 3, indicated the presence of non-framework aluminium species as penta- and octa-coordinated aluminium, besides the tetrahedral aluminium framework. Four chemical environments were also obtained for $\mathrm{Si}$, as shown in Fig. 4 for the ${ }^{29} \mathrm{Si}$ NMR solid state, which confirms that a shorter dealumination process was necessary to produce $320 \mathrm{HOA}$ USY. In addition, the Si/Al molar ratio for the framework was calculated to be 6.3, compared with 8.34 and 31.2 for CBV712 and CBV720 USY, respectively. Moreover, the ${ }^{27} \mathrm{Al}$ NMR peaks shapes and their corresponding chemical shifts were totally different from those for CBV712 and CBV720 USY, which may be explained by the different dealumination conditions that were applied to create these catalysts in the different structures. It can be concluded that most USY catalysts

Table 4 In-house characterisation of 320HOA USY

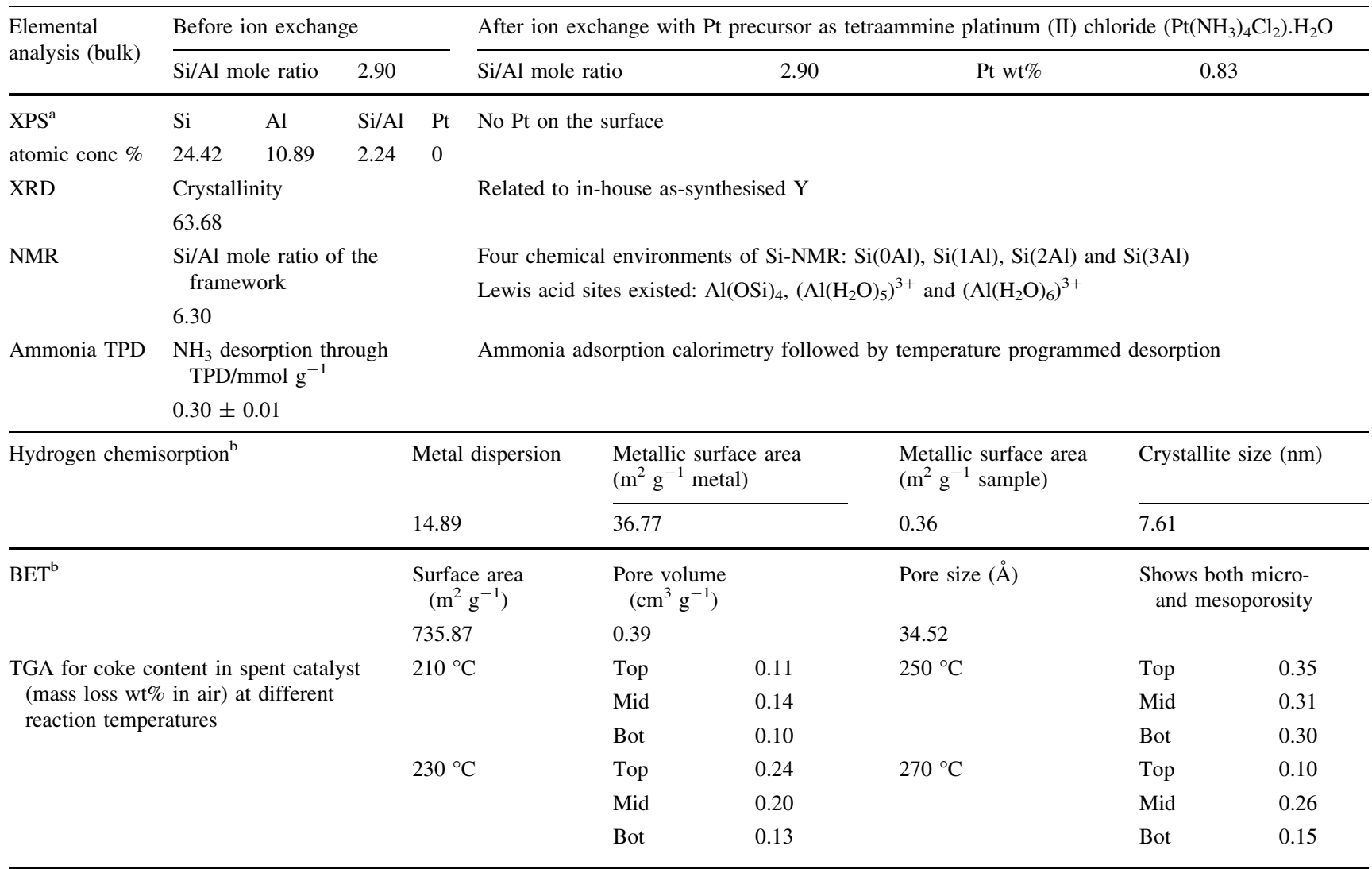

${ }^{a}$ LPD Laboratory Services Ltd.

${ }^{b}$ MCA Services 
Fig. $3{ }^{27} \mathrm{Al}$ NMR spectra of 320HOA USY

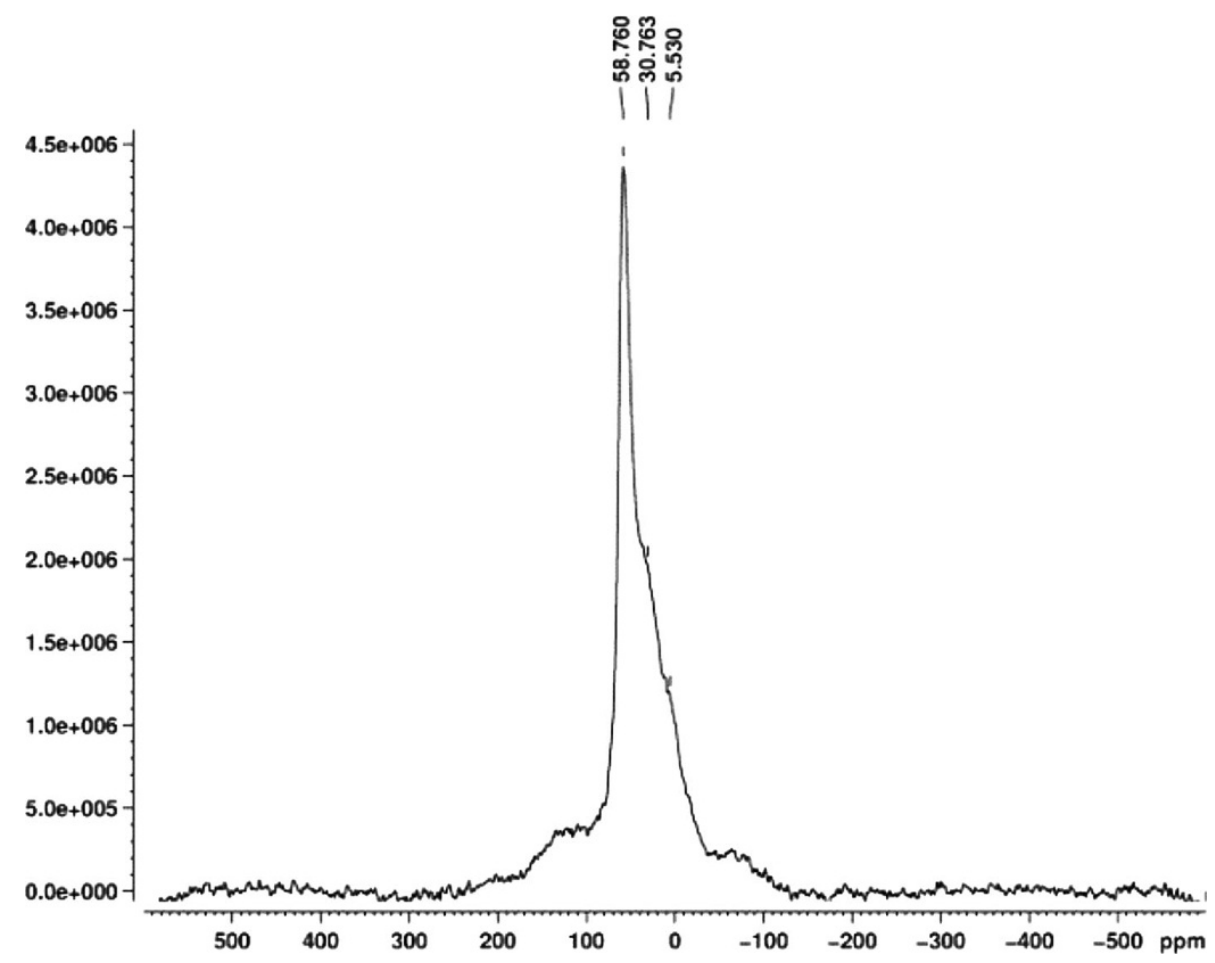

Fig. $4{ }^{29} \mathrm{Si}$ NMR spectra of 320HOA USY

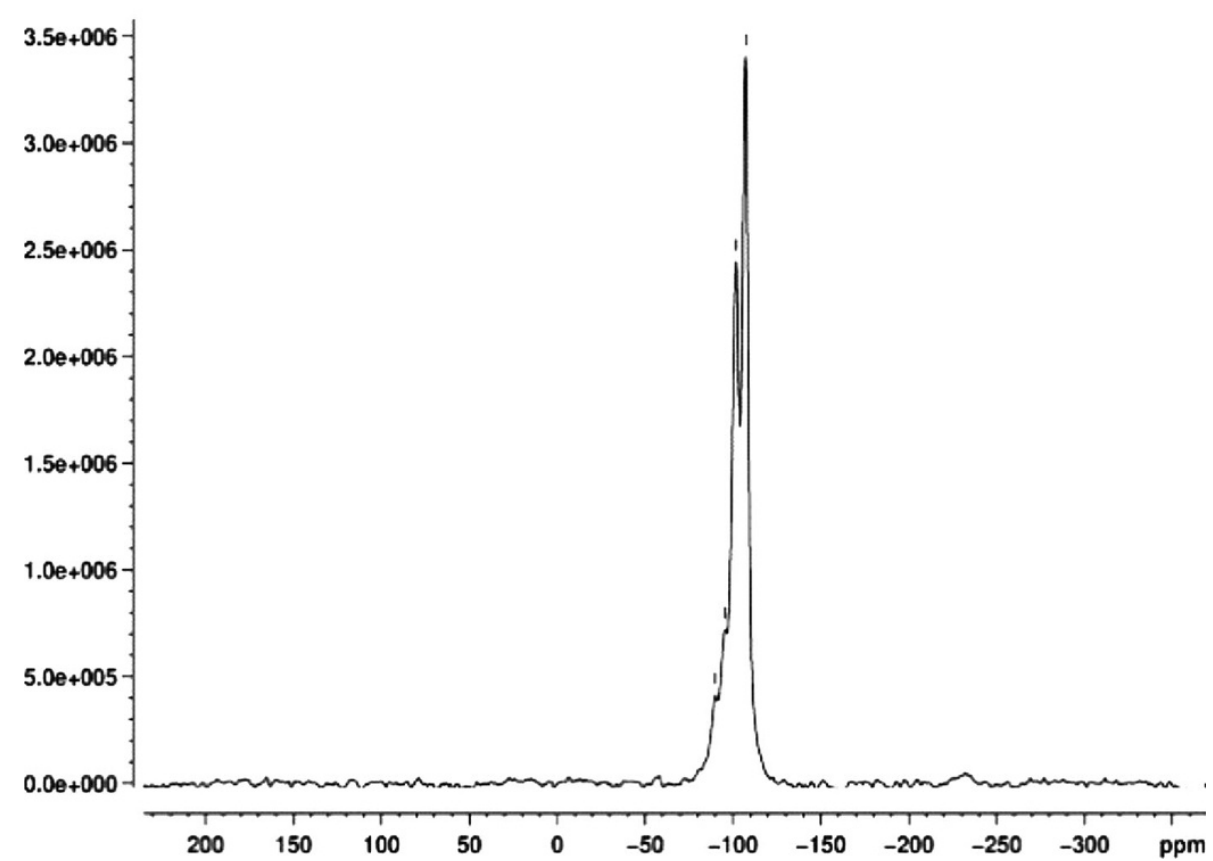

have non-framework aluminium species; the nature and crystallographic locations within the zeolite cavities of USY catalysts are different from other catalysts, due to the dealumination conditions that have been applied to create them. Similar observations can be made for the ${ }^{27} \mathrm{Al} N \mathrm{NR}$ peak shapes and the corresponding chemical shifts for USY-A compared with 320 HOA USY as was described in [31]. They were all produced via steaming with no acid leaching, which is clearly reflected in their catalytic performance and deactivation behaviour. 

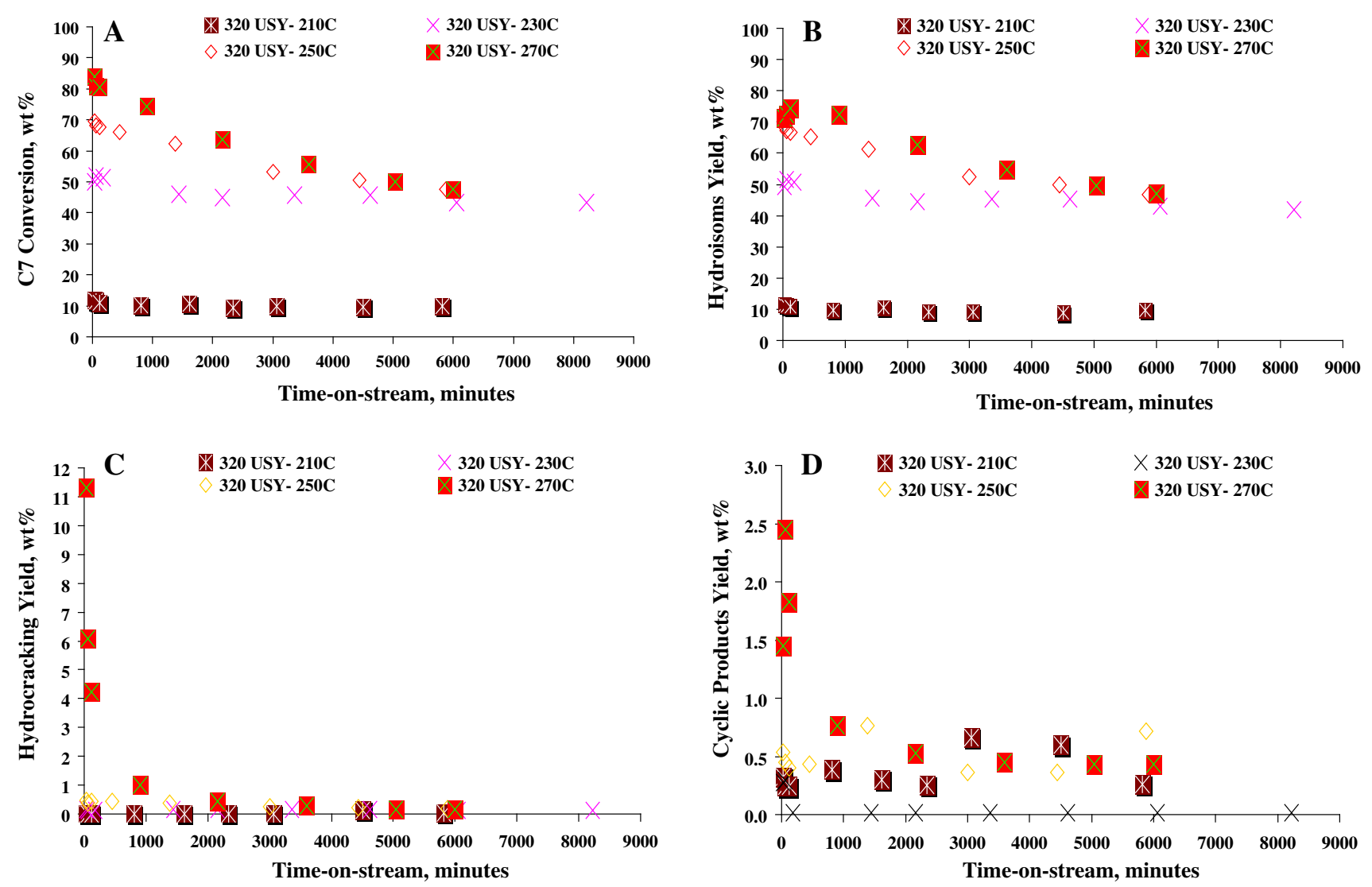

Fig. 5 Overall conversion (a), total yield of C7 isomers (mono $+\mathrm{di}+$ tribranched isomers) (b), total hydrocracking yield (c), total yield of the cyclic products (d) as a function of TOS for

The effect of TOS for the C7 conversion, hydroisomerisation, hydrocracking, and cyclic product yields at different reaction temperatures $210-270{ }^{\circ} \mathrm{C}$ are shown in Fig. 5a-d. Fresh catalyst was used for each run at each different temperature. Initially, the overall conversions were $12,50,70$, and $84 \mathrm{wt} \%$ after $30 \mathrm{~min}$ following introduction of the feed to the reactor at the temperatures of $210,230,250$, and $270{ }^{\circ} \mathrm{C}$, respectively. At $210^{\circ} \mathrm{C}$, the catalyst lost about $1-2 \mathrm{wt} \%$ of its activity before levelling off and reaching a constant value after $60 \mathrm{~h}$ on stream, whereas the deactivation rate at $230{ }^{\circ} \mathrm{C}$ for the new activated catalyst was slightly faster, as can be seen in Fig. 5a. The overall conversion was $50 \mathrm{wt} \%$ after $30 \mathrm{~min}$ from the point at which the feed was introduced to the reactor, which then decreased with the TOS to $46 \mathrm{wt} \%$ after the first $24 \mathrm{~h}$, and then decreased slowly within the deactivation rate range of $2-3 \mathrm{wt} \%$ every $24 \mathrm{~h}$ until the reaction terminated after about 6 days $(140 \mathrm{~h})$. A moderate drop in the catalyst activity occurred during the first few hours at the higher temperatures of 250 and $270{ }^{\circ} \mathrm{C}$, after which a constant deactivating value was reached, ranging from 3 to $5 \mathrm{wt} \%$ every $24 \mathrm{~h}$, until the reaction terminated. The initial selectivity towards the hydroisomerisation products was

$320 \mathrm{HOA}$ USY at various reaction temperatures. WHSV $=5.13 \mathrm{~h}^{-1}$; $\mathrm{H}_{2} / \mathrm{C} 7(\mathrm{~mol} / \mathrm{mol})=9 ;$ total pressure $=1 \mathrm{~atm} ;$ temperature $=210$, 230, 250 and $270{ }^{\circ} \mathrm{C} ; 1 \mathrm{wt} \%$ Pt loading

98.5 and $84 \%$ after 30 min following introduction of the feed to the reactor, which then increased throughout the TOS to 99 and $92 \%$ after $120 \mathrm{~min}$ at 250 and $270{ }^{\circ} \mathrm{C}$, respectively. The maximum isomer yield obtained was around $71 \mathrm{wt} \%$ at $270{ }^{\circ} \mathrm{C}$ and around $68 \mathrm{wt} \%$ at $250{ }^{\circ} \mathrm{C}$, and selectivity towards cracked products was fairly high at the higher temperatures during the first few hours of the deactivation reaction. The highest selectivity for cracked products was $13.5 \% 30 \mathrm{~min}$ after introducing the feed to the reactor at $270{ }^{\circ} \mathrm{C}$, decreasing rapidly throughout the TOS and finally reaching $5 \mathrm{wt} \%$ after $120 \mathrm{~min}$. The yield of cyclic products at the temperatures of 250 and $270{ }^{\circ} \mathrm{C}$ was also higher than at the lower temperatures.

It has been found that after the deactivation runs at temperatures of $210-270{ }^{\circ} \mathrm{C}$, the hard coke content is lower than that found for the previously studied catalysts: CBV712USY, CBV720USY, and USY-A [31], which can be linked to the acidity properties of each catalyst. Thus, it can be seen that 320HOA USY has a lower acidity than the above catalysts resulting in a lower cracking activity and thus a lower coke formation. However, the negative effect of the presence of extra-framework $\mathrm{Al}$ species (EFAL) could be expected to be lower in $320 \mathrm{HOA}$ USY due to the pore 
Table 5 The C7 conversion (wt \%), product yield (wt \%), and product selectivity (\%) at different reaction conditions using the pressure rig for $1 \mathrm{wt} \% \mathrm{Pt} / 320 \mathrm{HOA}$ USY

\begin{tabular}{|c|c|c|c|c|c|c|c|}
\hline & Conversion (wt\%) & $\begin{array}{l}\text { Hydroisoms } \\
\text { yield (wt } \%)\end{array}$ & $\begin{array}{l}\text { Hydrocrack } \\
\text { yield (wt } \%)\end{array}$ & $\begin{array}{l}\text { Cyclic yield } \\
(\mathrm{wt} \%)\end{array}$ & $\begin{array}{l}\text { Hydroisoms } \\
\text { selectivity (\%) }\end{array}$ & $\begin{array}{l}\text { Hydrocrack } \\
\text { selectivity }(\%)\end{array}$ & $\begin{array}{l}\text { Cyclic } \\
\text { selectivity }(\%)\end{array}$ \\
\hline WHSV $\left(\mathrm{h}^{-1}\right)$ & $T=210^{\circ} \mathrm{C}, P=1 \mathrm{bar}$ & & & & & & \\
\hline 2.57 & 28.45 & 28.16 & 0.01 & 0.29 & 98.97 & 0.02 & 1.01 \\
\hline 5.13 & 16.89 & 16.64 & 0.00 & 0.24 & 98.56 & 0.00 & 1.44 \\
\hline 10.26 & 7.99 & 7.73 & 0.00 & 0.26 & 96.76 & 0.00 & 3.23 \\
\hline WHSV $\left(h^{-1}\right)$ & $T=210^{\circ} \mathrm{C}, P=8$ bar & & & & & & \\
\hline 2.57 & 3.54 & 3.25 & 0.00 & 0.29 & 91.73 & 0.00 & 8.27 \\
\hline 5.13 & 4.27 & 3.98 & 0.00 & 0.29 & 93.14 & 0.00 & 6.86 \\
\hline 10.26 & 0.52 & 0.27 & 0.00 & 0.25 & 52.70 & 0.00 & 47.30 \\
\hline WHSV $\left(\mathrm{h}^{-1}\right)$ & $T=210^{\circ} \mathrm{C}, P=15 \mathrm{bar}$ & & & & & & \\
\hline 2.57 & 0.46 & 0.24 & 0.00 & 0.22 & 51.84 & 0.00 & 48.16 \\
\hline 5.13 & 0.77 & 0.54 & 0.00 & 0.23 & 69.70 & 0.00 & 30.17 \\
\hline 10.26 & 3.97 & 3.72 & 0.00 & 0.26 & 93.51 & 0.00 & 6.49 \\
\hline Pressure (bar) & $T=210^{\circ} \mathrm{C}, \mathrm{WHSV}=5.13 \mathrm{~h}^{-1}$ & & & & & & \\
\hline 1 & 16.89 & 16.64 & 0.00 & 0.24 & 98.56 & 0.00 & 1.44 \\
\hline 8 & 4.27 & 3.98 & 0.00 & 0.29 & 93.14 & 0.00 & 6.86 \\
\hline 15 & 0.77 & 0.54 & 0.00 & 0.23 & 69.70 & 0.00 & 30.17 \\
\hline WHSV $\left(\mathrm{h}^{-1}\right)$ & $T=230^{\circ} \mathrm{C}, P=1$ bar & & & & & & \\
\hline 2.57 & 46.38 & 45.89 & 0.16 & 0.33 & 98.94 & 0.35 & 0.71 \\
\hline 5.13 & 45.47 & 45.06 & 0.08 & 0.33 & 99.10 & 0.17 & 0.72 \\
\hline 10.26 & 26.11 & 25.36 & 0.03 & 0.28 & 97.16 & 0.11 & 1.06 \\
\hline WHSV $\left(\mathrm{h}^{-1}\right)$ & $T=230^{\circ} \mathrm{C}, P=8$ bar & & & & & & \\
\hline 2.57 & 32.35 & 32.00 & 0.04 & 0.31 & 98.91 & 0.13 & 0.97 \\
\hline 5.13 & 19.90 & 19.56 & 0.03 & 0.31 & 98.29 & 0.16 & 1.55 \\
\hline 10.26 & 9.08 & 8.80 & 0.00 & 0.28 & 96.94 & 0.00 & 3.05 \\
\hline WHSV $\left(h^{-1}\right)$ & $T=230{ }^{\circ} \mathrm{C}, P=15 \mathrm{bar}$ & & & & & & \\
\hline 2.57 & 16.95 & 16.60 & 0.02 & 0.33 & 97.94 & 0.09 & 1.97 \\
\hline 5.13 & 10.92 & 10.64 & 0.00 & 0.28 & 97.43 & 0.00 & 2.55 \\
\hline 10.26 & 6.28 & 6.02 & 0.00 & 0.26 & 95.81 & 0.00 & 4.17 \\
\hline Pressure (bar) & $T=230{ }^{\circ} \mathrm{C}, \mathrm{WHSV}=5.13 \mathrm{~h}^{-1}$ & & & & & & \\
\hline 1 & 45.47 & 45.06 & 0.08 & 0.33 & 99.10 & 0.17 & 0.72 \\
\hline 8 & 19.90 & 19.56 & 0.03 & 0.31 & 98.29 & 0.16 & 1.55 \\
\hline 15 & 10.92 & 10.64 & 0.00 & 0.28 & 97.43 & 0.00 & 2.55 \\
\hline WHSV $\left(h^{-1}\right)$ & $T=250{ }^{\circ} \mathrm{C}, P=1 \mathrm{bar}$ & & & & & & \\
\hline 2.57 & 78.83 & 76.38 & 1.82 & 0.62 & 96.90 & 2.31 & 0.79 \\
\hline 5.13 & 68.83 & 67.52 & 0.85 & 0.47 & 98.09 & 1.23 & 0.68 \\
\hline 10.26 & 39.93 & 38.96 & 0.55 & 0.43 & 97.55 & 1.36 & 1.08 \\
\hline WHSV $\left(\mathrm{h}^{-1}\right)$ & $T=250{ }^{\circ} \mathrm{C}, P=8$ bar & & & & & & \\
\hline 2.57 & 70.07 & 68.91 & 0.83 & 0.32 & 98.35 & 1.19 & 0.46 \\
\hline 5.13 & 52.62 & 51.99 & 0.66 & 0.31 & 98.81 & 1.25 & 0.58 \\
\hline 10.26 & 30.51 & 30.05 & 0.19 & 0.27 & 98.50 & 0.61 & 0.89 \\
\hline WHSV $\left(h^{-1}\right)$ & $T=250{ }^{\circ} \mathrm{C}, P=15$ bar & & & & & & \\
\hline 2.57 & 52.05 & 51.45 & 0.30 & 0.31 & 98.83 & 0.58 & 0.59 \\
\hline 5.13 & 42.85 & 42.32 & 0.25 & 0.29 & 98.76 & 0.58 & 0.68 \\
\hline 10.26 & 25.38 & 24.94 & 0.15 & 0.29 & 98.28 & 0.58 & 1.14 \\
\hline
\end{tabular}


Table 5 continued

\begin{tabular}{|c|c|c|c|c|c|c|c|}
\hline & Conversion (wt $\%$ ) & $\begin{array}{l}\text { Hydroisoms } \\
\text { yield (wt } \%)\end{array}$ & $\begin{array}{l}\text { Hydrocrack } \\
\text { yield (wt } \%)\end{array}$ & $\begin{array}{l}\text { Cyclic yield } \\
(\mathrm{wt} \%)\end{array}$ & $\begin{array}{l}\text { Hydroisoms } \\
\text { selectivity }(\%)\end{array}$ & $\begin{array}{l}\text { Hydrocrack } \\
\text { selectivity }(\%)\end{array}$ & $\begin{array}{l}\text { Cyclic } \\
\text { selectivity }(\%)\end{array}$ \\
\hline Pressure (bar) & $T=250^{\circ} \mathrm{C}, \mathrm{WHSV}=5.13 \mathrm{~h}^{-1}$ & & & & & & \\
\hline 1 & 68.83 & 67.52 & 0.85 & 0.47 & 98.09 & 1.23 & 0.68 \\
\hline 8 & 52.62 & 51.99 & 0.66 & 0.31 & 98.81 & 1.25 & 0.58 \\
\hline 15 & 42.85 & 42.32 & 0.25 & 0.29 & 98.76 & 0.58 & 0.68 \\
\hline WHSV $\left(h^{-1}\right)$ & $T=270^{\circ} \mathrm{C}, P=1$ bar & & & & & & \\
\hline 2.57 & 78.02 & 71.93 & 4.18 & 1.91 & 92.19 & 5.36 & 2.45 \\
\hline 5.13 & 72.53 & 69.68 & 1.88 & 0.97 & 96.07 & 2.59 & 1.34 \\
\hline 10.26 & 41.78 & 40.09 & 0.96 & 0.73 & 95.94 & 2.31 & 1.75 \\
\hline WHSV $\left(\mathrm{h}^{-1}\right)$ & $T=270^{\circ} \mathrm{C}, P=8 \mathrm{bar}$ & & & & & & \\
\hline 2.57 & 66.87 & 63.21 & 3.27 & 0.39 & 94.53 & 4.89 & 0.58 \\
\hline 5.13 & 54.19 & 50.28 & 3.65 & 0.26 & 92.79 & 6.74 & 0.48 \\
\hline 10.26 & 30.19 & 28.25 & 1.67 & 0.27 & 93.57 & 5.54 & 0.88 \\
\hline WHSV $\left(\mathrm{h}^{-1}\right)$ & $T=270{ }^{\circ} \mathrm{C}, P=15 \mathrm{bar}$ & & & & & & \\
\hline 2.57 & 58.01 & 54.98 & 2.71 & 0.32 & 94.78 & 4.68 & 0.54 \\
\hline 5.13 & 43.24 & 40.59 & 2.37 & 0.29 & 93.86 & 5.47 & 0.66 \\
\hline 10.26 & 29.63 & 27.47 & 1.90 & 0.26 & 92.69 & 6.42 & 0.89 \\
\hline Pressure (bar) & $T=270{ }^{\circ} \mathrm{C}, \mathrm{WHSV}=5.13 \mathrm{~h}^{-1}$ & & & & & & \\
\hline 1 & 72.53 & 69.68 & 1.88 & 0.97 & 96.07 & 2.59 & 1.34 \\
\hline 8 & 54.19 & 50.28 & 3.65 & 0.26 & 92.79 & 6.74 & 0.48 \\
\hline 15 & 43.24 & 40.59 & 2.37 & 0.29 & 93.86 & 5.47 & 0.66 \\
\hline
\end{tabular}

blockage effect, especially in the polymeric species [24], such that the coke content can be trapped within the pores since these will be smaller than those found for USY-A.

Effects of reaction pressure and contact time for $1 \mathrm{wt} \%$ $\mathrm{Pt} / 320$ HOA USY

The effect of increasing the hydrogen partial pressure, and hence the overall reaction pressure and variation in contact time, representing the time taken by reactants to pass through the catalyst bed during a reaction, has been studied in this work at a range of temperatures from 210 to $270{ }^{\circ} \mathrm{C}$ for the hydroisomerisation of $\mathrm{n}-\mathrm{C} 7$ over $1 \mathrm{wt} \%$ platinum-loaded 320HOA USY. A stainless-steel higher pressure unit was used, and the catalyst ( $1 \mathrm{wt} \% \mathrm{Pt} / 320 \mathrm{HOA}$ USY) was tested at temperatures ranging from 210 to $270{ }^{\circ} \mathrm{C}$, WHSV of 2.57 , 5.13 , and $10.26 \mathrm{~h}^{-1}$, and pressures of 1,8 and 15 bar. At each temperature, products of the reaction were collected at the point where steady-state conditions were achieved; catalysts were calcined and then re-reduced before proceeding to the next temperature. Unfortunately, the reaction rig could not operate overnight at high pressures due to the necessary safety precautions and therefore it was not possible to fully study deactivation behaviours at these pressures.

Table 5 shows the results from the $\mathrm{n}-\mathrm{C} 7$ conversion (wt\%), product yield (wt\%), and product selectivity (\%) at the different reaction conditions using the pressure rig for the hydroisomerisation of $\mathrm{n}-\mathrm{C} 7$ over $1 \mathrm{wt} \% \mathrm{Pt} / 320 \mathrm{HOA}$ USY. In general, it has been found that an increase in pressure results in a decrease in overall conversion and a slight decrease in selectivity to isomers with a noticeable increased selectivity to the cyclic products, particularly at the lower temperatures of 210 and $230{ }^{\circ} \mathrm{C}$. There was no obvious cracking activity at the lower temperatures of 210 and $230{ }^{\circ} \mathrm{C}$, and a constant WHSV was observed whilst changing reaction pressures. In contrast, at the highest temperature of $270{ }^{\circ} \mathrm{C}$ and WHSV of $5.13 \mathrm{~h}^{-1}$, increased selectivity towards the cracked products was observed with increased reaction pressures, with comparable results being reported by Chao et al. [32] who investigated the effect of reaction pressure over the range $1-41.3$ bar on mordenite catalysts with different $\mathrm{Si} / \mathrm{Al}$ ratios and the zeolite Beta. In addition, they showed that pressure reduced the cracking yield for all catalysts as well as improved the mordenite catalysts' stability. Additionally, an increase in hydrogen pressure has been found to reduce the hydroisomerisation reaction rate [33], where an increase in the hydrogenation activity at higher hydrogen pressure results in the hydrogenation of intermediate olefins, due to a shorter intermediate olefin residence time inside the catalyst [34]. This minimises the cracking activity, since pressure reduces overall conversion but improves hydroisomerisation selectivity compared with that of cracking, which to some extent, was not the case for catalyst $1 \mathrm{wt} \% \mathrm{Pt} / 320 \mathrm{HOA}$ 
Fig. 6 XRD pattern for $350 \mathrm{HOA}$ USY

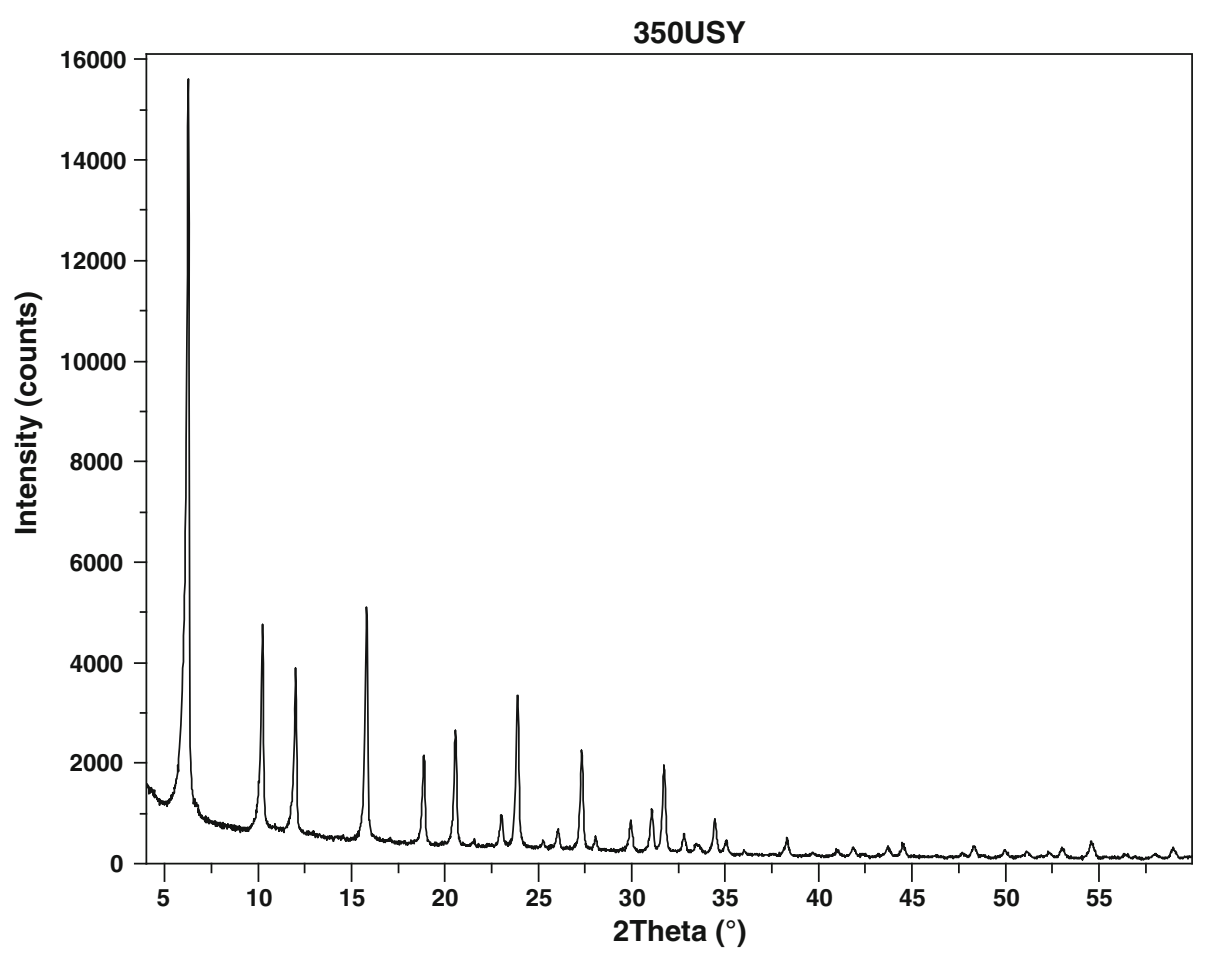

USY, whose small average pore diameter most likely limited the movement of larger molecules at high pressures, and therefore promoted cracking.

Table 5 illustrates that the conversion increased as the contact time increased (WHSV $\leq 10.26,5.13,2.57 \mathrm{~h}^{-1}$ ) at constant temperature and pressure. However, increasing contact time between the reaction feed (n-C7) and the catalyst appears to cause a reduction in cyclic product yield, giving rise to an increase in cracking and hydroisomerisation selectivity.

Wang et al. [35] found that increasing the contact time results in an increased overall conversion of $\mathrm{n}-\mathrm{C} 7$ at a constant temperature of $220{ }^{\circ} \mathrm{C}$ and in a reduced selectivity in hydroisomerisation versus cracking. Similar observations were made by Chica and Corma [36] when they tested the hydroisomerisation of $\mathrm{nC}_{5}, \mathrm{nC}_{6}$ and $\mathrm{nC}_{7}$ over platinumloaded zeolite supports. However, the decrease in selectivity to isomers was opposed by an increase in the overall yield of isomers at short contact times. It was also shown that with increasing contact times, the formation of multi-branched isomers also increases, leading to a lower mono/multibranched isomer ratio. This behaviour could result from an initial formation of mono-branched isomers and their subsequent transformation into multi-branched isomers.

Deactivation behaviour of $350 \mathrm{HOA}$ USY zeolite

350HOA USY zeolite was supplied by Tosoh Corporation in the form of a white powder with particle sizes between 6 and $10 \mu \mathrm{m}$. The Figs. 6 and 7, respectively, show the XRD

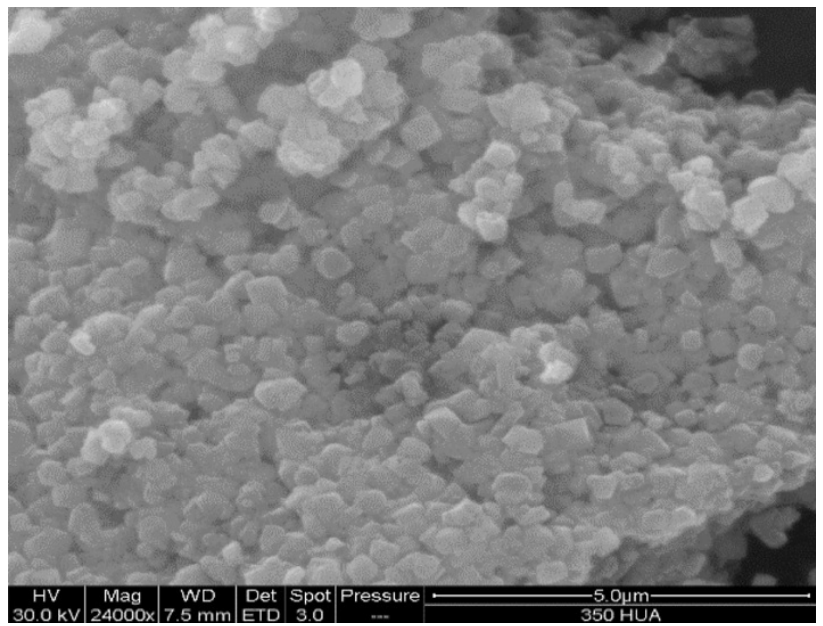

Fig. 7 SEM micrograph for 350HOA USY

pattern and SEM microgram for 350HOA USY, and Table 6 the in-house characterisation for 350HOA USY using different techniques.

Figures 8 and 9 show solid-state NMR spectra for ${ }^{27} \mathrm{Al}$ and ${ }^{29} \mathrm{Si}$, respectively. ${ }^{27} \mathrm{Al}$ MAS NMR analysis revealed that the catalyst had EFAL species even though it was a dealuminated and partially acid-leached zeolite. Information regarding the $\mathrm{Si}$ atoms coordinated (via oxygen) with neighbouring $\mathrm{T}$ atoms ( $\mathrm{Si}$ and $\mathrm{Al}$ ) is provided by ${ }^{29} \mathrm{Si}$ MAS NMR, indicating two different chemical configurations of $\mathrm{SiO}_{4}$, which were assigned to $(4 \mathrm{Si}, 0 \mathrm{Al})$ and $\mathrm{SiO}_{4}(3 \mathrm{Si}, 1 \mathrm{Al})$.

This confirms that $350 \mathrm{HOA}$ was produced by a dealumination process and acid leached to achieve a high $\mathrm{Si} / \mathrm{Al}$ 
Table 6 Some in-house characterisations of 350HOA USY

\begin{tabular}{|c|c|c|c|c|c|c|c|c|}
\hline \multirow[t]{2}{*}{ Elemental analysis (bulk) } & \multicolumn{4}{|c|}{ Before ion exchange } & \multicolumn{4}{|c|}{$\begin{array}{l}\text { After ion exchange with } \mathrm{Pt} \text { precursor as tetraammine platinum (II) chloride } \\
\left(\mathrm{Pt}\left(\mathrm{NH}_{3}\right)_{4} \mathrm{Cl}_{2}\right) \cdot \mathrm{H}_{2} \mathrm{O}\end{array}$} \\
\hline & \multicolumn{4}{|c|}{$\mathrm{Si} / \mathrm{Al}$ mole ratio 5.55} & $\mathrm{Si} / \mathrm{Al}$ mole ratio & 5.55 & Pt wt $\%$ & 0.90 \\
\hline \multirow{3}{*}{$\begin{array}{l}\text { XPS }^{\mathrm{a}} \\
\text { Atomic Conc } \% \\
\text { XRD }\end{array}$} & \multirow{2}{*}{$\begin{array}{l}\mathrm{Si} \\
28.32\end{array}$} & \multirow{2}{*}{$\begin{array}{l}\mathrm{Al} \\
5.69\end{array}$} & $\mathrm{Si} / \mathrm{Al}$ & \multirow{2}{*}{$\begin{array}{l}\mathrm{Pt} \\
0.07\end{array}$} & \multicolumn{4}{|c|}{ Pt is likely to be metallic } \\
\hline & & & 4.98 & & & & & \\
\hline & \multicolumn{4}{|c|}{$\begin{array}{l}\text { Crystallinity \% } \\
66\end{array}$} & \multicolumn{4}{|c|}{ Related to in-house as-synthesised $\mathrm{Y}$} \\
\hline NMR & \multicolumn{4}{|c|}{$\begin{array}{l}\mathrm{Si} / \mathrm{Al} \text { mole ratio for the framework } \\
12.38\end{array}$} & \multicolumn{4}{|c|}{$\begin{array}{l}\text { Two chemical environments for } \mathrm{Si}-\mathrm{NMR}: \mathrm{Si}(0 \mathrm{Al}) \text { and } \mathrm{Si}(1 \mathrm{Al}) \\
\text { Lewis acid sites are present }\end{array}$} \\
\hline Ammonia TPD & \multicolumn{4}{|c|}{$\begin{array}{l}\mathrm{NH}_{3} \text { desorption through TPD/ } \\
\mathrm{mmol} \mathrm{g}^{-1} \\
0.76 \pm 0.01\end{array}$} & \multicolumn{4}{|c|}{$\begin{array}{l}\text { Ammonia adsorption calorimetry followed by temperature programmed } \\
\text { desorption }\end{array}$} \\
\hline \multirow[t]{2}{*}{$\mathrm{BET}^{\mathrm{b}}$} & \multicolumn{3}{|c|}{ Surface area $\left(\mathrm{m}^{2} \mathrm{~g}^{-1}\right.$} & \multicolumn{2}{|c|}{ Pore volume $\left(\mathrm{cm}^{3} \mathrm{~g}^{-1}\right)$} & Pore size $(\AA)$ & \multicolumn{2}{|c|}{ Shows both micro and mesoporosity } \\
\hline & \multicolumn{2}{|c|}{872.97} & & 0.47 & & 26.10 & & \\
\hline \multirow{6}{*}{$\begin{array}{l}\text { TGA for coke content } \\
\text { in spent catalyst (mass lo } \\
\text { wt } \% \text { in air) after differen } \\
\text { reaction temperatures }\end{array}$} & \multicolumn{2}{|c|}{$210^{\circ} \mathrm{C}$} & & Top & 0.10 & $250^{\circ} \mathrm{C}$ & Top & 0.26 \\
\hline & & & & Mid & 0.13 & & Mid & 0.37 \\
\hline & & & & Bot & 0.13 & & Bot & 0.28 \\
\hline & \multirow{3}{*}{\multicolumn{2}{|c|}{$230^{\circ} \mathrm{C}$}} & & Top & 0.52 & $270{ }^{\circ} \mathrm{C}$ & Top & 1.20 \\
\hline & & & & Mid & 0.76 & & Mid & 1.12 \\
\hline & & & & Bot & 0.71 & & Bot & 1.29 \\
\hline
\end{tabular}

LPD Laboratory Services Ltd.

b MCA Services

mole ratio; thus a high surface area was obtained, as there were fewer EFAL species. This would result in a mesoporous channel network, due to the larger pore volume. Moreover, it should be noted that the dealumination process required to produce 350HOA USY was less severe than for the CBV720USY catalyst [31], which has a higher $\mathrm{Si} / \mathrm{Al}$ mole ratio in the framework than 350HOA USY. Nevertheless, both catalysts have mesoporous systems, due to larger pore volumes and surface areas, but less acidity and thus lower catalytic activity compared to just-dealuminated catalysts.

The effects of TOS on the C7 conversion, hydroisomerisation, hydrocracking, and cyclic product yields at different reaction temperatures $210-270{ }^{\circ} \mathrm{C}$ are shown in Fig. 10a-d, respectively. Fresh catalyst was used for each run at the different reaction temperatures. Initially, the overall conversion was $17,56,75$, and $84 \mathrm{wt} \%$ after $30 \mathrm{~min}$ from the point when the feed was introduced to the reactor at the temperatures of $210,230,250$, and $270{ }^{\circ} \mathrm{C}$, respectively. At $210{ }^{\circ} \mathrm{C}$, the catalyst lost about $1-2 \mathrm{wt} \%$ of its activity and then reached a pseudo-stable state for the initial $60 \mathrm{~min}$ on stream. The deactivation rate at $230{ }^{\circ} \mathrm{C}$ for the new activated catalyst was slightly faster, with the overall conversion being $56 \mathrm{wt} \%$ after $30 \mathrm{~min}$ after which it decreased with the TOS to $51 \mathrm{wt} \%$ after $27 \mathrm{~h}$, and then decreased slowly within the deactivation rate range of
2-3 wt \% every $24 \mathrm{~h}$ until the reaction finally terminated after about 6 days $(140 \mathrm{~h})$. Rapid initial deactivation occurred during the first few hours at the higher temperatures of 250 and $270{ }^{\circ} \mathrm{C}$, followed by a constant deactivating value being reached, ranging from 3 to $5 \mathrm{wt} \%$, every $24 \mathrm{~h}$ until the reaction terminated.

The initial selectivity towards the hydroisomerisation products was 98 and $85 \%$ after the initial $30 \mathrm{~min}$, and then increased throughout the TOS to 99 and $94 \%$ after $120 \mathrm{~min}$ at 250 and $270{ }^{\circ} \mathrm{C}$, respectively. Thus, the selectivity towards cracked products was fairly high at higher temperatures during the first few hours of the deactivation reaction, with the highest cracked product selectivity being $14 \% 30 \mathrm{~min}$ after introducing the feed to the reactor at $270{ }^{\circ} \mathrm{C}$; however, this decreased rapidly throughout the TOS to $4 \%$ after $120 \mathrm{~min}$. Additionally, the yield of cyclic products at the temperatures of 210 and $230{ }^{\circ} \mathrm{C}$ was higher than that at the higher temperatures.

The TOS results provide evidence that the higher activity of 350HOA USY compared to CBV720 USY [31] is related to the number of acid sites. Furthermore, moderately slow deactivation for both catalysts was observed, reaching the pseudo-stable state in the initial few minutes at the lower temperatures of 210 and $230{ }^{\circ} \mathrm{C}$. The $\mathrm{n}_{\mathrm{Pt}} / \mathrm{n}_{\mathrm{A}}$ ratio for $350 \mathrm{HOA}$ USY was calculated as 0.06 , which is in the suggested range of $0.03 \leq \mathrm{n}_{\mathrm{Pt}} / \mathrm{n}_{\mathrm{A}} \leq 0.17$ for a well- 
Fig. $8{ }^{27} \mathrm{Al}$ NMR spectra for 350HOA USY

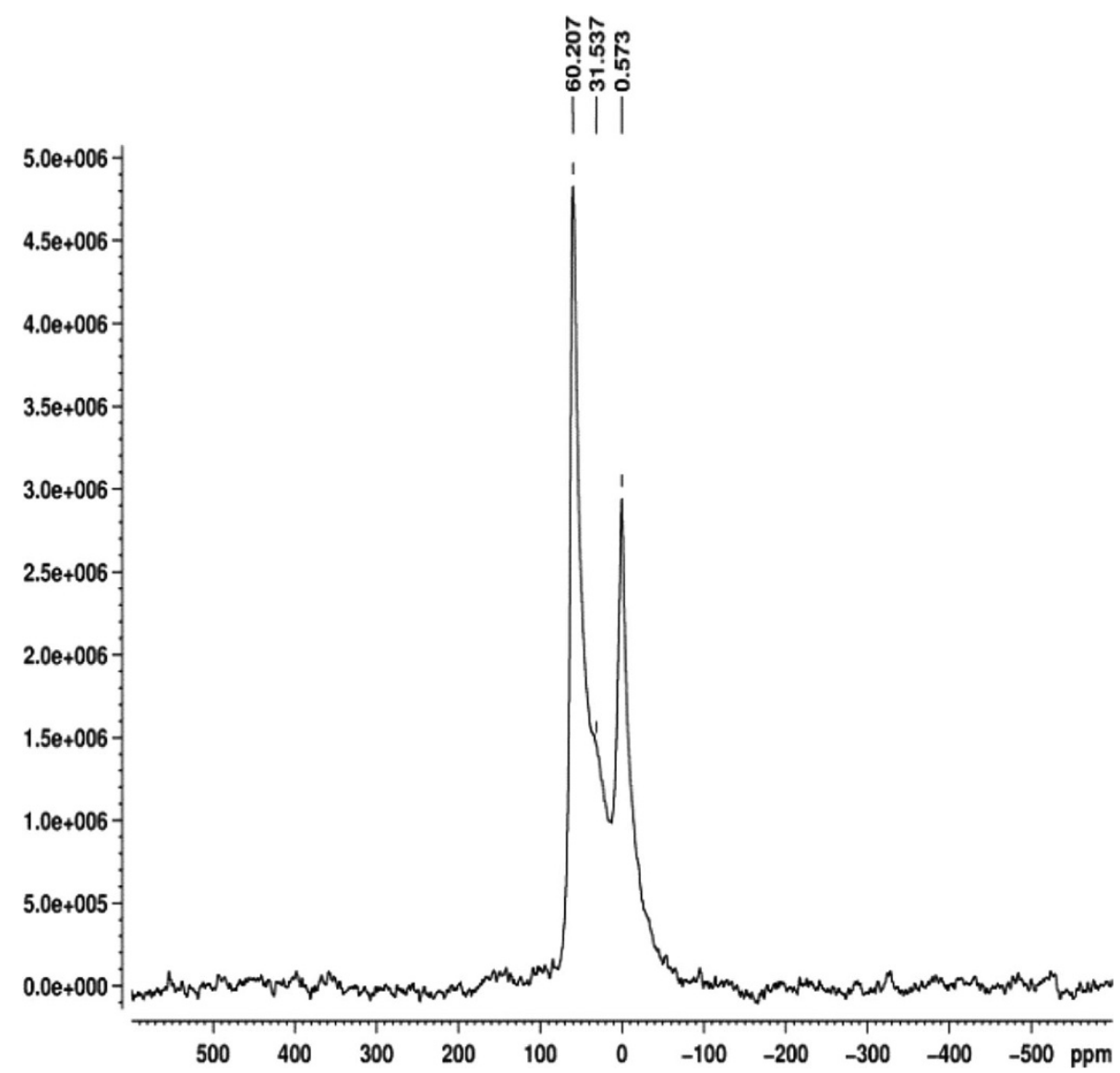

balanced bifunctional catalyst, in conjunction with 0.12 for CBV720 USY, which allowed deactivation to occur at reasonably low temperatures with lower coke content. Although the mesoporosity texture was similar for both catalysts, the average coke content was higher for $350 \mathrm{HOA}$ USY, which may be due to its higher acidity, as the framework $\mathrm{Si} / \mathrm{Al}$ was lower, resulting in cracking activity at temperatures of 250 and $270{ }^{\circ} \mathrm{C}$.

\section{Extraction of EFAL in USY zeolites by AHFS}

post-synthetic modification

Ammonium hexafluorosilicate solution was used to remove the EFAL from the USY samples: USY-A, USA-C, $320 \mathrm{HOA}$, and from the acid-leached $350 \mathrm{HOA}$, due to the samples having different silicon-to-aluminium ratios, and thus different numbers of aluminium atoms as non-framework on their crystal unit cells. As with dealumination, after the process the aluminium removed from the framework remains on the crystal and migrates to the surface in an extension that is dependent on the partial pressure of the steam used. This can be confirmed by $\mathrm{Si} / \mathrm{Al}$ ratio results on the above USYs surfaces by XPS analysis as shown in Tables 4 and 6 and it can be seen that the $\mathrm{Si} / \mathrm{Al}$ ratios on the surfaces are much lower for zeolites that have only been dealuminated, such as USY-A, USY-C, and 320HOA than for the acid-leached zeolites such as CBV712, CBV720 and 350HOA. The resulting AHFS modified zeolite samples were characterised by XRD, MAS NMR, ammonia TPD, ICP, XPS and BET, with the effects of the treatments on the total amount and type of EFAL, the relationship between amount and nature of acid sites, and the deactivation behaviour discussed below.

\section{Optimisation of chelating extraction parameters}

The USY sample $320 \mathrm{HOA}$ containing $2 \mathrm{wt} \%$ sodium with the ammonium form as the starting material has been fine tuned using a chelate compound (ammonium hexafluorosilicate $\left.\left(\mathrm{NH}_{4}\right)_{2} \mathrm{SiF}_{6}\right)$ to provide the best condition to remove only the non-framework aluminium whilst maintaining the aluminium framework and original zeolite crystallinity-as these are unaffected by this chelating agent. Four main factors were considered when optimising the chemical treatments: (1) the AHFS and USY mixture volume, (2) the treatment duration time, (3) the zeolite to AHFS weight ratio, and (4) the temperature used during the chemical treatment. Table 7 lists the resulting modified sample characteristics for each factor and illustrates, for the AHFS modified samples, that the increase in mixture volume 
Fig. $9{ }^{29} \mathrm{Si}$ NMR spectra for 350HOA USY

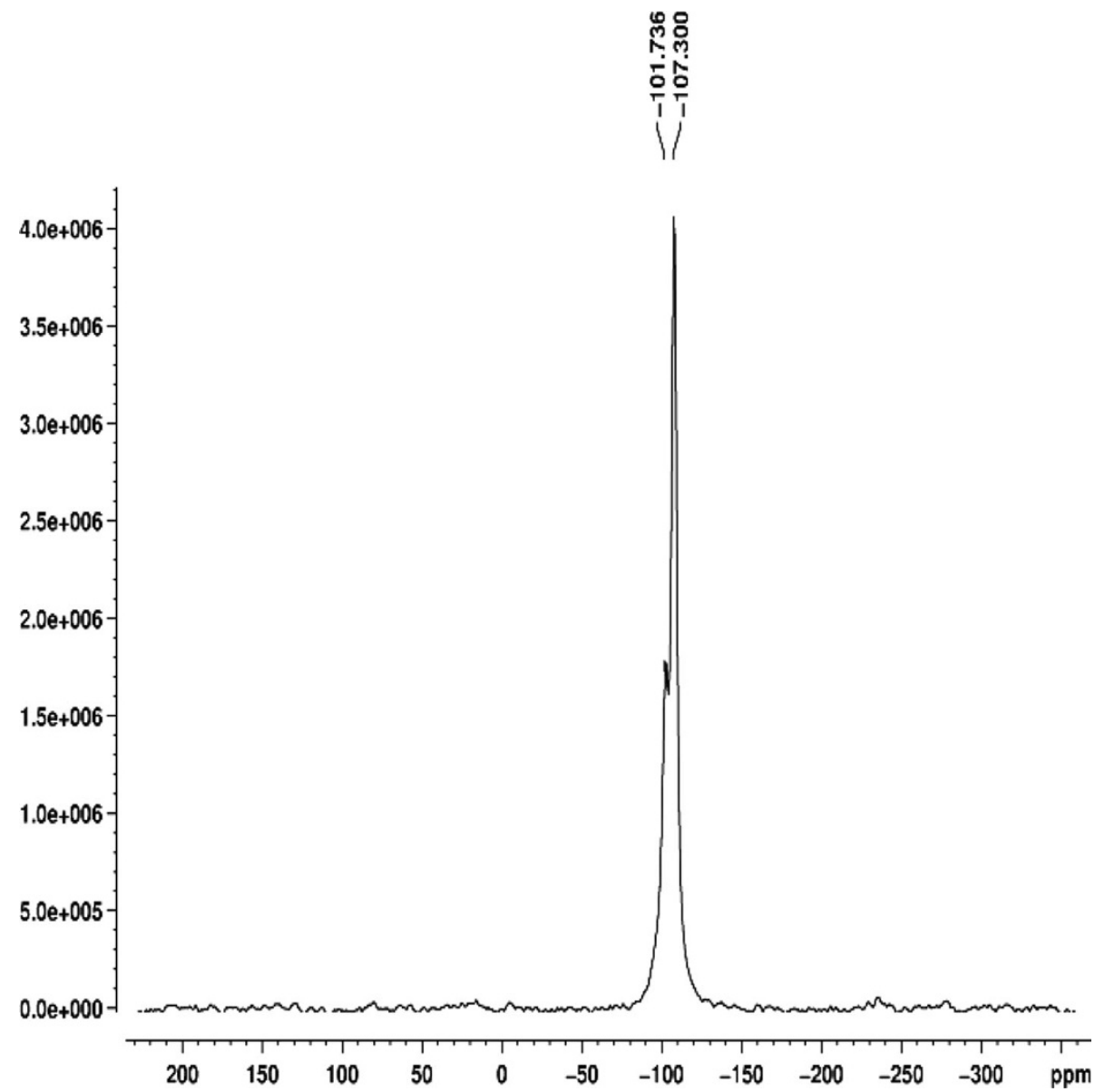

caused the total aluminium content in the bulk to decrease from $9.73 \mathrm{wt} \%$ before the modification to between 4.83 and $5.51 \mathrm{wt} \%$. Additionally, both the $\mathrm{Si} / \mathrm{Al}$ mole ratio in the framework and the crystallinity were maintained in the ranges of $6.45-6.75 \mathrm{~mol}$ ratio and 57-68\%, respectively. There was no significant effect on the mixing time factors, such that the Si/Al mole ratio in the framework and the crystallinity were maintained in the ranges of $6.45-6.75$ and 57-66 \%, respectively. The zeolite to AHFS mass ratio was optimised in the range of 6.67-1.67, so the framework structure had been attacked by the AHFS at a ratio of $1.67 \mathrm{~mol}$, leading to a $\mathrm{Si} / \mathrm{Al}$ mole ratio in the framework which increased to 11.10 .

A temperature range of $25-100{ }^{\circ} \mathrm{C}$ was used during the chemical treatment and it was found that the resulting modified samples had the total aluminium content in the range of 4.79-5.56 wt\%, and crystallinity in the range of 57-64\%. As well as this, the framework was unaffected as the temperature rose, leaving the $\mathrm{Si} / \mathrm{Al}$ in the framework in the range of $6.43-6.53 \mathrm{~mol}$ ratio. It can be seen that the total $\mathrm{Si}$ content in the modified samples is higher than that detected for the original sample 320HOA before the acid chelating treatment, which can explained by the existence of the silicon fluoride containing species on the outer surfaces of the modified zeolites, an effect that has been reported in the literature [27, 37]. The detected residual fluoride species was removed from the structure by applying an extra ammonium ion-exchange step.

Table 8 shows the unit cell for the AHFS modified samples, the starting material sample (320HOA), the total aluminium number $\mathrm{Al}_{\text {total }}$ (based on the elemental analysis), the framework aluminium number $\mathrm{Al}_{\mathrm{F}}$ (measured using ${ }^{29} \mathrm{Si}$ MAS NMR $(\mathrm{Si} / \mathrm{Al})_{\mathrm{F}}$, and on the basis of $192 \mathrm{~T}$ atoms ( $\mathrm{Si}$ or $\mathrm{Al}$ ) per unit cell with the composition of $\left.\mathrm{H}_{\mathrm{x}}\left(\mathrm{AlO}_{2}\right)_{\mathrm{x}}\left(\mathrm{SiO}_{2}\right)_{192-\mathrm{x}}\right)$ and the EFAL number $\mathrm{Al}_{\mathrm{nF}}$, (the difference between the $\mathrm{Al}_{\text {total }}$ and $\mathrm{Al}_{\mathrm{F}}$ ) [26, 27, 38, 39]. To some extent, the value for $\mathrm{Al}_{\mathrm{F} / \mathrm{u} . \mathrm{c}}$ was greater than the value for the total $\mathrm{Al}_{\text {total/u.c }}$ as shown for the samples designated as F9, F10, and F22 in the table, so this difference reflects the errors in analyses for some AHFS modified samples which may have resulted from the existence of silicon fluoride containing species during the chemical treatment. The $\mathrm{Al}_{\mathrm{nF}}$ extraction efficiency percentage was calculated for each resulting sample by dividing the difference between $\mathrm{Al}_{\mathrm{nF}}$ for the modified sample and $\mathrm{Al}_{\mathrm{nF}}$ for the starting material, which is equal to 23 atoms for $320 \mathrm{HOA}$.

It is clear from Table 8 that the most effective extraction of EFAL by AHFS chelating agent was for the samples F4, 

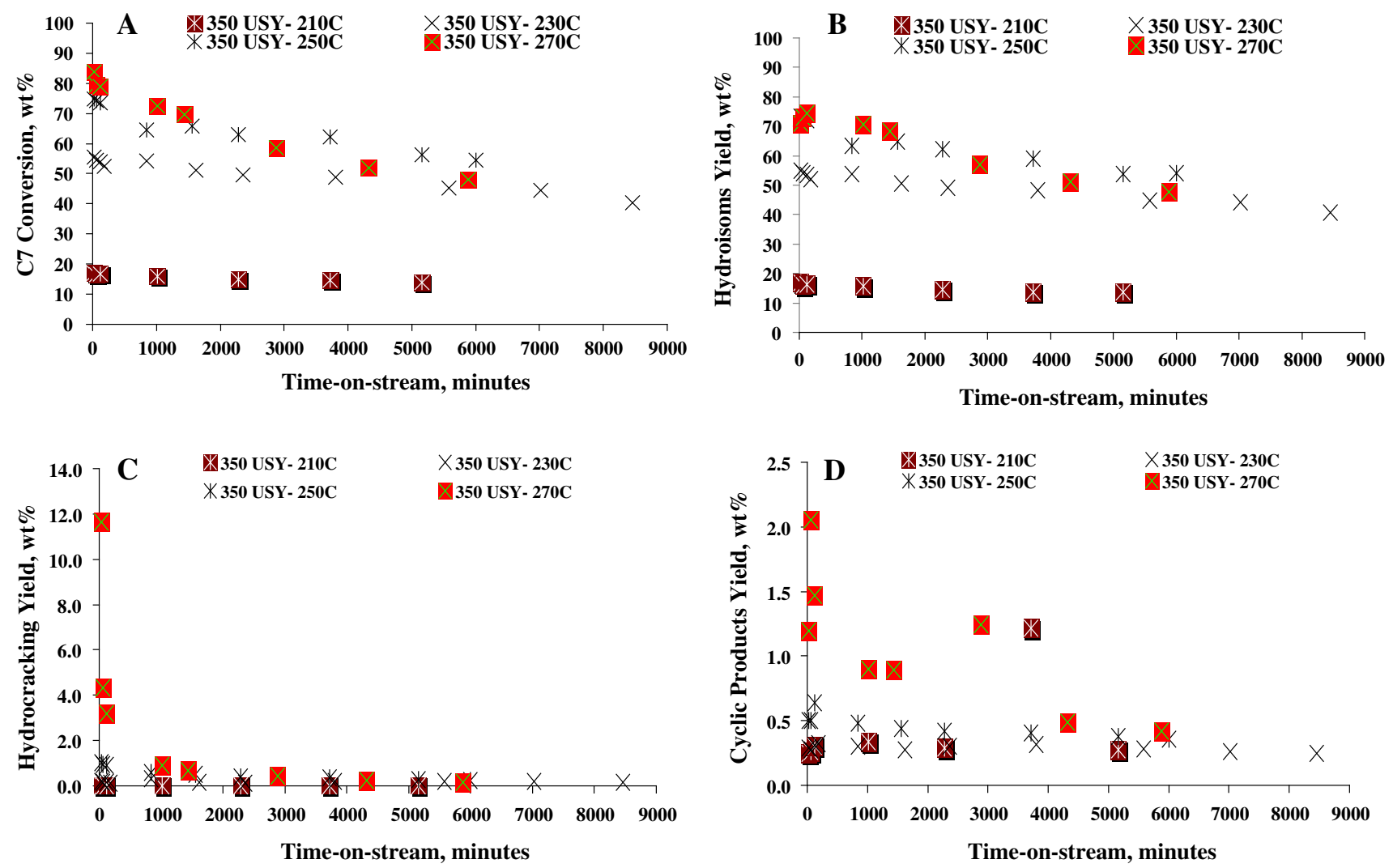

Fig. 10 Overall conversion (a), total yield of C7 isomers (mono $+\mathrm{di}+$ tribranched isomers) (b), total hydrocracking yield (c), and total yield of the cyclic products (d) as a function of TOS for

F5, F6, F7, and F11. The results for the starting material (320HOA) are arranged in the table according to the chemical treatment conditions applied, where the EFAL formed represents approximately $47 \%$ of the total aluminium. Furthermore, the obtained $(\mathrm{Si} / \mathrm{Al})_{\mathrm{T}}$ as bulk (measured by the chemical analysis) is almost in agreement with $(\mathrm{Si} / \mathrm{Al})_{\mathrm{F}}$ measured by NMR analysis for those samples $(\mathrm{F} 4$, F5, F6, F7, and F11) which has $100 \%$ extraction efficiency. The lowest extraction efficiency was found to be $46 \%$ for the modified sample F8, which was prepared by the chemical treatment using the highest mass ratio (6.67 wt/wt) of zeolite to AHFS, which can be considered as the mildest condition, with moderate extraction efficiency observed for the modified samples F1, F2, F3, and F12 in which partial extraction occurred, leaving the framework aluminium unaffected, and maintaining the framework $(\mathrm{Si} / \mathrm{Al})_{\mathrm{F}}$ ratio as prior to modification. This resulted in reasonable crystallinity values in the range of 61-66 \% compared with the original crystallinity of $64 \%$ for the starting material.

Catalysts USY-A, USY-C, 320HOA USY, and 320HOA USY were chemically treated by AHFS to remove the EFAL as these have a detrimental effect on catalytic and transport properties, and consequently adversely affects the

$350 \mathrm{HOA}$ USY at various reaction temperatures. WHSV $=5.13 \mathrm{~h}^{-1}$; $\mathrm{H}_{2} / \mathrm{C} 7$ (molar) $=9$; total pressure $=1 \mathrm{~atm}$; temperature $=210,230$, 250 and $270{ }^{\circ} \mathrm{C} ; 1 \mathrm{wt} \% \mathrm{Pt}$ loading

coke formation and deactivation behaviour. The EFAL was removed from the catalysts in their ammonium form using the chelating agent AHFS under the same chemical treatment conditions as sample F2. This involved $50 \mathrm{ml}$ of a solution mixture, stirred for $1 \mathrm{~h}$ at room temperature, with a zeolite to AHFS mass ratio of $3.33 \mathrm{wt} / \mathrm{wt}$. From Table 9, it can be seen that samples F20 and F21, the modified samples of catalysts USY-A and USY-C, respectively, still have EFAL which has not been extracted by AHFS, and that framework $\mathrm{Al}$ atoms were attacked. In contrast, F2 was partially extracted but was not attacked by the AHFS. It can be interpreted that F2 was produced by the AHFS treatment of 320HOA USY which in its ammonium form contains approximately $2 \mathrm{wt} \%$ sodium, and thus the presence of sodium inhibits aluminium extraction [27]. Table 9 shows the in-house characterisation for the original and modified catalysts using different techniques, and it can be seen that the $(\mathrm{Si} / \mathrm{Al})_{\mathrm{F}}$ increased for modified samples F20 and F21, confirming that the AHFS has dealuminated the framework $\mathrm{Al}$ atoms, and subsequently decreased their crystallinity. It was also observed that the zeolites prepared with AHFS retained less than $0.6 \mathrm{wt} \%$ fluorine based on the ion chromatography analysis, which was not seen by XPS analysis measurements for the

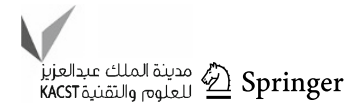


Table 7 The chemical treatment parameters of AHFS and the resulting samples characteristics

\begin{tabular}{|c|c|c|c|c|c|c|c|c|c|c|}
\hline & \multicolumn{5}{|c|}{ The chemical treatment conditions } & \multicolumn{3}{|c|}{ Elemental analysis ICP } & \multirow{2}{*}{$\begin{array}{l}\text { MAS NMR } \\
\text { Framework (Si/Al) } \\
(\mathrm{mol} / \mathrm{mol})\end{array}$} & \multirow{2}{*}{$\begin{array}{l}\text { XRD } \\
\text { Crystallinity } \\
(\%)\end{array}$} \\
\hline & $\begin{array}{l}\text { AHFSwt } \\
(\mathrm{g})\end{array}$ & $\begin{array}{l}\text { 320USYwt } \\
(\mathrm{g})\end{array}$ & $\begin{array}{l}\text { Mixing } \\
\text { time (h) }\end{array}$ & $\begin{array}{l}\text { Temp } \\
\left({ }^{\circ} \mathrm{C}\right)\end{array}$ & $\begin{array}{l}\text { Vol } \\
(\mathrm{ml})\end{array}$ & $\begin{array}{l}\mathrm{Si} \\
(\mathrm{wt} \%)\end{array}$ & $\begin{array}{l}\mathrm{Al} \\
(\mathrm{wt} \%)\end{array}$ & $\begin{array}{l}\text { Bulk (Si/Al) } \\
(\mathrm{mol} / \mathrm{mol})\end{array}$ & & \\
\hline 320 USY & - & - & - & - & - & 29.36 & 9.73 & 2.9 & 6.41 & 63.68 \\
\hline \multicolumn{11}{|c|}{ Optimising the mixture volume } \\
\hline $\mathrm{F} 1$ & 0.6 & 2 & 1 & 25 & 25 & 30.01 & 5.51 & 5.23 & 6.71 & 63.57 \\
\hline $\mathrm{F} 2$ & 0.6 & 2 & 1 & 25 & 50 & 30.71 & 5.22 & 5.65 & 6.45 & 57.27 \\
\hline F3 & 0.6 & 2 & 1 & 25 & 75 & 31.18 & 5.33 & 5.62 & 6.75 & 66.47 \\
\hline F4 & 0.6 & 2 & 1 & 25 & 100 & 32.37 & 4.83 & 6.44 & 6.23 & 68.46 \\
\hline \multicolumn{11}{|c|}{ Optimising the mixing time } \\
\hline $\mathrm{F} 2$ & 0.6 & 2 & 1 & 25 & 50 & 30.71 & 5.22 & 5.65 & 6.45 & 57.27 \\
\hline F5 & 0.6 & 2 & 3.5 & 25 & 50 & 33.12 & 4.75 & 6.70 & 6.75 & 66.28 \\
\hline F6 & 0.6 & 2 & 7 & 25 & 50 & 33.73 & 4.81 & 6.74 & 6.60 & 62.91 \\
\hline F7 & 0.6 & 2 & 14 & 25 & 50 & 33.72 & 4.6 & 7.04 & 6.59 & 66.69 \\
\hline \multicolumn{11}{|c|}{ Optimising the AHFS weight } \\
\hline F8 & 0.3 & 2 & 1 & 25 & 50 & 30.94 & 7.37 & 4.03 & 6.51 & 60.57 \\
\hline $\mathrm{F} 2$ & 0.6 & 2 & 1 & 25 & 50 & 30.71 & 5.22 & 5.65 & 6.45 & 57.27 \\
\hline F9 & 1.2 & 2 & 1 & 25 & 50 & 37.68 & 1.68 & 21.55 & 11.10 & 67.11 \\
\hline \multicolumn{11}{|c|}{ Optimising the mixture temperature } \\
\hline $\mathrm{F} 2$ & 0.6 & 2 & 1 & 25 & 50 & 30.71 & 5.22 & 5.65 & 6.45 & 57.27 \\
\hline F10 & 0.6 & 2 & 1 & 50 & 50 & 33.37 & 4.58 & 7.00 & 6.51 & 63.53 \\
\hline F11 & 0.6 & 2 & 1 & 75 & 50 & 32.5 & 4.79 & 6.52 & 6.43 & 64.47 \\
\hline F12 & 0.6 & 2 & 1 & 100 & 50 & 32.16 & 5.56 & 5.56 & 6.53 & 61.13 \\
\hline
\end{tabular}

samples surface. In addition, the XPS measurements revealed that the surface atomic concentration for the aluminium atoms decreased for the AHFS modified samples; thus, it can observed that the $(\mathrm{Si} / \mathrm{Al})_{\mathrm{F}}$ mole ratio measured by NMR, (Si/Al) measured by the elemental analysis, and $\mathrm{Si} / \mathrm{Al}$ measured by XPS present a closer match to each other, particularly in the case of sample F2 as opposed to samples F21 and F22 in which the $\mathrm{Al}_{\mathrm{F}}$ was attacked by the AHFS. In terms of the obtained texture of the samples treated with AHFS, some mesoporosity developed within the crystal as the pore volume increased and pore size decreased, thus the total surface area was consequently increased for all of the modified samples.

Figure 11a-d shows the effect of TOS on the n-C7 conversion, hydroisomerisation, hydrocracking and cyclic product yields at the reaction temperature of $230{ }^{\circ} \mathrm{C}$ for the samples F2, F20 and F21, which are the AHFS modified samples for the catalysts 320HOA USY, USY-A, and USY-C, respectively. Figure 11 a shows that the initial overall conversion was $63 \mathrm{wt} \%$ after $30 \mathrm{~min}$ from introducing the feed to the reactor at the temperature of $230{ }^{\circ} \mathrm{C}$ for F21 compared to $50 \mathrm{wt} \%$ for $320 \mathrm{HOA}$ USY before the modification, and that the catalyst lost about 1-2 wt $\%$ of its activity before reaching a constant "level-off" value after $60 \mathrm{~h}$ on stream. The deactivation rate for the F2 catalyst was slightly faster than the parent catalyst along the TOS to be in the range of 3-4 wt\% and then reached a constant "level-off" value until the reaction terminated after about 4 days (5,580 $\mathrm{min})$.

Figure $11 \mathrm{~b}$ shows that the initial selectivity towards the hydroisomerisation products was $98 \%$ for F2 compared to $99 \%$ for 320 HOA USY before the modification and kept almost the same along the deactivation run. As demonstrated in Fig. 11c and d, the selectivity towards cracked and cyclic products was fairly high for F2 in comparison with 320 HOA USY which may be due to the $n_{\mathrm{Pt}} / \mathrm{n}_{\mathrm{A}}$ ratio being disturbed as a consequence of increasing the number of acid sites for F2.

Figure 12a shows that the initial overall conversion was $60 \mathrm{wt} \%$ after $30 \mathrm{~min}$ from the point when the feed was introduced to the reactor at the temperature of $230{ }^{\circ} \mathrm{C}$ for F20 compared to $70 \mathrm{wt} \%$ for USY-A before the modification [31], which is then decreasing with the TOS to $43 \mathrm{wt} \%$ after $780 \mathrm{~min}$ and decreasing slowly within the deactivation rate ranging between 1 and $3 \mathrm{wt} \%$ every $24 \mathrm{~h}$ until the reaction terminated after almost 4 days. In comparison with USY-A, which was completely deactivated in the initial few minutes, F20 deactivated much more steadily with TOS, which may be explained by the effect of pore blockage by the polymeric EFAL species being overcome even in the presence of some EFAL due to further dealumination occurring during the acid leaching 
Table $8 \mathrm{Al}$ content of AHFS modified samples and extraction efficiency

\begin{tabular}{|c|c|c|c|c|c|}
\hline & $\mathrm{Al}_{\text {total }} /$ u.c & $\mathrm{Al}_{\mathrm{F}} /$ u.c & $\mathrm{Al}_{\mathrm{nF}} / \mathrm{u} . \mathrm{c}$ & $\mathrm{Al}_{\mathrm{nF}} \%$ & $\begin{array}{l}\text { Extraction } \\
\text { efficiency (\%) }\end{array}$ \\
\hline 320USY & 49 & 26 & 23 & 47 & - \\
\hline $\mathrm{F} 1$ & 31 & 25 & 6 & 19 & 75 \\
\hline $\mathrm{F} 2$ & 29 & 26 & 3 & 11 & 87 \\
\hline F3 & 29 & 25 & 4 & 15 & 82 \\
\hline $\mathrm{F} 4$ & 26 & 26 & 0 & 0 & 100 \\
\hline F5 & 25 & 25 & 0 & 0 & 100 \\
\hline F6 & 25 & 25 & 0 & 0 & 100 \\
\hline F7 & 24 & 24 & 0 & 0 & 100 \\
\hline F8 & 38 & 26 & 13 & 33 & 46 \\
\hline F9 & 9 & 16 & $*$ & $*$ & - \\
\hline F10 & 24 & 26 & $*$ & $*$ & - \\
\hline F11 & 26 & 26 & 0 & 0 & 100 \\
\hline F12 & 29 & 26 & 4 & 13 & 84 \\
\hline USY-A & 50 & 24 & 26 & 52 & $* *$ \\
\hline $\mathrm{F} 20$ & 24 & 18 & 6 & 25 & $* *$ \\
\hline USY-C & 51 & 22 & 29 & 57 & $* *$ \\
\hline $\mathrm{F} 21$ & 24 & 15 & 9 & 38 & $* *$ \\
\hline 350USY & 29 & 14 & 15 & 52 & $* *$ \\
\hline F22 & 5 & 13 & $*$ & $*$ & - \\
\hline
\end{tabular}

* This difference reflects the errors in the analyses. $* * \mathrm{Al}_{\mathrm{F}}$ attacked by AHFS

via the AHFS chelating agent. Figure $12 \mathrm{~b}$ illustrates that the initial selectivity towards the hydroisomerisation products was $97 \%$ for F20 compared to $92 \%$ for USY-A before the modification and was maintained fairly steadily along the deactivation run. As shown in Fig. 12c, d, the selectivity towards cracked and cyclic products was fairly high for F20 compared with USY-A, which may be due to the $\mathrm{n}_{\mathrm{Pt}} / \mathrm{n}_{\mathrm{A}}$ ratio being disturbed as a consequence of increasing the number of the acid sites $\left(\mathrm{n}_{\mathrm{A}}\right)$ for F20, and also due to the presence of some EFAL species.

From the Fig. 13a, the initial overall conversion was $36 \mathrm{wt} \%$ after $30 \mathrm{~min}$ from introducing the feed to the reactor at the temperatures of $230{ }^{\circ} \mathrm{C}$ for $\mathrm{F} 21$ compared to $46 \mathrm{wt} \%$ for USY-C before the modification, and then decreasing with the TOS to $32 \mathrm{wt} \%$ after $1,000 \mathrm{~min}$ compared to $43 \mathrm{wt} \%$ after the same period of time, and decreasing slowly within the deactivation rate ranging between 1 and $3 \mathrm{wt} \%$ every $24 \mathrm{~h}$ until the reaction was terminated after almost 4 days. Figure $13 \mathrm{~b}$ shows that the initial selectivity towards the hydroisomerisation products was $99 \%$ for F21, which was the same as USY-C before the modification, and kept almost same along the deactivation run. As shown in Fig. 13c and d, the selectivity towards cracked and cyclic products was fairly similar for F21 compared with USY-C.
The influence of nickel on the stability of $\mathrm{Pt} / 350 \mathrm{HOA}$ USY in the hydroisomerisation of $\mathrm{n}-\mathrm{C} 7$

The catalytic properties of a bifunctional catalyst depend on the balance between its acidity and its hydrogenating functions. With respect to its selectivity and stability, increasing the proportion of the hydrogenation function at constant acidity leads to an improved catalyst performance, and for this reason, a series of monometallic and bimetallic bifunctional catalysts was formed by loading the H-USY (350HOA USY, with a global Si $/ \mathrm{Al}=5 \mathrm{~mol} / \mathrm{mol}$, supplied by Tosoh Corporation) with different amounts of platinum, nickel and platinum-nickel by competitive ion exchange, then investigating the effects of nickel as a second metal to $\mathrm{Pt}$ on the stability of the $\mathrm{Pt} / 350 \mathrm{HOA}$ USY catalyst in the hydroisomerisation of $\mathrm{n}-\mathrm{C} 7$ at $230{ }^{\circ} \mathrm{C}$ and 1 atm using $\mathrm{H}_{2} /$ $\mathrm{C} 7=9$ and WHSV $=5.13 \mathrm{~h}^{-1}$. The first series comprised monometallic bifunctional catalysts containing $0.5,1,1.5$ and $2 \mathrm{wt} \%$ of platinum supported on H-USY (350HOA USY), the second was a series of monometallic bifunctional catalysts containing $0.5,1,1.5,2,10$ and $20 \mathrm{wt} \%$ of nickel, also supported on 350HOA USY, and the third series was of bimetallic bifunctional catalysts containing $1 \mathrm{wt} \%$ of platinum and $0.25,0.5,0.75$ and $1 \mathrm{wt} \%$ of nickel, again supported on 350HOA USY. The monometallic catalysts were prepared using the ion-exchange method, while the method used for the bimetallic catalysts was simultaneous competitive ion exchange, which means that the platinum and nickel precursors, $\mathrm{Pt}\left(\mathrm{NH}_{3}\right)_{4} \mathrm{Cl}_{2} \mathrm{H}_{2} \mathrm{O}$ and $\mathrm{Ni}\left(\mathrm{NO}_{3}\right)_{2} 6 \mathrm{H}_{2} \mathrm{O}$, respectively, were mixed together with the zeolite, at the liquid-to-solid ratio of $50(1 \mathrm{~g}$ of zeolite to $50 \mathrm{ml}$ of the metal complex solution), using ammonium hydroxide solution to adjust the $\mathrm{pH}$ of the suspension obtained at $>9$ in order to enhance the uptake and homogenous distribution of the metals within the zeolite grain.

Table 10 shows some characteristics of the mono- and bimetallic bifunctional catalysts so formulated using characterisation techniques such as ICP, XRD, NMR and TGA. Some results were also obtained using XPS and TEM. The quantitative uptake of the loaded metals was verified by elemental analysis using inductively coupled plasma spectroscopy for the hydrofluoric acid digested zeolite samples. It was observed that the uptake of metals by the zeolite support was less than the calculated value. It has been reported that the USY zeolite in its ammonium form had greater ion-exchange efficiency than the zeolite $\mathrm{H}$-USY, due to the greater reduction in the $\mathrm{pH}$ of the reaction medium in the latter case [40]. The $\mathrm{pH}$ was adjusted for this reason, even though the desired molar ratio for the bimetallic catalyst $\mathrm{Pt}-\mathrm{Ni} / \mathrm{USY}$ was obtained. Using X-ray diffraction, it was found that all the diffraction patterns of the metal-loaded catalysts were identical to that of the parent sample of 350HOA USY. Moreover, no

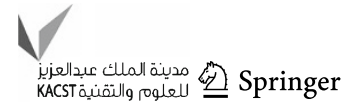




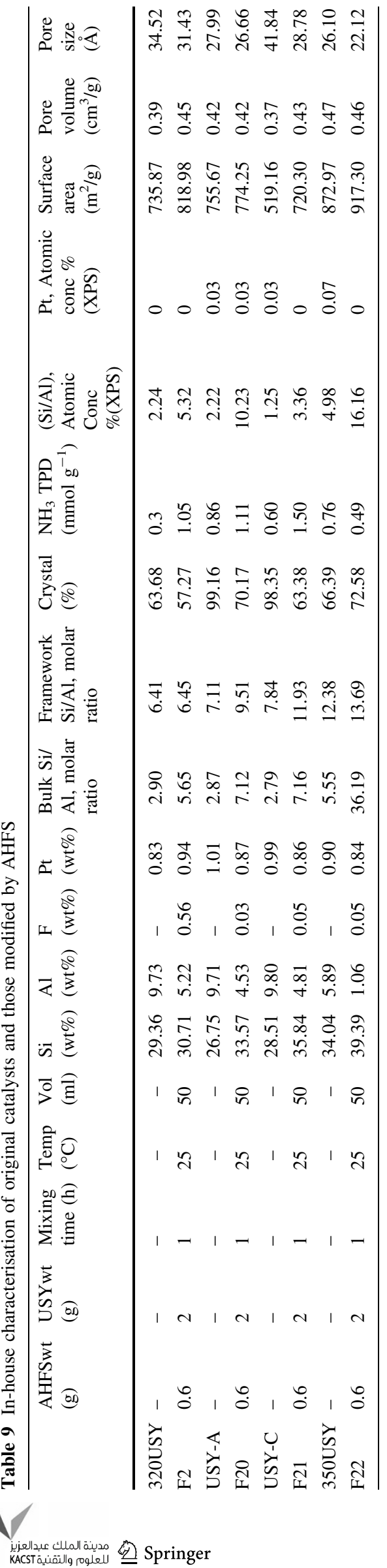

diffraction peaks were assigned to $\mathrm{Pt}$ or $\mathrm{Ni}$, which may indicate high dispersion of these metals. The crystallinity results obtained were in the range of $60-78$, versus $66 \%$ for the parent material. The TEM images for the $1 \mathrm{wt} \% \mathrm{Pt}-$ $1 \mathrm{wt} \% \mathrm{Ni}, 2 \mathrm{wt} \% \mathrm{Pt}$ and spent $2 \mathrm{wt} \% \mathrm{Pt} / 350 \mathrm{USY}$ catalysts are shown in Fig. 14. The black dots appearing on the support matrix are assumed to be $\mathrm{Pt}$ or Pt-Ni particles. The average size of the visible metal particles was found to be in the range of 3-7 nm for the Pt-Ni bimetallic catalyst and in the range of 3-30 $\mathrm{nm}$ for the monometallic samples, as measured manually and averaged [41], indicating that the presence of nickel and platinum in the bimetallic catalysts enhanced greatly the formation of metal particles and reduced their sizes. It was also found that the presence of platinum improved the nickel reduction in comparison to the presence of nickel only [40]. As in the faujasite zeolite structure (zeolite Y), the cavities had a maximum diameter of $1.3 \mathrm{~nm}$, which means that the observed metal particles were located outside the zeolite cavities. Nevertheless, these metallic particles could have been located within the mesopore channels which were created during the hydrothermal dealumination of the $\mathrm{Y}$ zeolite, or at the outer surface of the catalyst grains, as has been reported [40]. It has also been suggested that there are likely to be smaller metal particles inside the cavities which are not detectable by TEM [42, 43]. It was observed that the average metallic particle size in the case of the $2 \mathrm{wt} \% \mathrm{Pt} / 350 \mathrm{USY}$ was unchanged by the deactivation reaction, which may indicate that no metal sintering occurred; however, this conclusion cannot be assured, as TEM was able to study only limited regions of the samples and consequently the results should be interpreted as mainly local [43].

The Figs. 15, 16, and 17 show the effect of TOS on the n-C7 conversion, hydroisomerisation, hydrocracking and cyclic product yields at the reaction temperature of $230{ }^{\circ} \mathrm{C}$ for the first, second and third series of monometallic and bimetallic bifunctional catalysts containing platinum and nickel, supported on H-USY (350HOA USY). Figure 15a indicates that the initial overall conversion values were 47 , 56,57 , and $51 \mathrm{wt} \%$ for the monometallic catalysts containing Pt of $0.5,1,1.5$, and $2 \mathrm{wt} \%$, respectively, after $30 \mathrm{~min}$ from introducing the feed to the reactor at the temperature of $230{ }^{\circ} \mathrm{C}$. All the catalysts underwent small decreases in conversion with TOS up to $12 \mathrm{~h}$, after which there was a significant decrease in conversion for the catalyst containing $0.5 \mathrm{wt} \% \mathrm{Pt}$. The catalyst containing $2 \mathrm{wt} \%$ $\mathrm{Pt}$ was found to have the smaller drop in conversion, while that containing $0.5 \mathrm{wt} \% \mathrm{Pt}$ underwent greatest fall in activity during the TOS. The higher sustainability of the catalyst containing $2 \mathrm{wt} \% \mathrm{Pt}$ can be explained by the formation of catalytically active metallic particles and better balance between metal and acid sites, as shown in Table 10. 

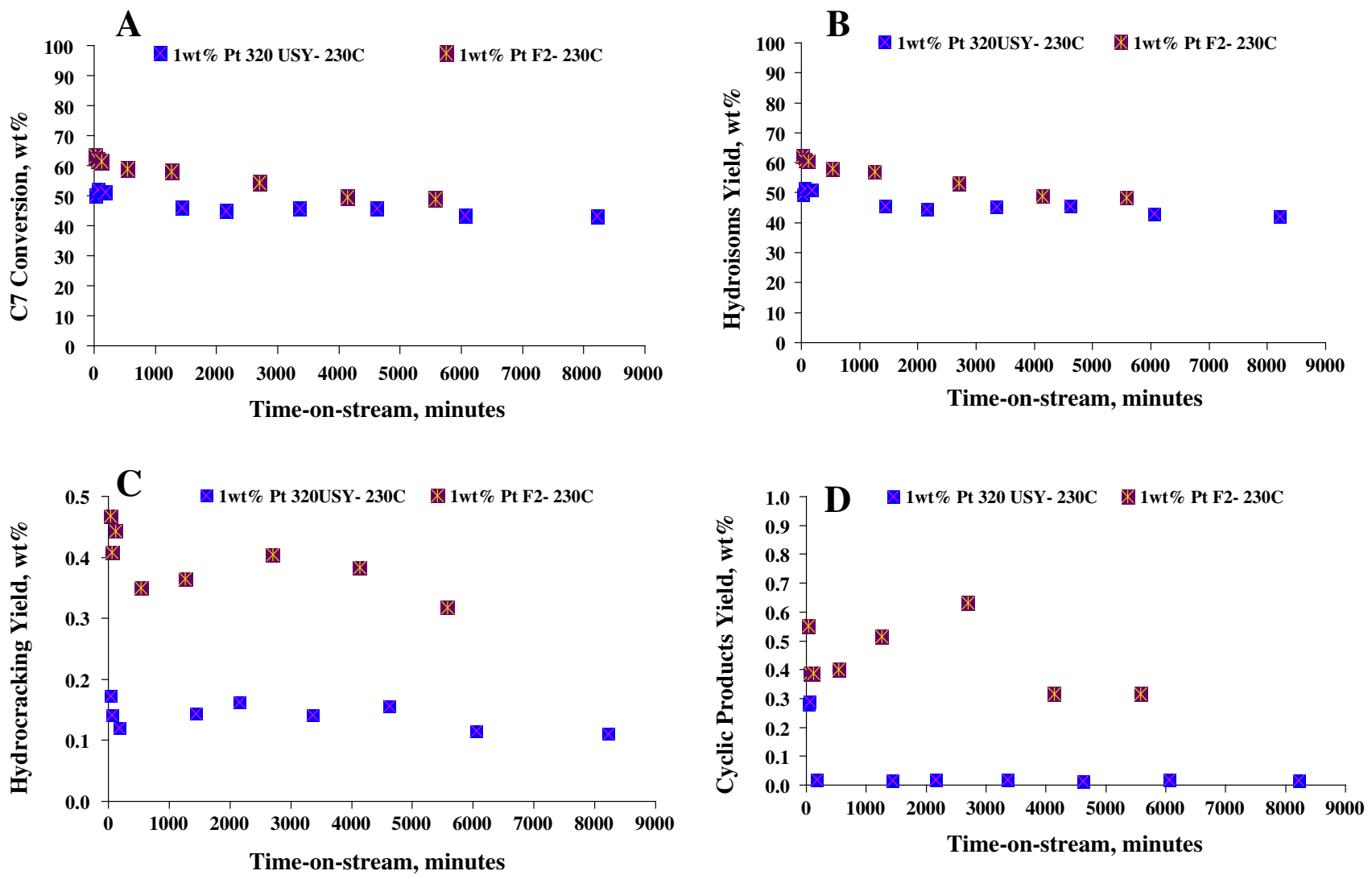

Fig. 11 Overall conversion (a), total yield of C7 isomers (mono $+\mathrm{di}+$ tribranched isomers) (b), total hydrocracking yield (c), and total yield of the cyclic products (d) as a function of TOS for

Figure $15 \mathrm{~b}$ shows that the initial selectivity towards the hydroisomerisation products ranged between 98 and $99 \%$ for all the catalysts, remaining almost unchanged throughout the deactivation run. Furthermore, as shown in the Fig. 15c and d, the selectivity towards cracked and cyclic products respectively was fairly in the range of 1 and $2 \%$ for all the catalysts even if their $n_{\mathrm{Pt}} / \mathrm{n}_{\mathrm{A}}$ ratio is quite different. Nevertheless, $\mathrm{n}_{\mathrm{P}} / \mathrm{n}_{\mathrm{A}}$ ratio was found to be within the optimum balance limits of 0.03 and $0.17\left(0.03 \leq \mathrm{n}_{\mathrm{Pt}} /\right.$ $\left.\mathrm{n}_{\mathrm{A}} \leq 0.17\right)$ for the most catalysts, which may reflect the great dehydrogenation-hydrogenation function capacity of platinum even at the lower contents [40, 41, 44]. The average hard coke contents were found to be in the range of $0.1-0.2 \mathrm{wt} \%$ for all the catalysts except that containing $1 \mathrm{wt} \%$ platinum, for which the coke content was about $0.7 \mathrm{wt} \%$, which may due to the effect of the longer TOS when compared with the other catalysts.

Figure 16a shows that $30 \mathrm{~min}$ after introducing the feed into the reactor at $230{ }^{\circ} \mathrm{C}$, the initial overall conversion rates were 52 and $59 \mathrm{wt} \%$, respectively, for the monometallic catalysts containing 10 and $20 \mathrm{wt} \% \mathrm{Ni}$. After $180 \mathrm{~min}$ on stream, there was a large drop in activity to 30 and $45 \mathrm{wt} \%$, then a sustained and rapid deactivation rate until a pseudo-stable state was reached at activity levels of

F2 catalyst at various reaction temperatures. WHSV $=5.13 \mathrm{~h}^{-1} ; \mathrm{H}_{2} /$ $\mathrm{C} 7(\mathrm{~mol} / \mathrm{mol})=9 ;$ total pressure $=1 \mathrm{~atm} ;$ temperature $=230{ }^{\circ} \mathrm{C} ; 1$ wt\% Pt loading

10 and $16 \mathrm{wt} \%$, respectively, persisting until the reactions terminated. Deactivation was also found to be very rapid for the monometallic catalysts containing $\mathrm{Ni}$ at $0.5,1,1.5$ and $2 \mathrm{wt} \%$. This behaviour may be explained in terms of the poor hydrogenating capacity of Ni compared to Pt [44], making it more difficult for the $\mathrm{Ni}$ atoms to be fully reduced, so that not enough $\mathrm{Ni}$ metallic sites were available to sustain the reaction, since the hydroisomerisation reaction includes a dehydrogenation step [40, 42]. Therefore, selectivity to form the $\mathrm{C} 7$ isomers was lower than for the catalysts containing $\mathrm{Pt}$, while higher cracked and cyclic product yields were obtained, which means that higher coke content was formed, possibly blocking and poisoning the active sites of the catalysts during the deactivation reaction. In addition, the low stability of catalysts with higher nickel content may be explained by the tendency of $\mathrm{Ni}$ to polymerise olefins and hence to form coke [42].

Figure 17a shows that the initial overall conversion rates were $66,72,66$ and $67 \mathrm{wt} \%$ for the bimetallic bifunctional catalysts containing $1 \mathrm{wt} \% \mathrm{Pt}$ and $0.25,0.5,0.75$ and $1 \mathrm{wt} \% \mathrm{Ni}$, respectively, $30 \mathrm{~min}$ after introducing the feed into the reactor. All of these catalysts showed small decreases in conversion with TOS up to $12 \mathrm{~h}$, after which there was a continuous moderate decrease in conversion 

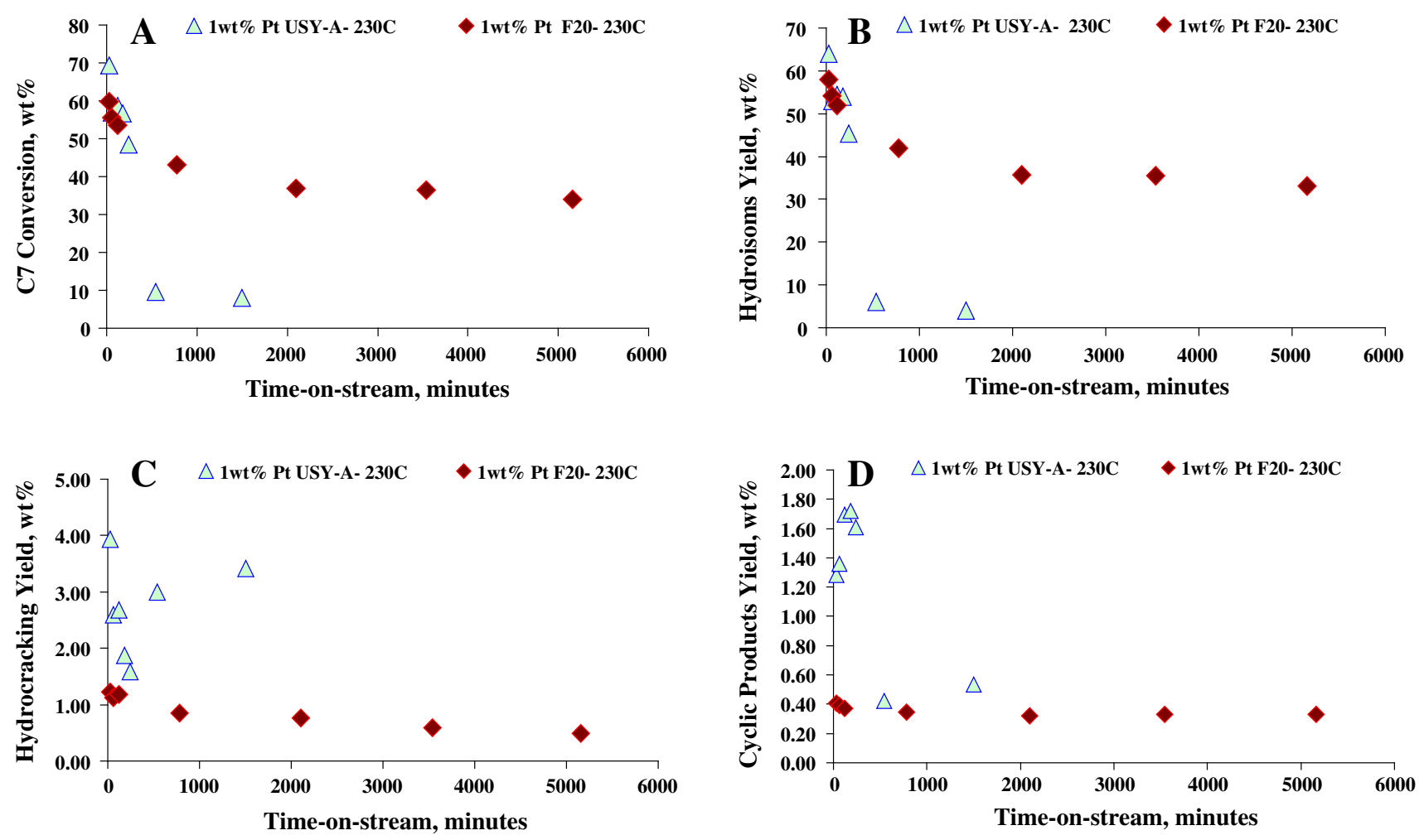

Fig. 12 Overall conversion (a), total yield of C7 isomers (mono $+\mathrm{di}+$ tribranched isomers) (b), total hydrocracking yield (c), and total yield of the cyclic products (d) as a function of TOS for

until the reactions terminated. Figure $17 \mathrm{~b}$ indicates that initial selectivity towards the hydroisomerisation products ranged between 98 and $99 \%$ for all of the catalysts, remaining almost constant throughout the deactivation run. Furthermore, as shown in the Fig. 17c and d, selectivity towards cracked and cyclic products respectively was broadly in the range of 1-2\% for all of the catalysts. On the other hand, the maximum hard coke content was found in the bimetallic catalyst containing $1 \mathrm{wt} \% \mathrm{Pt}$ and $1 \mathrm{wt} \%$ $\mathrm{Ni}$, as shown in the Table 10.

It can be concluded that a small addition of Pt motivated a substantial increase in hydrogenating activity when compared with the catalysts containing only $\mathrm{Ni}$, as reported in the literature [30]. It also appears that the presence of platinum enhanced the reduction of the nickel cations, increasing the dispersion of the two metals as the nickel particles provided support for the Pt atoms, indicating that the Pt atoms were inserted into the nickel crystallite [40, 42]. On the other hand, it was found that increasing $\mathrm{Ni}$ loadings inhibited both the activity and selectivity of the catalyst, which may be interpreted as indicating that the formation of larger bimetallic Ni-Pt particles at higher $\mathrm{Ni}$ loadings resulted in some $\mathrm{Ni}$ content not being reduced, thus contributing to pore blockage of the catalyst and reducing the availability of catalyst acid sites accordingly [44].

F20 catalyst at various reaction temperatures. WHSV $=5.13 \mathrm{~h}^{-1}$; $\mathrm{H}_{2} / \mathrm{C} 7 \quad(\mathrm{~mol} / \mathrm{mol})=9 ;$ total pressure $=1 \mathrm{~atm} ;$ temperature $=$ $230{ }^{\circ} \mathrm{C} ; 1 \mathrm{wt} \%$ Pt loading

Effect of platinum loading method on CP814E beta

Bifunctional zeolite catalysts typically have two types of active centres, the hydrogenation/dehydrogenation sites provided by the metal (such as platinum) for the formation of olefinic intermediates, and the acidic site for isomerisation and cracking. In the case of Pt-loaded zeolite catalysts in the ammonium form, the method most commonly used to introduce platinum into the pores and obtain a homogeneous filling in the crystallites of the zeolite is cationic exchange, using platinum tetraammine $\left[\mathrm{Pt}\left(\mathrm{NH}_{3}\right)_{4}\right]^{2+}$ complexes in an aqueous solution in the presence of a competing cation, generally an ammonium ion, $\mathrm{NH}_{4}{ }^{+}$. A second method to introduce platinum in the pores is incipient wetness impregnation by which the platinum tetraammine will randomly be deposited in the zeolite pores whereas only one platinum tetraammine complex can be associated with an aluminium site, and thus an atomic dispersion of the complexes inside the pores is expected with the ionexchange method. Therefore, more dispersed platinum and consequently smaller particles using the ion-exchange method would be produced than via the impregnation method [27, 29, 45]. The purpose of this study was to examine the effects of platinum loading of beta zeolite by ion-exchange and impregnation methods, examining the 

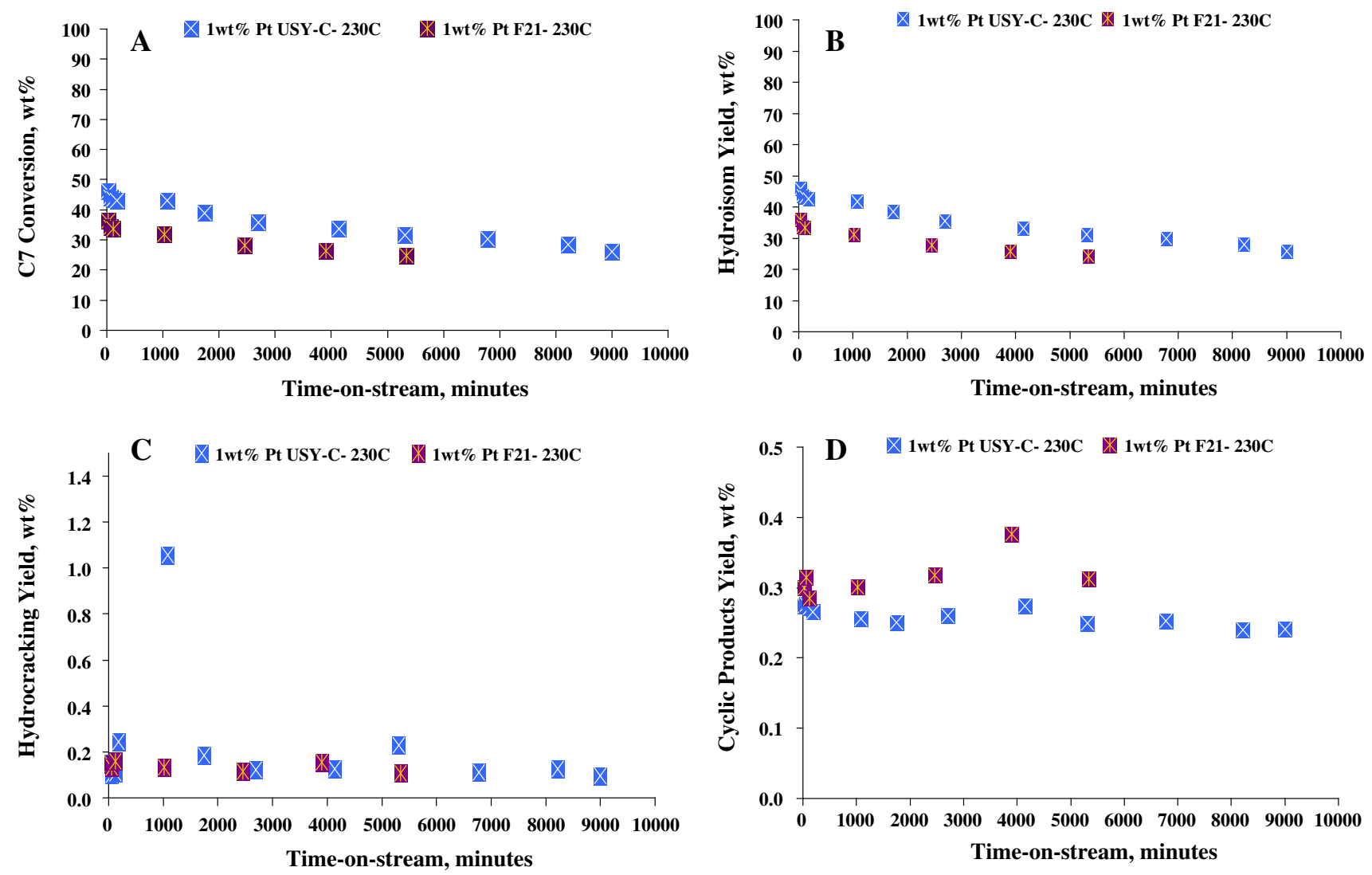

Fig. 13 Overall conversion (a), total yield of C7 isomers (mono $+\mathrm{di}+$ tribranched isomers) $(\mathbf{b})$, total hydrocracking yield (c), and total yield of the cyclic products (d) as a function of TOS for

TOS stability of $1 \mathrm{wt} \%$ Pt-loaded CP814 beta, where its deactivation behaviour was studied in the previous work [31], in the hydroisomerisation of $\mathrm{n}-\mathrm{C} 7$ at constant reaction conditions and the effect of $\mathrm{pH}$ on the ion-exchange process.

Figure 18a-d shows the effects of TOS for the C7 conversion, hydroisomerisation, hydrocracking, and cyclic product yields for the catalyst with $1 \mathrm{wt} \% \mathrm{Pt} / \mathrm{CP} 814 \mathrm{E}$ in which the platinum was loaded by one of three procedures: (1) preparation of the ion-exchange system using an aqueous solution of tetraammine platinum (II) chloride complex mixed with the ammonium-beta zeolite CP814E and the addition of the competing cation $\mathrm{NH}_{4}^{+}$using ammonia solution at $\mathrm{pH}>9$, (2) preparation of the ionexchange system using an aqueous solution of tetraammine platinum (II) chloride complex mixed with the ammoniumbeta zeolite CP814E without adding ammonia solution such that the $\mathrm{pH}=4-5$, and (3) preparation by wet impregnation using an aqueous solution of tetraammine platinum (II) chloride complex mixed with the ammoniumbeta zeolite CP814E without adding ammonia solution, such that the $\mathrm{pH}=4-5$. As Fig. 18a shows, initially the overall conversion of $\mathrm{C} 7$ for the three catalysts was 77,88 ,

F21 catalyst at various reaction temperatures. WHSV $=5.13 \mathrm{~h}^{-1}$; $\mathrm{H}_{2} / \mathrm{C} 7 \quad(\mathrm{~mol} / \mathrm{mol})=9 ; \quad$ total pressure $=1 \mathrm{~atm} ; \quad$ temperature $=230{ }^{\circ} \mathrm{C} ; 1 \mathrm{wt} \%$ Pt loading

and $90 \mathrm{wt} \%$ after $30 \mathrm{~min}$ from the point when the feed was introduced to the reactor at $230^{\circ} \mathrm{C}$, prepared by the three procedures described above. The catalysts lost about $1-2 \mathrm{wt} \%$ of their activity before reaching a pseudo-stable state for the initial $60 \mathrm{~min}$ on stream, and then slightly decreased with a further increase in time until the reactions were finally terminated. On the other hand, the selectivity towards hydroisomerisation products was 99,85 , and $85 \%$ after $30 \mathrm{~min}$ and then increased with time to 99,89 , and $89 \%$ for the three catalysts, respectively. Furthermore, the greatest selectivity towards cracked products was $15 \%$ and slightly decreased with TOS to approximately $9 \%$ for the catalysts which were prepared by the ion-exchange method with $\mathrm{pH}=4-5$ and by the wet impregnation method. The selectivity towards the cyclic products was very low for the three catalysts along the deactivation runs.

The variation in $\mathrm{C} 1 / \mathrm{C} 3$ mass ratio with TOS for the three catalysts at constant reaction conditions is shown in Fig. 19, with both the acid and metal functions being initially active and deactivated rapidly as indicated by the $\mathrm{C} 1 /$ $\mathrm{C} 3$ ratio. This could be explained by a change occurring in the balance between the two functions with TOS due to coke depositions for both functions. Furthermore, in all the

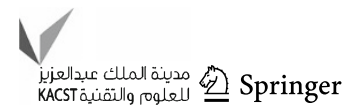


Table 10 Different metal loadings wt $\%$ on $350 \mathrm{HOA}$ USY

\begin{tabular}{|c|c|c|c|c|c|c|c|c|c|c|c|c|}
\hline & $\begin{array}{l}\mathrm{Al} \\
(\mathrm{wt} \%)\end{array}$ & $\begin{array}{l}\mathrm{Si} \\
\text { (wt\%) }\end{array}$ & $\begin{array}{l}\text { Bulk (Si/ } \\
\mathrm{Al})(\mathrm{mol} / \\
\mathrm{mol})\end{array}$ & $\begin{array}{l}\text { Framework } \\
(\mathrm{Si} / \mathrm{Al})(\mathrm{mol} / \\
\mathrm{mol})\end{array}$ & $\begin{array}{l}\text { Crystallinity } \\
(\%)\end{array}$ & $\begin{array}{l}\text { Actual } \\
\mathrm{Ni} \\
(\mathrm{wt} \%)\end{array}$ & $\begin{array}{l}\text { Actual } \\
\mathrm{Pt} \\
(\mathrm{wt} \%)\end{array}$ & $\begin{array}{l}\text { Theoretical } \\
\mathrm{Ni}(\mathrm{wt} \%)\end{array}$ & $\begin{array}{l}\text { Theoretical } \\
\text { Pt (wt\%) }\end{array}$ & $\begin{array}{l}\mathrm{Ni} / \mathrm{Pt} \\
(\mathrm{mol} / \\
\mathrm{mol})\end{array}$ & $\begin{array}{l}\mathrm{n}_{\mathrm{Pt}} / \\
\mathrm{n}_{\mathrm{A}}\end{array}$ & $\begin{array}{l}\text { Hard } \\
\text { coke } \\
(\mathrm{wt} \%)\end{array}$ \\
\hline $\begin{array}{c}350 \mathrm{HOA} \\
\text { USY }\end{array}$ & 5.89 & 34.04 & 5.55 & 12.38 & 66 & - & - & - & - & - & - & - \\
\hline \multicolumn{13}{|c|}{$\mathrm{Pt} / 350 \mathrm{HOA}$ USY } \\
\hline $0.5 \% \mathrm{Pt}$ & - & - & - & - & - & - & 0.36 & - & 0.50 & - & 0.02 & 0.19 \\
\hline $1 \% \mathrm{Pt}$ & 5.89 & 34.04 & 5.55 & 12.38 & 66 & - & 0.90 & - & 1.00 & - & 0.06 & 0.66 \\
\hline $1.5 \% \mathrm{Pt}$ & - & - & - & - & - & - & 1.17 & - & 1.50 & - & 0.08 & 0.13 \\
\hline $2 \% \mathrm{Pt}$ & - & - & - & - & - & - & 1.46 & - & 2.00 & - & 0.10 & 0.14 \\
\hline \multicolumn{13}{|c|}{$\mathrm{Pt}-\mathrm{Ni} / 350 \mathrm{HOA}$ USY } \\
\hline $\begin{array}{l}1 \% \mathrm{Pt}- \\
0.25 \% \mathrm{Ni}\end{array}$ & 5.29 & 27.50 & 5.00 & - & 60 & 0.22 & 0.90 & 0.25 & 1.00 & 0.81 & 0.11 & 0.47 \\
\hline $\begin{array}{l}1 \% \mathrm{Pt}- \\
0.5 \% \mathrm{Ni}\end{array}$ & 5.29 & 27.60 & 5.01 & - & 63 & 0.44 & 0.91 & 0.50 & 1.00 & 1.61 & 0.16 & 0.62 \\
\hline $\begin{array}{l}1 \% \text { Pt- } \\
0.75 \%\end{array}$ & 5.31 & 27.65 & 5.00 & - & 61 & 0.68 & 0.92 & 0.75 & 1.00 & 2.46 & 0.21 & 0.43 \\
\hline $\begin{array}{l}1 \% \mathrm{Pt}- \\
1 \% \mathrm{Ni}\end{array}$ & 5.31 & 27.97 & 5.06 & 11.57 & 60 & 0.92 & 0.91 & 1.00 & 1.00 & 3.36 & 0.27 & 1.01 \\
\hline \multicolumn{13}{|c|}{ Ni/350HOA USY } \\
\hline $0.5 \% \mathrm{Ni}$ & - & - & - & - & - & 0.44 & - & 0.50 & - & - & 0.10 & - \\
\hline $1 \% \mathrm{Ni}$ & - & - & - & - & - & 0.88 & - & 1.00 & - & - & 0.20 & - \\
\hline $1.5 \% \mathrm{Ni}$ & - & - & - & - & - & 1.28 & - & 1.50 & - & - & 0.29 & - \\
\hline $2 \% \mathrm{Ni}$ & - & - & - & 11.03 & - & 1.86 & - & 2.00 & - & - & 0.42 & - \\
\hline $10 \% \mathrm{Ni}$ & 4.74 & 27.74 & 5.62 & 10.86 & 73 & 7.48 & - & 10.00 & - & - & 1.68 & - \\
\hline $20 \% \mathrm{Ni}$ & 4.28 & 24.83 & 5.57 & 10.58 & - & 11.96 & - & 20.00 & - & - & 2.68 & - \\
\hline
\end{tabular}

three catalysts, the metal function deactivated faster than the acid function; however, this was not severe enough to cause a drop in the $\mathrm{n}-\mathrm{C} 7$ conversion. The worst metal/acid balance was found for the catalysts that were prepared by ion exchange with the $\mathrm{pH}=4-5$ and by the wet impregnation method, as indicated by the lower values of $\mathrm{C} 1 / \mathrm{C} 3$, and as such higher cracking activity was observed for those two catalysts. Moreover, the two catalysts demonstrated poor metal dispersion resulting in some of the metal being deposited on the outside of the crystals and not within the zeolite pores, as compared to the catalyst that was prepared by ion exchange with the $\mathrm{pH}>9$.

\section{Effect of CP814E composites}

The zeolite-based composite materials consisting of two distinct phases with entirely different pore structure and acidity have been used extensively both as catalysts, and to minimise the formation of coking, thus increasing the lifetime of the catalyst. Beta zeolite can also be used as an additive to FCC cracking catalysts because it favours reactions that improve the octane number of gasoline since the feedstocks consist of bulky poly-nuclear molecules which cannot diffuse inside the zeolite pores. Composite catalysts made of a zeolitic and a non-zeolitic active oxide/ poly-oxide as a matrix can be used to crack the bulky feed molecules into smaller molecules which can diffuse inside the zeolite pores providing a two-phase system of the composite that operates synergistically. This synergism is a result of the open structure of the matrix that allows easy intra-particle diffusion and favours the primary cracking of the bulky feed molecules, as a result of the balance between the acidic sites and the metallic sites due to the dispersion of Pt throughout the matrix [27, 46, 47].

In this work, TOS experiments were carried out on the hydroisomerisation of n-C7 using hybrid catalysts consisting of CP814E and USY-C at identical reaction conditions, and thus the relation between zeolite pore structure and its resistance to coke deactivation is examined for the composite catalysts formed. Two composite bifunctional catalysts were prepared as follows: (1) the catalysts $1 \mathrm{wt} \%$ $\mathrm{Pt} / \mathrm{CP} 814 \mathrm{E}$ and $1 \mathrm{wt} \% \mathrm{Pt} / \mathrm{USY}-\mathrm{C}$ were mixed physically at mass ratio of $1: 1$. (2) $\mathrm{CP} 814 \mathrm{E}$ and USY-C in their ammonium forms were mixed at mass ratio of $1: 1$, and were loaded by $1 \mathrm{wt} \% \mathrm{Pt}$ using the ion-exchange method.

The effect of TOS on the C7 conversion, hydroisomerisation, hydrocracking, and cyclic product yields at reaction temperature of $230{ }^{\circ} \mathrm{C}$ are shown in the Fig. 20a-d, 

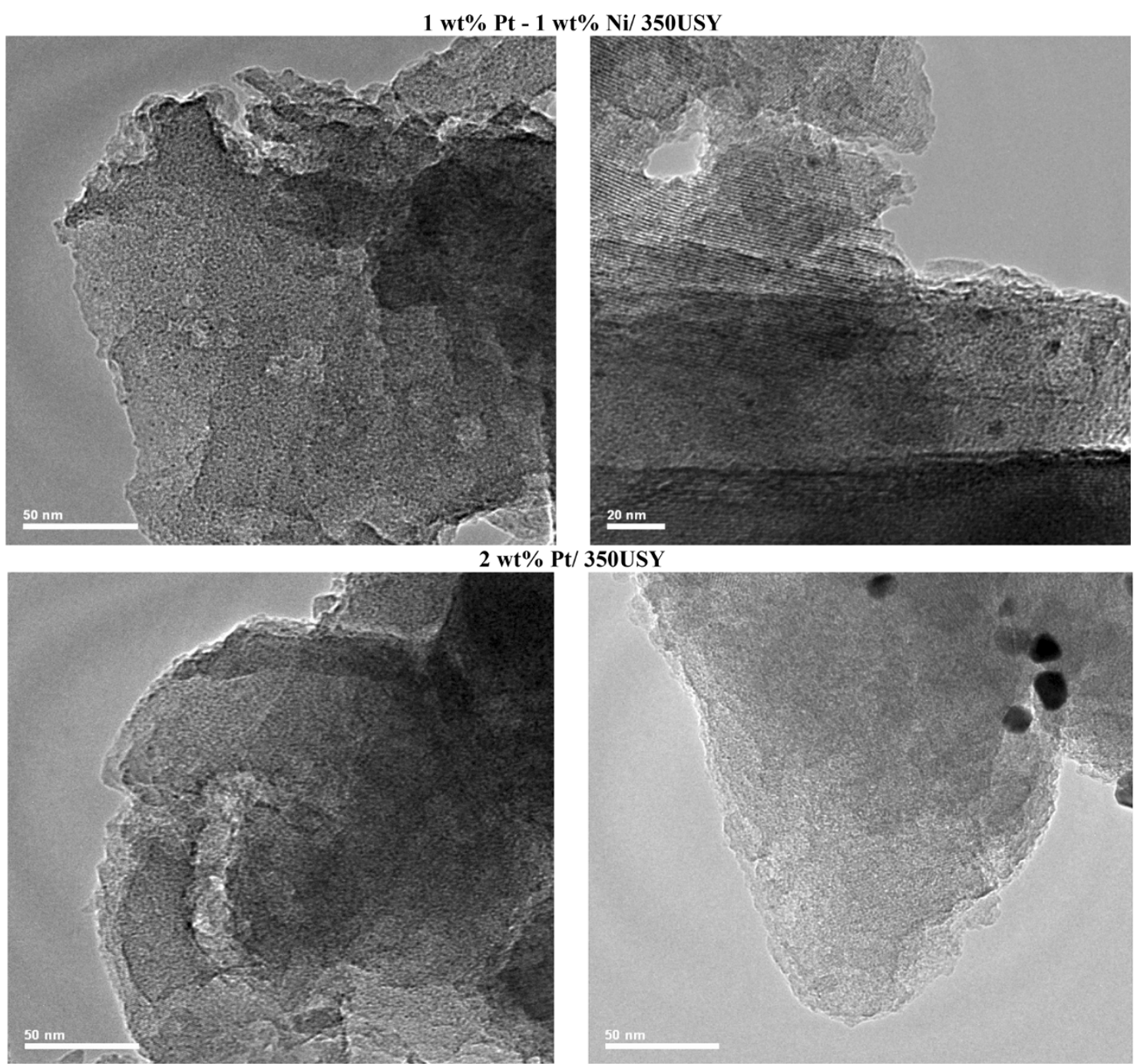

Spent 2 wt\% Pt/ 350USY
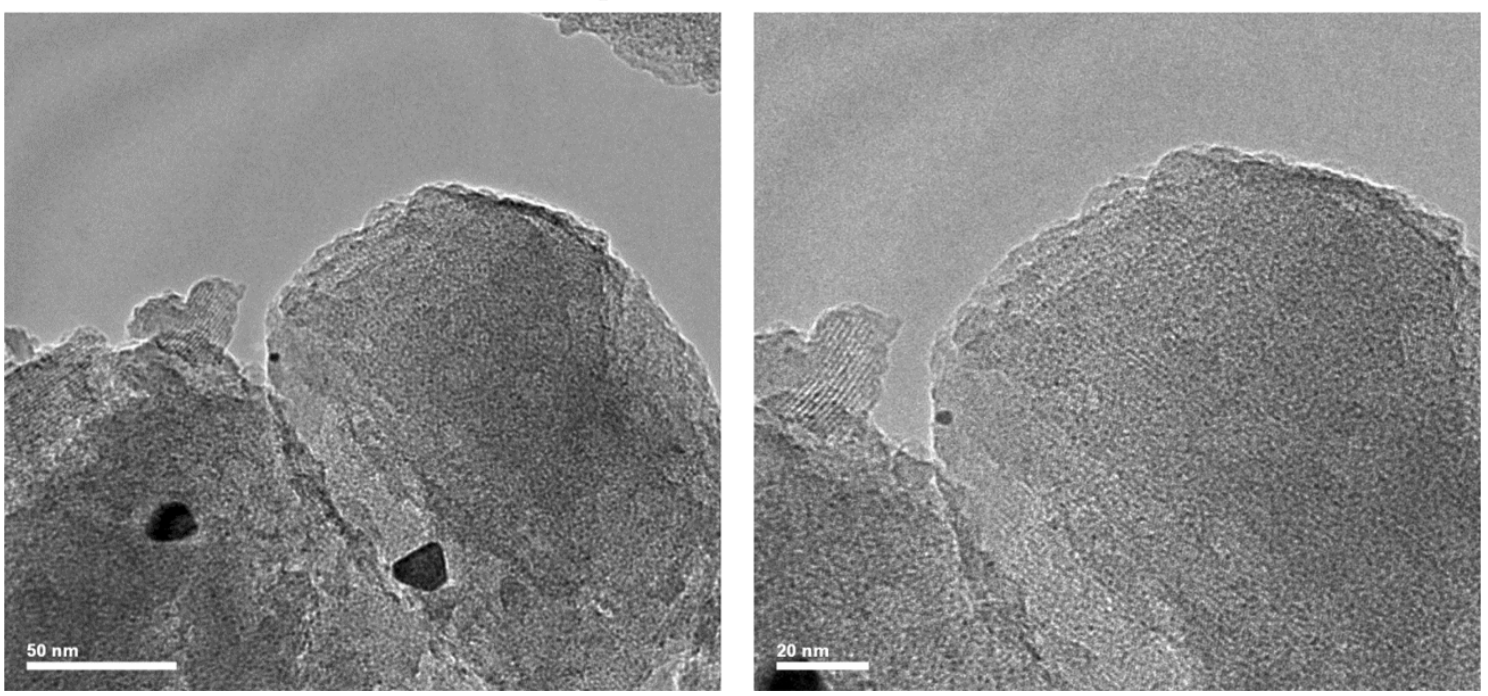

Fig. 14 TEM images of $1 \mathrm{wt} \% \mathrm{Pt}-1 \mathrm{wt} \% \mathrm{Ni}, 2 \mathrm{wt} \% \mathrm{Pt}$ and spent $2 \mathrm{wt} \% \mathrm{Pt} / 350 \mathrm{USY}$ 

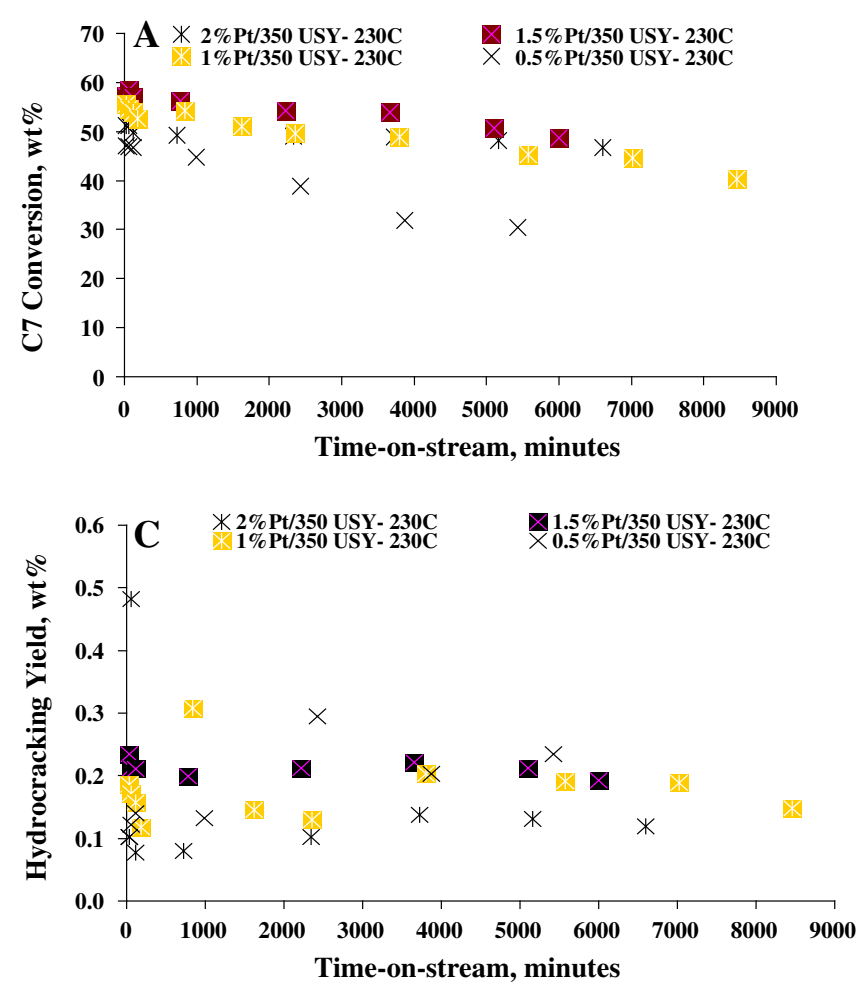

Fig. 15 Overall conversion (a), total yield of C7 isomers (mono $+\mathrm{di}+$ tribranched isomers) (b), total hydrocracking yield (c), and total yield of the cyclic products (d) as a function of TOS for

respectively, for the catalysts: $1 \mathrm{wt} \% \mathrm{Pt} / \mathrm{CP} 814 \mathrm{E}, 1 \mathrm{wt} \% \mathrm{Pt} /$ USY-C, $1 \mathrm{wt} \% \mathrm{Pt} / \mathrm{USY}-\mathrm{CP} 814 \mathrm{E}$ physically mixed, and $1 \mathrm{wt} \% \mathrm{Pt} / \mathrm{USY}-\mathrm{CP} 814 \mathrm{E}$ physically mixed and loaded by $\mathrm{Pt}$ together by the ion-exchange method with ammonia added to adjust the $\mathrm{pH}$ to be more than 9 . As Fig. 20a shows, initially the overall conversion of $\mathrm{C} 7$ for the $1 \mathrm{wt} \% \mathrm{Pt} / \mathrm{USY}-\mathrm{CP} 814 \mathrm{E}$ physically mixed was $66 \mathrm{wt} \%$, which is in between that of the corresponding individual catalysts, compared with 77 and $46 \mathrm{wt} \%$ for the catalysts $1 \mathrm{wt} \% \mathrm{Pt} / \mathrm{CP} 814 \mathrm{E}$ and $1 \mathrm{wt} \% \mathrm{Pt} /$ USY-C, respectively. The conversion then decreased abruptly at the initial stages of the reaction, and finally reached a relatively steady value, after which the conversion decreased steeply with the TOS until the reaction was terminated after $183 \mathrm{~h}$. Thus, this composite catalyst demonstrated a better TOS activity than $1 \mathrm{wt} \% \mathrm{Pt} / \mathrm{USY}-\mathrm{C}$ catalyst, but slightly worse than $1 \mathrm{wt} \% \mathrm{Pt} / \mathrm{CP} 814 \mathrm{E}$. Even its selectivity toward the $\mathrm{C} 7$ isomers and cracked products was very similar to both catalysts along the deactivation run.

On the other hand, the composite catalyst $1 \mathrm{wt} \% \mathrm{Pt} / \mathrm{USY}$ CP814E, physically mixed and loaded with Pt using ion exchange and subsequently deactivated as with the $1 \mathrm{wt} \% \mathrm{Pt} /$ CP814E catalyst, offered slightly higher activity towards the cracked products along the deactivation run, with the initial conversion of $78 \mathrm{wt} \%$ decreasing slightly with TOS to $67 \mathrm{wt} \%$ with the reaction terminating after $83 \mathrm{~h}$. The
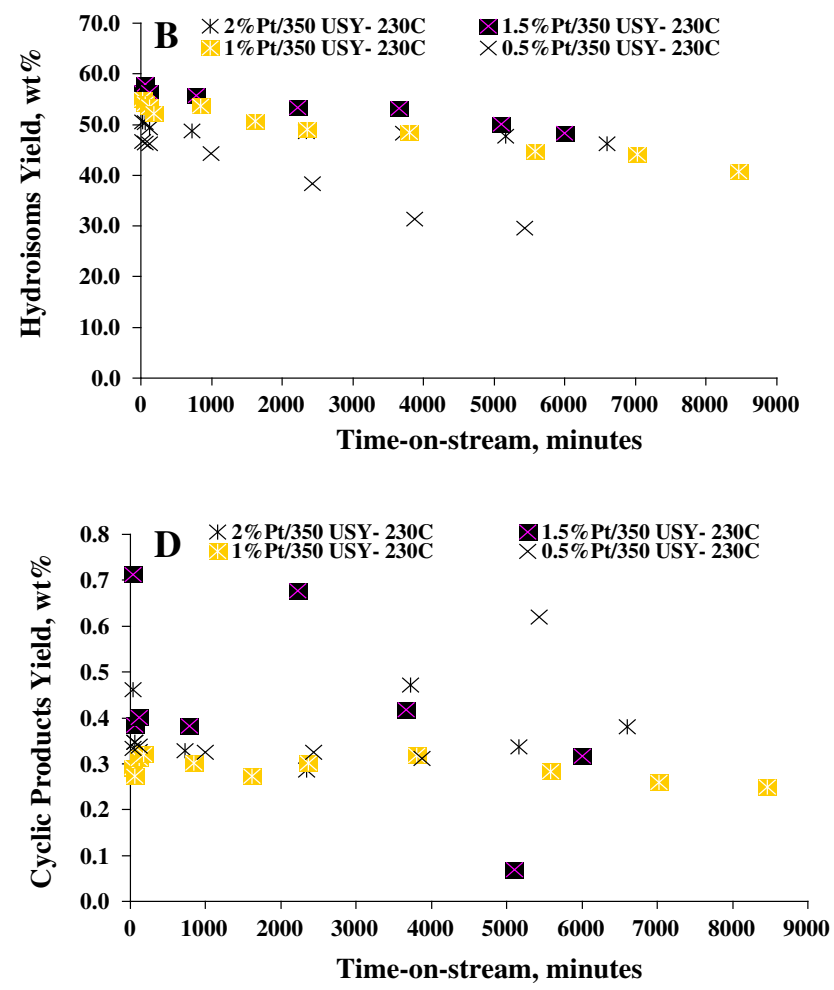

the monometallic catalysts containing $\mathrm{Pt}$ at various reaction temperatures. $\mathrm{WHSV}=5.13 \mathrm{~h}^{-1} ; \mathrm{H}_{2} / \mathrm{C} 7(\mathrm{~mol} / \mathrm{mol})=9$; total pressur$\mathrm{e}=1 \mathrm{~atm}$; temperature $=230{ }^{\circ} \mathrm{C} ; 1 \mathrm{wt} \%$ Pt loading

selectivity towards the $\mathrm{C} 7$ isomers and cracked products was 96 and $3 \%$, respectively, and the composite catalyst demonstrated a better TOS activity than the $1 \mathrm{wt} \%$ Pt/USY-C catalyst, and a similar deactivation pattern to the $1 \mathrm{wt} \% \mathrm{Pt} /$ CP814E even though the selectivity towards the cracked products was higher. This indicates that the $1 \mathrm{wt} \% \mathrm{Pt} / \mathrm{USY}-\mathrm{C}$ catalyst was the dominant component in the formulated composite catalyst of $1 \mathrm{wt} \% \mathrm{Pt} / \mathrm{USY}-\mathrm{CP} 814 \mathrm{E}$ and provided a better TOS stability and higher activity. On the other hand, the $1 \mathrm{wt} \% \mathrm{Pt} / \mathrm{CP} 814 \mathrm{E}$ catalyst was the dominant component for the composite catalyst $1 \mathrm{wt} \% \mathrm{Pt} / \mathrm{USY}-\mathrm{CP} 814 \mathrm{E}$ loaded with Pt using ion exchange. Figure 21 shows the deposited hard coke contents over the top, middle, and bottom zones of the individual and composite catalysts. It can be seen that the lowest hard coke content was found for the $1 \mathrm{wt} \% \mathrm{Pt} / \mathrm{USY}-\mathrm{C}$ and the highest for the $1 \mathrm{wt} \% \mathrm{Pt} / \mathrm{CP} 814 \mathrm{E}$ catalyst, with the composite catalyst having a hard coke content part way between that of the corresponding individual catalysts. The total acidity for ammonia TPD for the $1 \mathrm{wt} \%$ Pt/CP814E, $1 \mathrm{wt} \%$ Pt/USY-C, and $1 \mathrm{wt} \% \mathrm{Pt} / \mathrm{USY}$-CP814E physically mixed was found to be $0.63,0.60$ and $1.88 \mathrm{mmol} \mathrm{g}^{-1}$, respectively. Thus, it can be seen that even the composite catalyst has the highest acidity which is almost double compared with the corresponding individual catalysts. It has moderate hard coke content and fairly good TOS catalytic stability. 

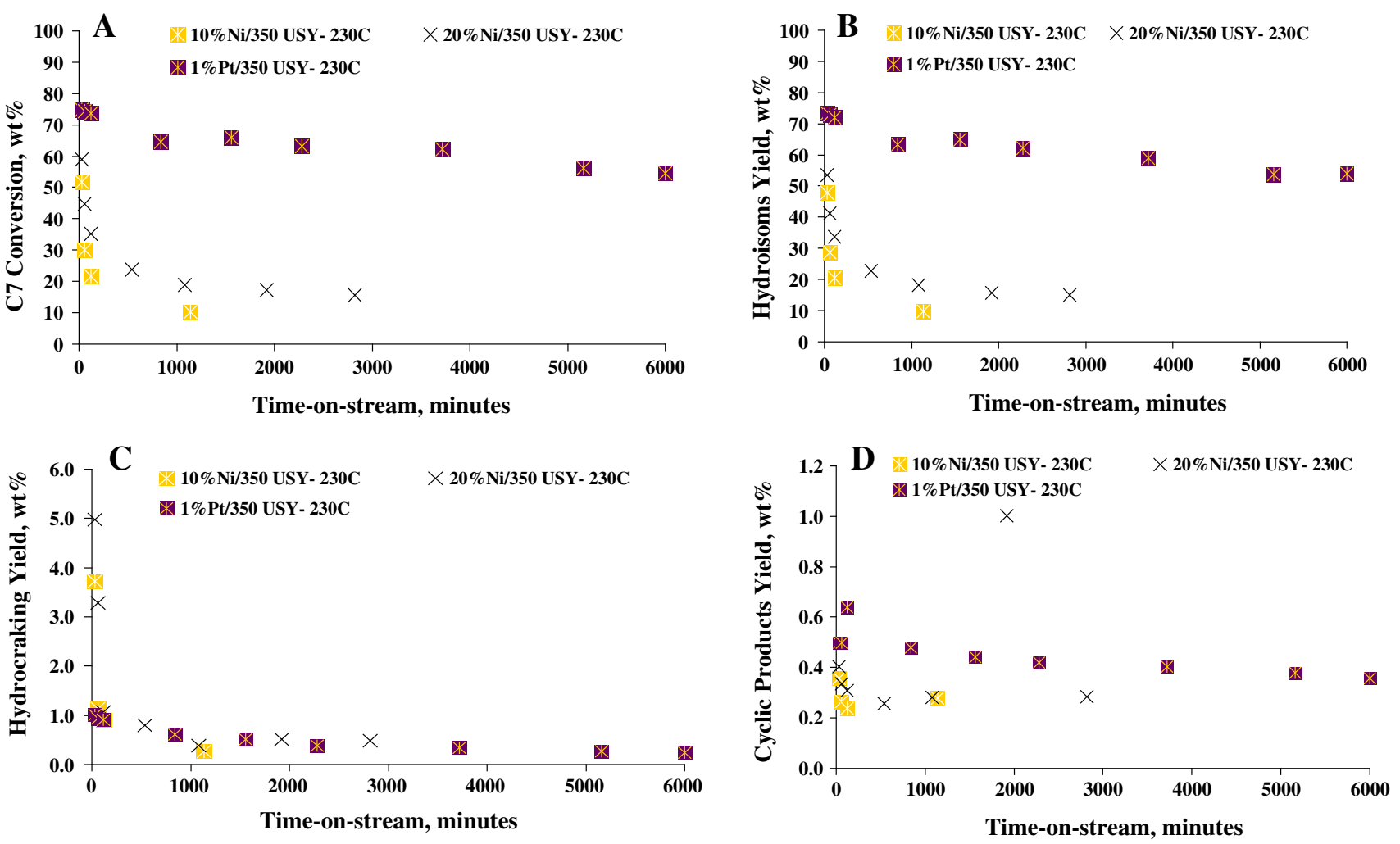

Fig. 16 Overall conversion (a), total yield of C7 isomers (mono $+\mathrm{di}+$ tribranched isomers) (b), total hydrocracking yield (c), and total yield of the cyclic products (d) as a function of TOS for

Main characteristics of in-house mordenite zeolites

Mordenite zeolite was synthesised using the molar gel composition of $\left(6 \mathrm{Na}_{2} \mathrm{O}: \mathrm{Al}_{2} \mathrm{O}_{3}: 30 \mathrm{SiO}_{2}: 780 \mathrm{H}_{2} \mathrm{O}\right)$, which is the synthesis recipe of mordenite obtained from a verified synthesis handbook [21]. The mordenite phase with the highest purity and crystallinity was optimised against certain synthesis parameters while keeping this composition ratio constant. Three factors were optimised: the ageing time of the synthesis gel, the crystallisation time and the crystallisation temperature. Table 11 shows the phase crystallinity, the bulk $\mathrm{Si} / \mathrm{Al}$ ratio and the framework $\mathrm{Si} / \mathrm{Al}$ ratio of the mordenite obtained by optimising these three factors. It can be seen that the optimum synthesis conditions were when the ageing time was $12 \mathrm{~h}$, crystallisation time was $24 \mathrm{~h}$ and crystallisation temperature was $180{ }^{\circ} \mathrm{C}$. Under these conditions, the mordenite zeolite phase obtained had a crystallinity of $82 \%$, bulk Si/Al ratio of $8.44(\mathrm{~mol} / \mathrm{mol})$ and framework Si/Al ratio of $9.02(\mathrm{~mol} /$ $\mathrm{mol}$ ). This procedure was repeated more than 10 times and reproducible results were obtained in terms of the yield, crystallinity, bulk and framework $\mathrm{Si} / \mathrm{Al}$ ratio, as well as of the crystal morphology and size.

Figures 22 and 23 show the SEM microgram and XRD pattern of this in-house mordenite catalyst. The former

the monometallic catalysts containing $\mathrm{Ni}$ at different reaction temperatures. WHSV $=5.13 \mathrm{~h}^{-1} ; \mathrm{H}_{2} / \mathrm{C} 7(\mathrm{~mol} / \mathrm{mol})=9$; total pressure $=1 \mathrm{~atm}$; temperature $=230{ }^{\circ} \mathrm{C} ; 1 \mathrm{wt} \%$ Pt loading

shows that the catalyst contained large crystallites of 15-20 $\mu \mathrm{m}$ whose elliptical shape was different from that of commercial catalysts, and it has been previously reported that synthetic mordenite presents several morphologies, as a function of the crystallisation conditions [48]. The XRD patterns show a pure phase of mordenite consistent with that found previously [49]. However, it had a lower crystallinity than CBV21A [31], which also has a higher bulk $\mathrm{Si} / \mathrm{Al}$ ratio. Figure $24 \mathrm{a}$ and $\mathrm{b}$ shows respectively the ${ }^{27} \mathrm{Al}$ and ${ }^{29} \mathrm{Si}$ solid-state NMR spectra of this in-house mordenite catalyst. It can be seen that the catalyst had only one ${ }^{27} \mathrm{Al}$ peak at about $56 \mathrm{ppm}$, which was assigned to tetrahedrally coordinated aluminium, and there were no additional EFAL peaks. In the ${ }^{29} \mathrm{Si}$ MAS NMR spectrum, two peaks at 112 and $106 \mathrm{ppm}$ were assigned to $\mathrm{Si}(0 \mathrm{Al})$ and $\mathrm{Si}(1 \mathrm{Al})$ configurations, respectively.

Post-synthesis modification of in-house mordenite zeolite

Post-synthesis treatment by steam or acid attack, often referred to as dealumination, can remove aluminium from the zeolite framework. Steaming, which is performed at temperatures above $450{ }^{\circ} \mathrm{C}$, extracts aluminium atoms from the framework and deposits them on the external

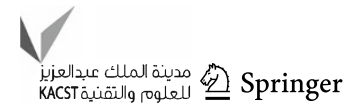



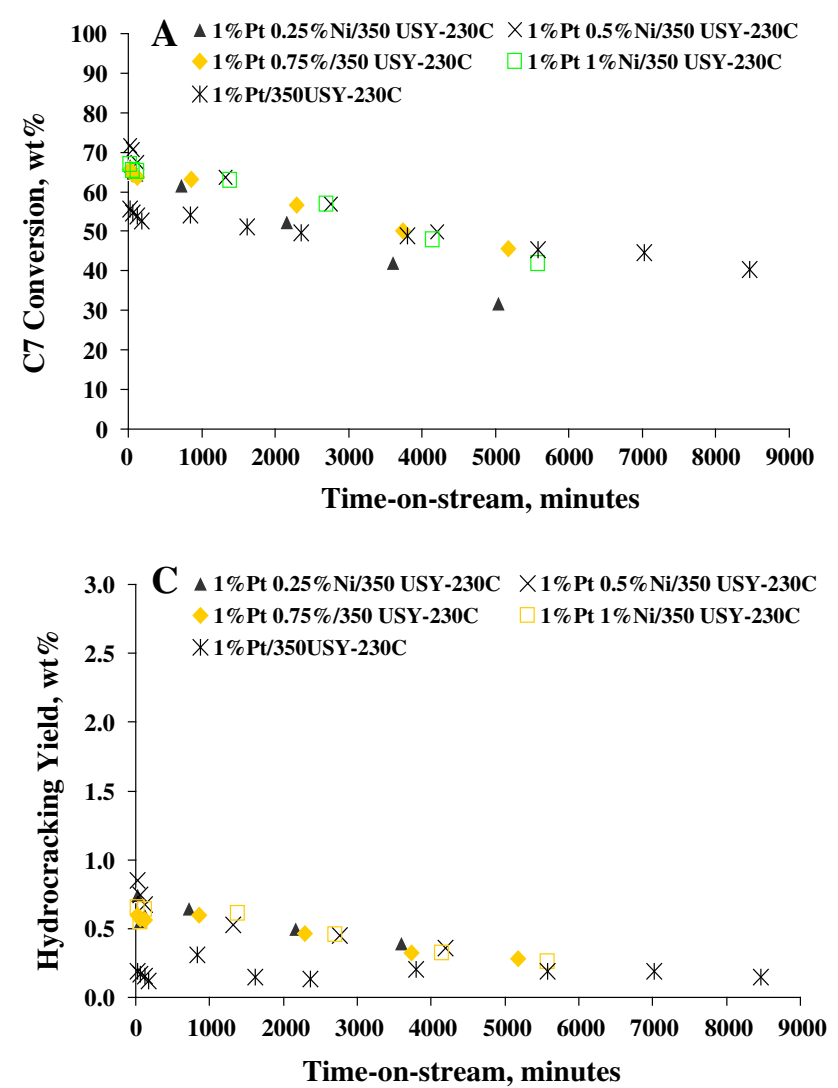

Fig. 17 Overall conversion (a), total yield of C7 isomers (mono $+\mathrm{di}+$ tribranched isomers) (b), total hydrocracking yield (c), and total yield of the cyclic products (d) as a function of TOS for

surface of the zeolite. An additional acid treatment can also be employed to completely remove aluminium atoms from the zeolite pore system. Increasing the framework $\mathrm{Si} / \mathrm{Al}$ ratio by reducing the aluminium content in this way can result in the isolation of the remaining aluminium atoms, which in turn increases the strength of the acid sites and decreases the total number of active sites. This serves to improve both thermal and hydrothermal stability, while also generating mesopores, thus making the crystallite more accessible and reducing the severity of the diffusion limitations. Shortening the diffusion path length is of paramount importance for increasing the activity and stability of mordenite, as it is a one-dimensional, non-mesoporous zeolite. A small number of blockages can deactivate large parts of the mordenite structure [18, 50-52].

Two series of dealuminated mordenite catalysts were prepared by acid leaching and steaming applied to the in-house synthesised mordenite in its ammonium form. Table 12 shows the different acid leaching conditions that were applied to produce different catalysts with differing $\mathrm{Si} / \mathrm{Al}$ ratios (acidity) based on the severity of acid leaching. In addition, three dealuminated mordenite catalysts were produced via the steaming dealumination technique at temperatures of 500,600
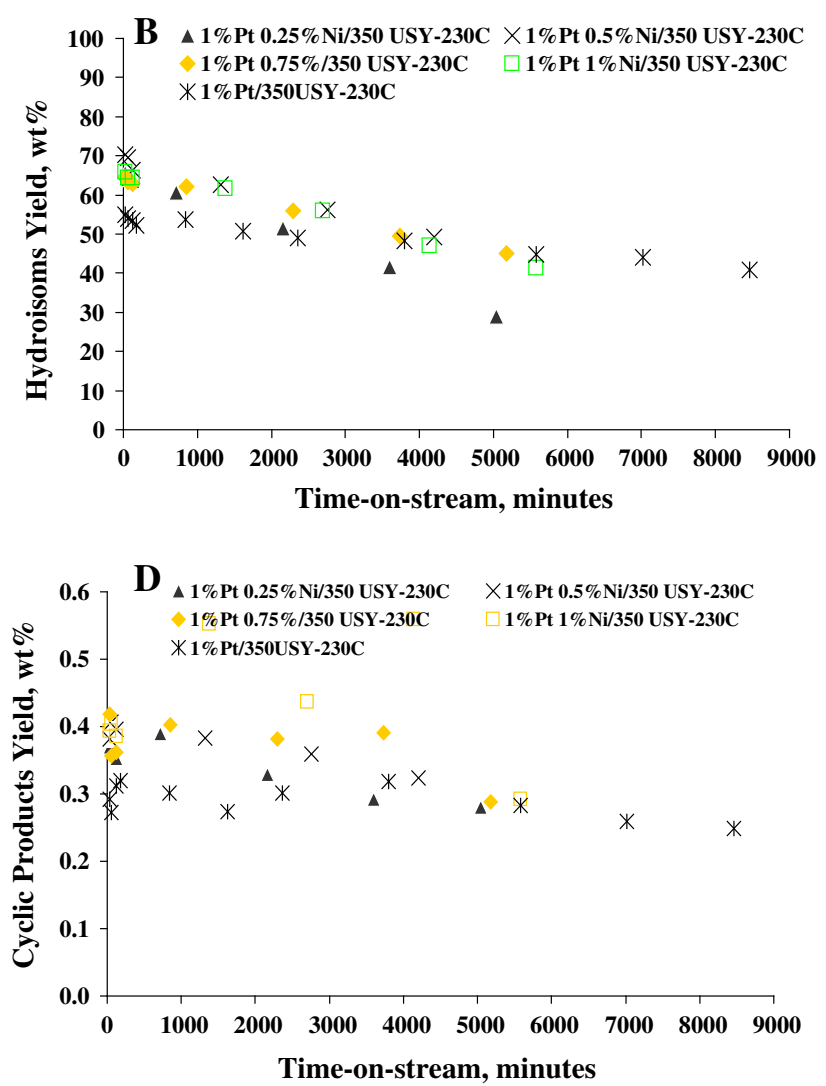

the bimetallic catalysts containing $\mathrm{Pt}-\mathrm{Ni}$ at different reaction temperatures. WHSV $=5.13 \mathrm{~h}^{-1} ; \mathrm{H}_{2} / \mathrm{C} 7(\mathrm{~mol} / \mathrm{mol})=9$; total pressure $=1 \mathrm{~atm}$; temperature $=230{ }^{\circ} \mathrm{C} ; 1 \mathrm{wt} \%$ Pt loading

and $700{ }^{\circ} \mathrm{C}$. Table 13 shows the main characteristics of the acid-leached and steamed catalysts.

From Tables 5 and 6, it can be seen that the highest Si/ $\mathrm{Al}$ molar ratios obtained for the framework and bulk were 19.13 and $42.76(\mathrm{~mol} / \mathrm{mol})$, respectively, by acid leaching using nitric acid at a concentration of 10 molar, a temperature of $120{ }^{\circ} \mathrm{C}$ and a leaching time of $87 \mathrm{~h}$ (3.6 days), as in condition 15 in Table 12. A similar $\mathrm{Si} / \mathrm{Al}$ ratio for the framework was obtained by increasing the acid leaching time to $168 \mathrm{~h}$ (7 days) at the same mixing temperature, as in condition 16, the most severe that was applied. It is generally expected that the bulk $\mathrm{Si} / \mathrm{Al}$ molar ratio should remain the same even after steaming modification and that the steamed mordenite should have the same bulk Si/Al molar ratio as synthesised mordenite, but the framework $\mathrm{Si} /$ $\mathrm{Al}$ molar ratio was higher and increased as the steaming temperature increased from 500 to $700{ }^{\circ} \mathrm{C}$, as shown in Table 13, which means that the framework aluminium atoms were dealuminated by steam to become EFAL.

Figures 25 and 26 show the SEM micrograms of steamed mordenites and the XRD patterns of acid-leached and steamed mordenites, respectively. From the SEM images, it can be seen that the steamed catalysts contained 

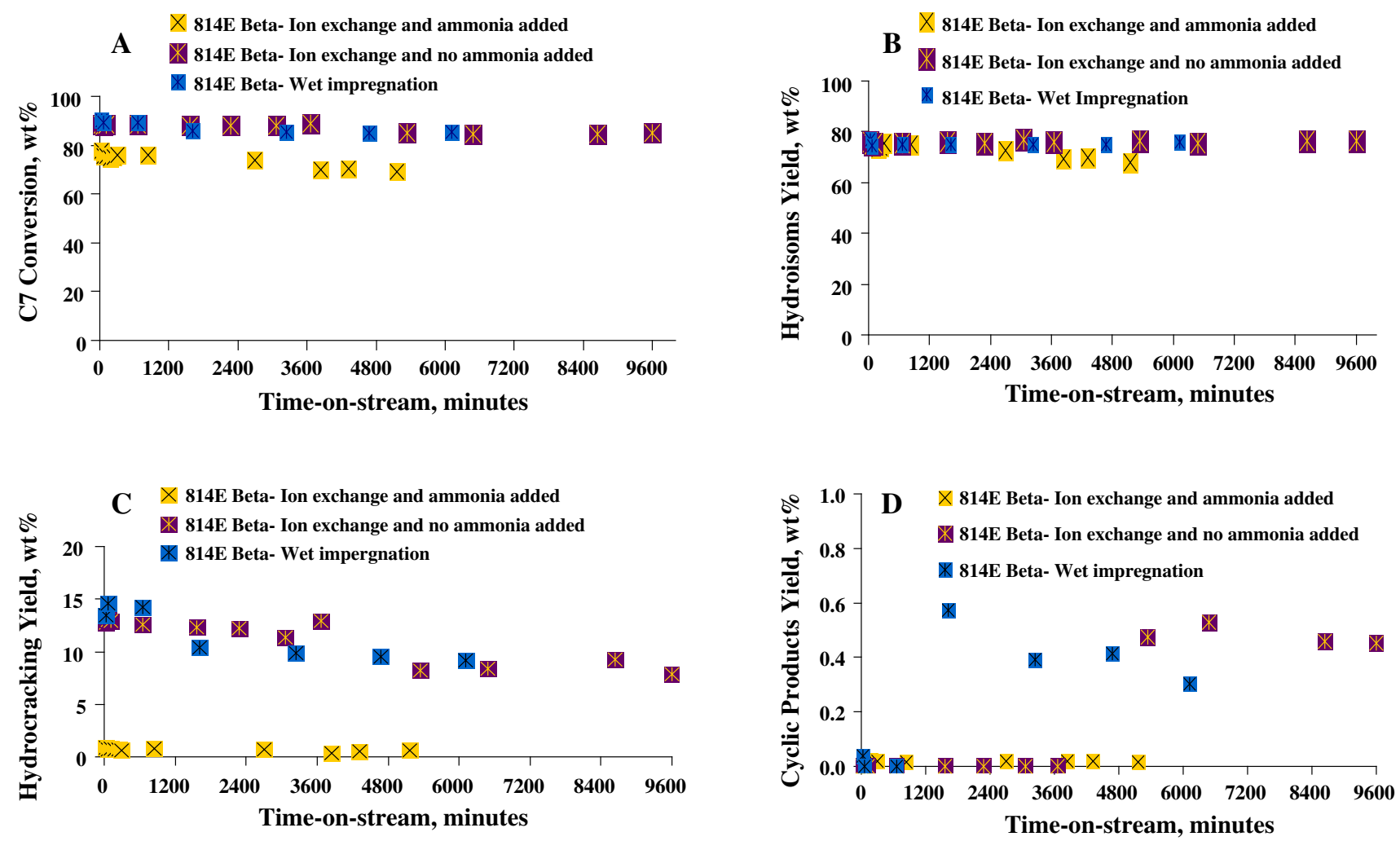

Fig. 18 Overall conversion (a), total yield of C7 isomers (mono $+\mathrm{di}+$ tribranched isomers) (b), total hydrocracking yield (c), and total yield of the cyclic products (d) as a function of TOS for

CP814E. WHSV $=5.13 \mathrm{~h}^{-1} ; \mathrm{H}_{2} / \mathrm{C} 7(\mathrm{~mol} / \mathrm{mol})=9$; total pressur$\mathrm{e}=1 \mathrm{~atm}$; temperature $=230{ }^{\circ} \mathrm{C} ; 1 \mathrm{wt} \%$ Pt loaded by different methods
Fig. 19 Variation of the $\mathrm{C} 1 / \mathrm{C} 3$ mass ratio as a function of TOS of CP814E

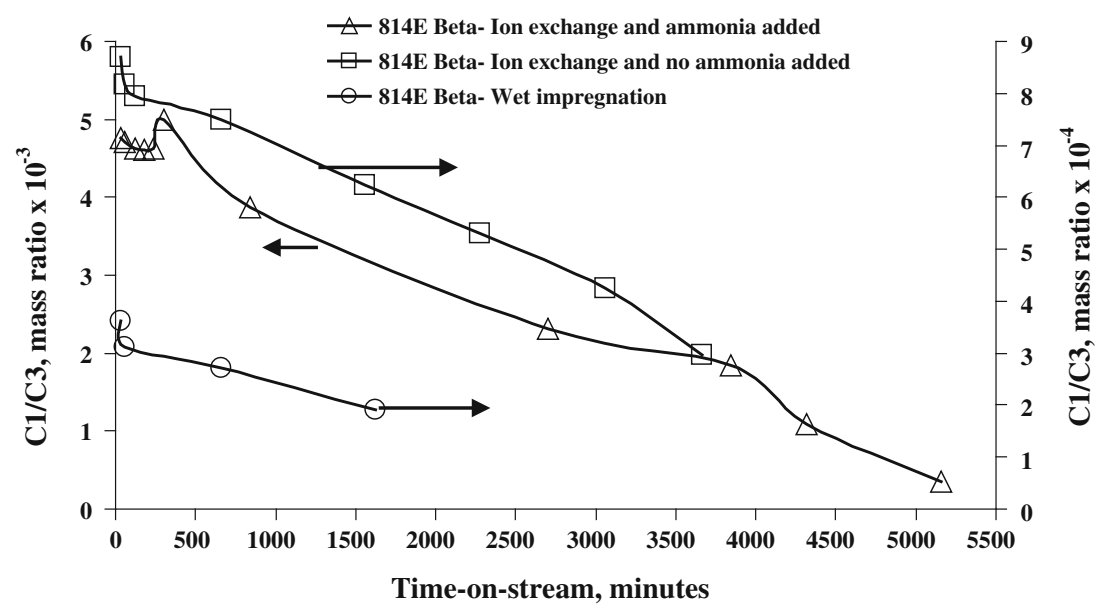

large and small crystallites of different sizes with some smaller debris and agglomerates whereas the acid-leached catalyst kept almost its original large crystal shape with some holes on the crystal surface. The XRD patterns confirm the pure mordenite phase for the steamed and acidleached samples, with less overall crystallinity than assynthesised mordenite.

Figures 27 and 28 show the ${ }^{27} \mathrm{Al}$ and ${ }^{29} \mathrm{Si}$ solid-state NMR spectra of acid-leached and steamed samples. It can be seen that the acid-leached catalysts had two ${ }^{27} \mathrm{Al}$ peaks, at about 56 and $0 \mathrm{ppm}$, assigned to a tetrahedrally coordinated aluminium atom in the framework and a smaller quantity of octahedrally coordinated aluminium as EFAL. Conversely, the steamed samples showed a very large quantity of EFAL at unique resonance spectra for octahedral and tetrahedral aluminium atoms at about 1 and 3 ppm, respectively, alongside in-framework aluminium in tetrahedral coordination. The quantity of EFAL also 

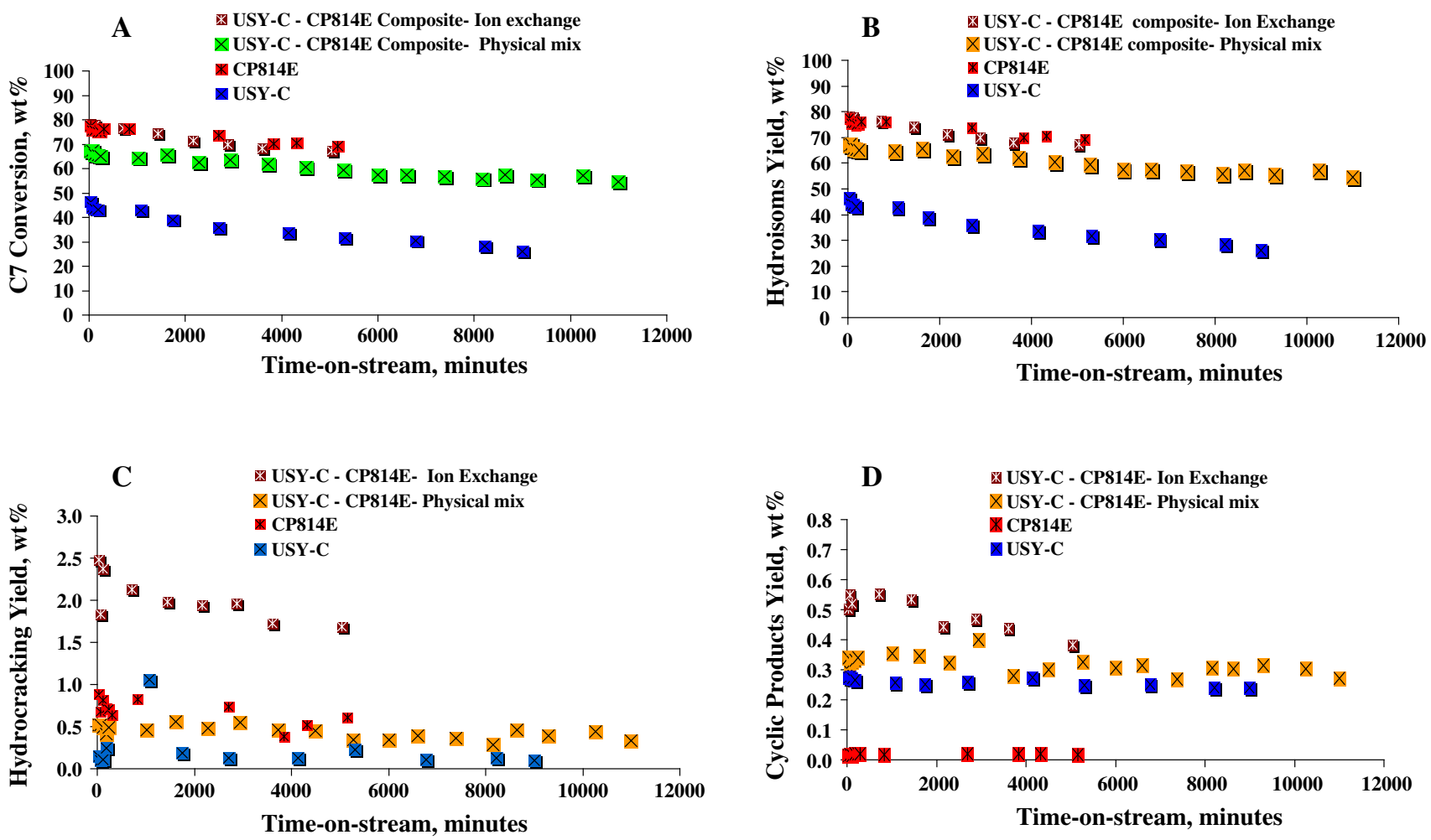

Fig. 20 Overall conversion (a), total yield of C7 isomers (mono $+\mathrm{di}+$ tribranched isomers) (b), total hydrocracking yield (c), and total yield of the cyclic products (d) as a function of TOS for

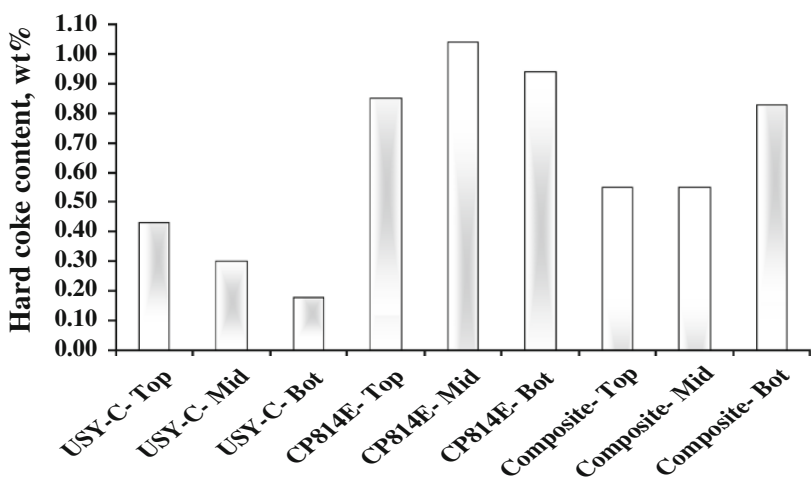

Fig. 21 The hard coke content over the aged CP814E, USY-C, and USY-CP814E physically mixed

increased as the steaming temperature increased. In the ${ }^{29} \mathrm{Si}$ MAS NMR spectra, two peaks at about 114 and $107 \mathrm{ppm}$ were assigned respectively to $\mathrm{Si}(0 \mathrm{Al})$ and $\mathrm{Si}(1 \mathrm{Al})$ configurations, and these chemical shifts differ slightly from the sample produced by steaming. In addition, silicon atoms are different crystallographically as indicated by the different peak shape, depending upon the steaming temperature that was employed. However, the strong increase in the $\mathrm{Si}(0 \mathrm{Al})$ signal intensity as the steaming temperature increased indicates that the replacement of $\mathrm{Al}$ by $\mathrm{Si}$ in the framework was more effective [20].

USY and CP814E composites. WHSV $=5.13 \mathrm{~h}^{-1} ; \mathrm{H}_{2} / \mathrm{C} 7(\mathrm{~mol} /$ mol) $=9$; total pressure $=1 \mathrm{~atm}$; temperature $=230{ }^{\circ} \mathrm{C} ; 1 \mathrm{wt} \% \mathrm{Pt}$ loading

Table 13 and Fig. 29 show that the dealumination treatments by acid leaching and steaming resulted in an increase in mesoporosity, as illustrated with $\mathrm{N}_{2}$-physisorption as a sharp increase in adsorption at high relative pressures, indicating the formation of large mesopores and a corresponding increase in the external surface area. Additionally, an average pore size of $27 \AA$ was observed in the treated samples, compared with $18 \AA$ for as-synthesised mordenite.

TOS behaviour during C7 hydroisomerisation conversion was examined for the following commercial and inhouse mordenite catalysts: CBV10A, CBV21A, 640HOA, 660HOA, 690HOA [31], acid-leached mordenite and inhouse mordenite steamed at $600{ }^{\circ} \mathrm{C}$. All of the above catalysts were loaded with $1 \mathrm{wt} \% \mathrm{Pt}$ by the ion-exchange method. Three very acidic commercial catalysts-1 wt $\%$ $\mathrm{Pt} / \mathrm{CBV} 10 \mathrm{~A}, 1 \mathrm{wt} \% \mathrm{Pt} / 640 \mathrm{HOA}$ and $1 \mathrm{wt} \% \mathrm{Pt} / 660 \mathrm{HOA}-$ and the acid-leached mordenite deactivated very rapidly during the initial few seconds, due to a rapid coking that may have poisoned the acid sites of these catalysts and changed the effective acid site density needed for an ideal bifunctional conversion. As a consequence, no TOS results were reported for these catalysts. Figure $30 \mathrm{a}-\mathrm{d}$ shows the effects of TOS at a reaction temperature of $230{ }^{\circ} \mathrm{C}$ on $\mathrm{C} 7$ conversion, hydroisomerisation, hydrocracking and cyclic 
Table 11 In-house mordenite synthesis parameters and the resulting sample characteristics

\begin{tabular}{|c|c|c|c|c|c|c|}
\hline $\begin{array}{l}\text { Ageing } \\
\text { time }(\mathrm{h})\end{array}$ & $\begin{array}{l}\text { Crystallisation } \\
\text { time }(\mathrm{h})\end{array}$ & $\begin{array}{l}\text { Crystallisation } \\
\text { temp }\left({ }^{\circ} \mathrm{C}\right)\end{array}$ & $\begin{array}{l}\text { XRD crystallinity } \\
(\%)\end{array}$ & $\begin{array}{l}\text { ICP Si/Al } \\
(\mathrm{mol} / \mathrm{mol})\end{array}$ & $\begin{array}{l}\text { ICP Na } \\
(\text { wt } \%)\end{array}$ & $\begin{array}{l}\text { NMR Si/Al } \\
(\mathrm{mol} / \mathrm{mol})\end{array}$ \\
\hline 1 & \multirow[t]{9}{*}{1 day } & \multirow[t]{9}{*}{180} & 43 & 9.50 & 3.63 & 8.03 \\
\hline 3 & & & 64 & 9.70 & 3.99 & 9.13 \\
\hline 4 & & & 75 & 8.36 & 3.26 & 8.97 \\
\hline 6 & & & 77 & 8.13 & 3.15 & 8.97 \\
\hline 8 & & & 75 & 7.83 & 3.08 & 8.98 \\
\hline 10 & & & 75 & 7.92 & 3.07 & 8.98 \\
\hline 12 & & & 82 & 8.44 & 3.14 & 9.02 \\
\hline 15 & & & 80 & 7.99 & 3.23 & 8.97 \\
\hline 24 & & & 49 & 8.92 & 3.09 & 8.62 \\
\hline \multirow[t]{9}{*}{12} & 12 & \multirow[t]{9}{*}{180} & Amorphous & - & - & - \\
\hline & 20 & & 76 & - & - & 8.71 \\
\hline & 22 & & 75 & - & - & 8.89 \\
\hline & 23 & & 71 & - & - & 8.92 \\
\hline & 24 & & 82 & 8.44 & 3.14 & 9.02 \\
\hline & 25 & & 76 & - & - & 8.63 \\
\hline & 26 & & 72 & - & - & 8.63 \\
\hline & 28 & & 70 & - & - & 8.65 \\
\hline & 36 & & Amorphous & - & - & - \\
\hline \multirow[t]{5}{*}{12} & \multirow[t]{5}{*}{1 day } & 170 & Amorphous & - & - & - \\
\hline & & 175 & 32 & - & - & 7.67 \\
\hline & & 180 & 82 & 8.44 & 3.14 & 9.02 \\
\hline & & 185 & 72 & - & - & 8.80 \\
\hline & & 190 & 71 & - & - & 8.63 \\
\hline
\end{tabular}

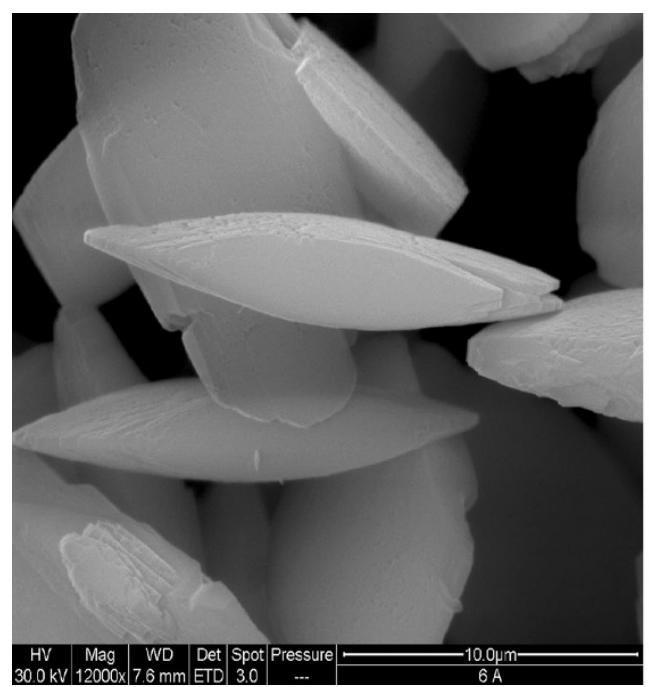

Fig. 22 SEM micrograph of in-house and as-synthesised mordenite

product yields respectively for the following catalysts: $1 \mathrm{wt} \% \mathrm{Pt} / \mathrm{CBV} 21 \mathrm{~A}, 1 \mathrm{wt} \% \mathrm{Pt} / 690 \mathrm{HOA}$ and in-house mordenite steamed at $600{ }^{\circ} \mathrm{C}$.

Initially, the overall conversions were 12,41 and $52 \mathrm{wt} \%$ after $60 \mathrm{~min}$ from the point when the feed was

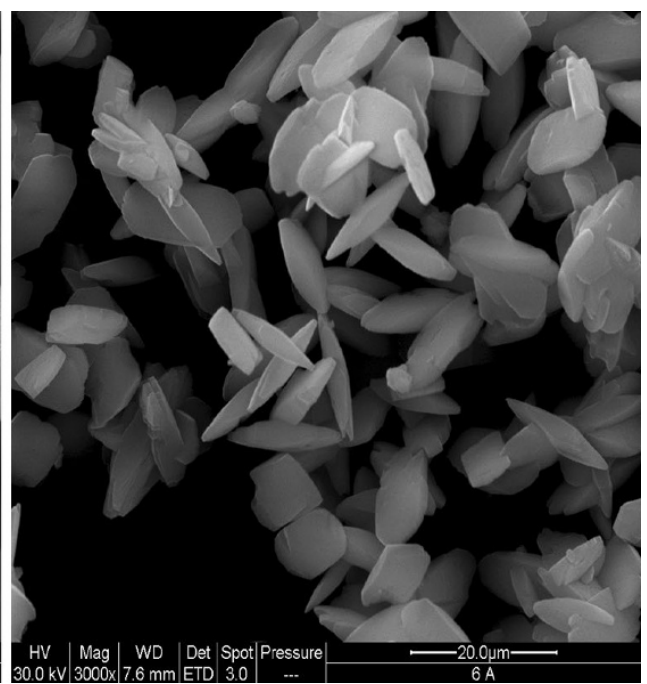

introduced to the reactor at $230{ }^{\circ} \mathrm{C}$, for the $1 \mathrm{wt} \% \mathrm{Pt} /$ CBV21A, $1 \mathrm{wt} \% \mathrm{Pt} / 690 \mathrm{HOA}$ and steamed mordenite catalysts, respectively. A rapid deactivation occurred for the $1 \mathrm{wt} \% \mathrm{Pt} / \mathrm{CBV} 21 \mathrm{~A}$ catalyst with high cracking activity, resulting in selectivity towards the cracked products at 
Fig. 23 XRD patterns of inhouse and as-synthesised mordenite
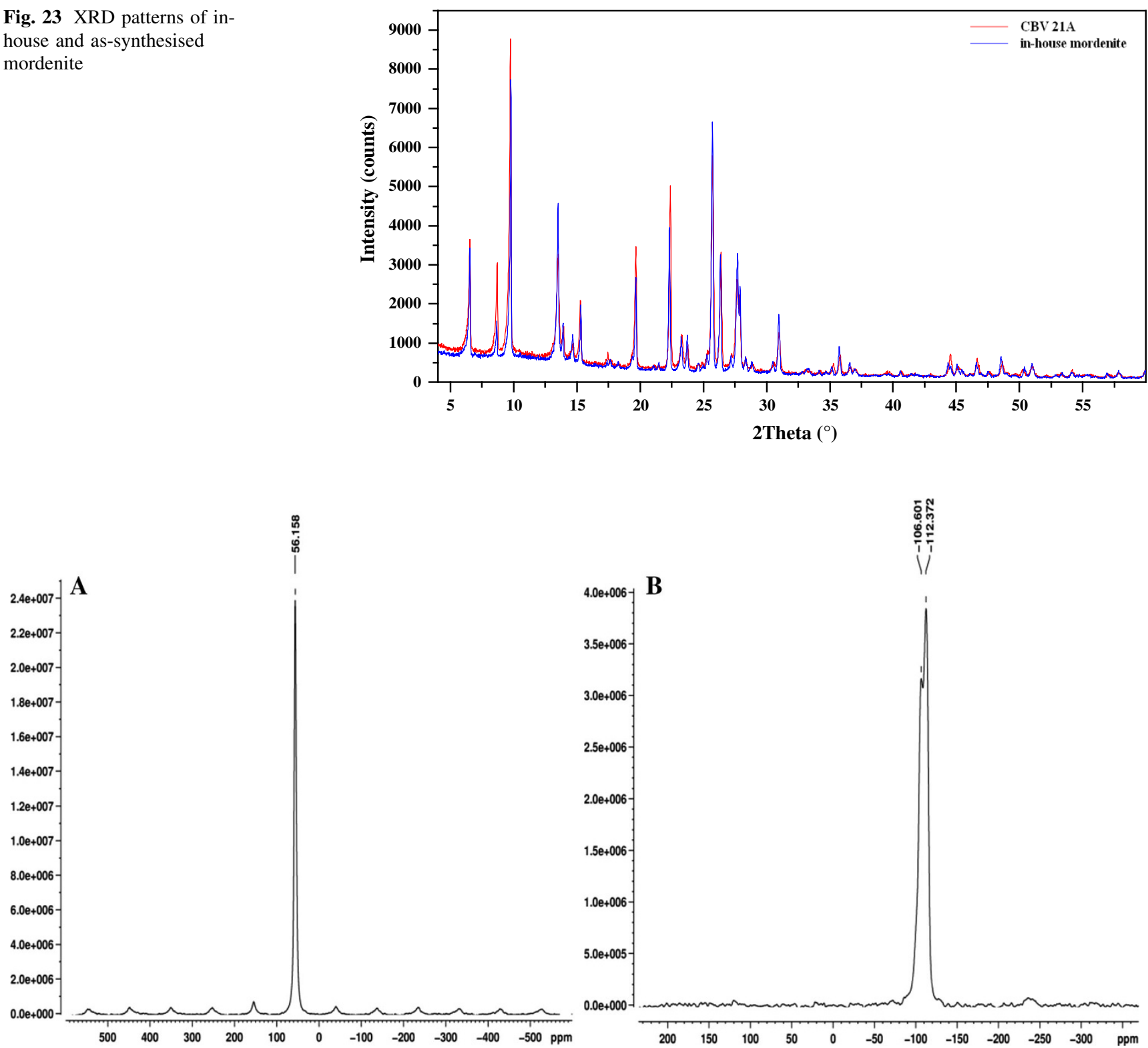

Fig. $24{ }^{27} \mathrm{Al}$ (a) and ${ }^{29} \mathrm{Si}$ (b) MAS NMR spectra of in-house and as-synthesised mordenite

$24 \%$, compared with $71 \%$ for the isomer products, and thereafter the catalyst was almost deactivated after $240 \mathrm{~min}$ on stream. On the other hand, greater TOS stability was shown by the $1 \mathrm{wt} \% \mathrm{Pt} / 690 \mathrm{HOA}$ and steamed mordenite catalysts. However, a shorter coking rate was observed for the steamed mordenite, so it preserved its initial activity for almost $24 \mathrm{~h}$, after which it deactivated at the rate of 8-10 wt\% every day before achieving a pseudo-stable state at the end of the reaction. In contrast, the $1 \mathrm{wt} \% \mathrm{Pt} /$ $690 \mathrm{HOA}$ catalyst deactivated continuously from the point when the feed was introduced to the reactor at the slower rate of 3-5 wt\% every day, before achieving a pseudostable state at the end of the reaction. In addition, selectivity towards $\mathrm{C} 7$ isomers and cyclic products for both catalysts was in the range of $97-98$ and $2-3 \%$, respectively.

Faster deactivation and the mono-dimensional pore system of $1 \mathrm{wt} \% \mathrm{Pt} / \mathrm{CBV} 21$, coupled with a higher density of strong acid sites and as-synthesised zeolite, may have caused the lower activity, which may also be attributable to platinum crystallites blocking the pore openings, as previously reported $[35,53]$. There are side pockets in the pore topology of mordenite that match the $12 \mathrm{MR}$ and $8 \mathrm{MR}$ crossing. The higher number of Brønsted acid sites in the cavities also increases the sensitivity of the 8 MR pores to coking and they can easily fill up and become blocked by carbonaceous deposits [54]. The average lifetime of the carbocations on the surface can be lengthened by strong 
Table 12 Acid leaching conditions applied and the main characteristics of samples obtained

\begin{tabular}{|c|c|c|c|c|c|c|c|c|c|}
\hline Condition & $\begin{array}{l}\mathrm{NH}_{4}-\mathrm{MOR} \\
\text { (wt) }\end{array}$ & $\begin{array}{l}\text { Acid } \\
\text { type }\end{array}$ & $\begin{array}{l}\text { Acid conc. } \\
\text { (molar) }\end{array}$ & $\begin{array}{l}\text { Acid, Vol. } \\
(\mathrm{ml})\end{array}$ & $\begin{array}{l}\text { Leaching } \\
\text { time }(\mathrm{h})\end{array}$ & $\begin{array}{l}\text { Temp } \\
\left({ }^{\circ} \mathrm{C}\right)\end{array}$ & $\begin{array}{l}\text { XRD } \\
\text { crystallinity (\%) }\end{array}$ & $\begin{array}{l}\text { NMR Si/Al } \\
(\mathrm{mol} / \mathrm{mol})\end{array}$ & $\begin{array}{l}\mathrm{ICP} \mathrm{Si} / \mathrm{Al}(\mathrm{mol} / \\
\mathrm{mol})\end{array}$ \\
\hline 1 & 1 & $\mathrm{HCl}$ & 6 & 50 & 12 & 25 & 71 & 9.53 & - \\
\hline 2 & 1 & $\mathrm{HCl}$ & 6 & 50 & 24 & 25 & 73 & 9.63 & - \\
\hline 3 & 1 & $\mathrm{HCl}$ & 6 & 100 & 24 & 25 & 74 & 9.69 & - \\
\hline 4 & 1 & $\mathrm{HCl}$ & Conc & 100 & 24 & 120 & 70 & 15.32 & - \\
\hline 5 & 1 & $\mathrm{HNO}_{3}$ & 10 & 100 & 16 & 25 & 73 & 9.24 & - \\
\hline 6 & 1 & $\mathrm{HNO}_{3}$ & 6 & 50 & 24 & 25 & 70 & 9.32 & - \\
\hline 7 & 1 & $\mathrm{HNO}_{3}$ & Conc & 100 & 24 & 25 & 70 & 9.36 & - \\
\hline 8 & 1 & $\mathrm{HNO}_{3}$ & Conc & 50 & 24 & 25 & 72 & 9.39 & - \\
\hline 9 & 1 & $\mathrm{HNO}_{3}$ & Conc & 100 & 24 & 120 & 78 & 15.30 & - \\
\hline 10 & 1 & $\mathrm{HNO}_{3}$ & 6 & 100 & 24 & 120 & 73 & 16.09 & - \\
\hline 11 & 1 & $\mathrm{HNO}_{3}$ & 6 & 100 & 48 & 120 & 75 & 16.78 & - \\
\hline 12 & 2 & $\mathrm{HNO}_{3}$ & 10 & 100 & 24 & 120 & 70 & 17.10 & - \\
\hline 13 & 1 & $\mathrm{HNO}_{3}$ & 10 & 100 & 16.5 & 120 & 77 & 17.88 & - \\
\hline 14 & 1 & $\mathrm{HNO}_{3}$ & 10 & 100 & 48 & 120 & 74 & 18.75 & - \\
\hline 15 & 1 & $\mathrm{HNO}_{3}$ & 10 & 100 & 87 & 120 & 74 & 19.13 & 42.76 \\
\hline 16 & 1 & $\mathrm{HNO}_{3}$ & 10 & 100 & 168 & 120 & 76 & 19.25 & - \\
\hline
\end{tabular}

Table 13 The main characteristics of acid-leached and steamed mordenite samples

\begin{tabular}{|c|c|c|c|c|c|c|c|}
\hline $\begin{array}{l}\text { Bulk (Si/Al) } \\
\mathrm{mol} / \mathrm{mol}\end{array}$ & $\begin{array}{l}\text { Framework (Si/Al) } \\
(\mathrm{mol} / \mathrm{mol})\end{array}$ & $\begin{array}{l}\text { Crystallinity } \\
(\%)\end{array}$ & $\begin{array}{l}\text { Bulk Pt } \\
\text { (wt\%) }\end{array}$ & $\begin{array}{l}\text { Acidity } \\
\left(\mathrm{mmol} \mathrm{g}^{-1}\right)\end{array}$ & $\begin{array}{l}\text { Surface area } \\
\left(\mathrm{m}^{2} \mathrm{~g}^{-1}\right)\end{array}$ & $\begin{array}{l}\text { Pore volume } \\
\left(\mathrm{cm}^{3} \mathrm{~g}^{-1}\right)\end{array}$ & $\begin{array}{l}\text { Pore size } \\
(\AA)\end{array}$ \\
\hline \multicolumn{8}{|c|}{ As-synthesised mordenite } \\
\hline 8.44 & 9.02 & 82 & - & 1.24 & 406.95 & 0.17 & 18.02 \\
\hline \multicolumn{8}{|c|}{ Acid-leached mordenite } \\
\hline 42.76 & 19.13 & 74 & - & 0.48 & 478.85 & 0.23 & 26.57 \\
\hline \multicolumn{8}{|c|}{ Mordenite steamed at $500{ }^{\circ} \mathrm{C}$} \\
\hline 8.97 & 20.38 & 66 & - & 0.30 & 419.52 & 0.21 & 26.97 \\
\hline \multicolumn{8}{|c|}{ Mordenite steamed at $600{ }^{\circ} \mathrm{C}$} \\
\hline 9.06 & 28.84 & 64 & 0.58 & 0.22 & 415.00 & 0.20 & 26.12 \\
\hline \multicolumn{8}{|c|}{ Mordenite steamed at $700{ }^{\circ} \mathrm{C}$} \\
\hline 8.89 & $\infty$ & 67 & - & - & 404.93 & 0.20 & 26.68 \\
\hline
\end{tabular}

acidity and narrow pore diameter, while the diffusion of the branched products can be slowed down. Each of these factors will help to crack the tertiary carbocations that have formed during isomerisation prior to desorption and will assist in the re-adsorption and cracking of the branched paraffins before they leave the pores and enter the gas stream [55].

There are various possible explanations for the slower deactivation of $1 \mathrm{wt} \% \mathrm{Pt} / 690 \mathrm{HOA}$ and steamed mordenite. First, it may be due to the medium acid strength of the catalysts and their reduced acid site density. Alternatively, it may be due to the balance between acid and metal active sites. It could also be ascribed to the existence of mesopores and to the slight increase in the pore volume, which may be beneficial to the diffusion of bulky moieties.
Finally, it may be due to post-synthesised mordenite having smaller crystallites. The last two characteristics can be seen as reducing the resistance of the product molecules to formation and diffusion, resulting in less cracking and deactivation of the catalyst caused either by blockages at the site or by plugging of channels. The method of dealumination applied to the final lattice $\mathrm{Si} / \mathrm{Al}$ ratio influences catalyst activity. For example, steam dealumination leaves the lattice with aluminium removed as EFAL, whereas samples that are practically free of EFAL can result from acid leaching, so EFAL may have a negative effect by blocking pores and preventing the $\mathrm{Pt}$ from being well dispersed during the ion-exchange process. This may explain the deactivation of the $1 \mathrm{wt} \% \mathrm{Pt} / 690 \mathrm{HOA}$ steamed mordenite catalysts. 

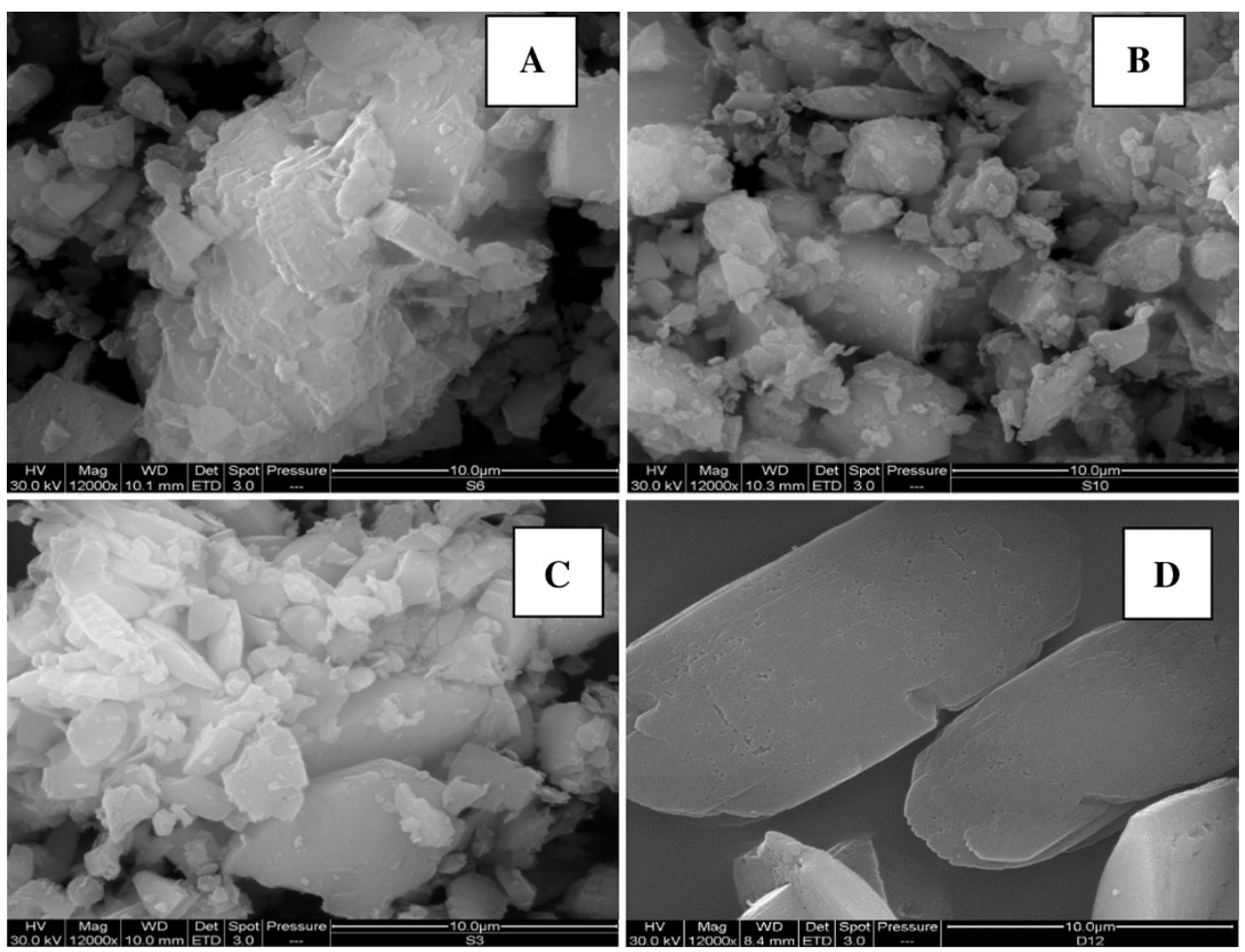

Fig. 25 SEM micrographs of mordenites steamed at $500{ }^{\circ} \mathrm{C}(\mathbf{a}), 600{ }^{\circ} \mathrm{C}(\mathbf{b}), 700{ }^{\circ} \mathrm{C}(\mathbf{c})$ and acid leached (d)

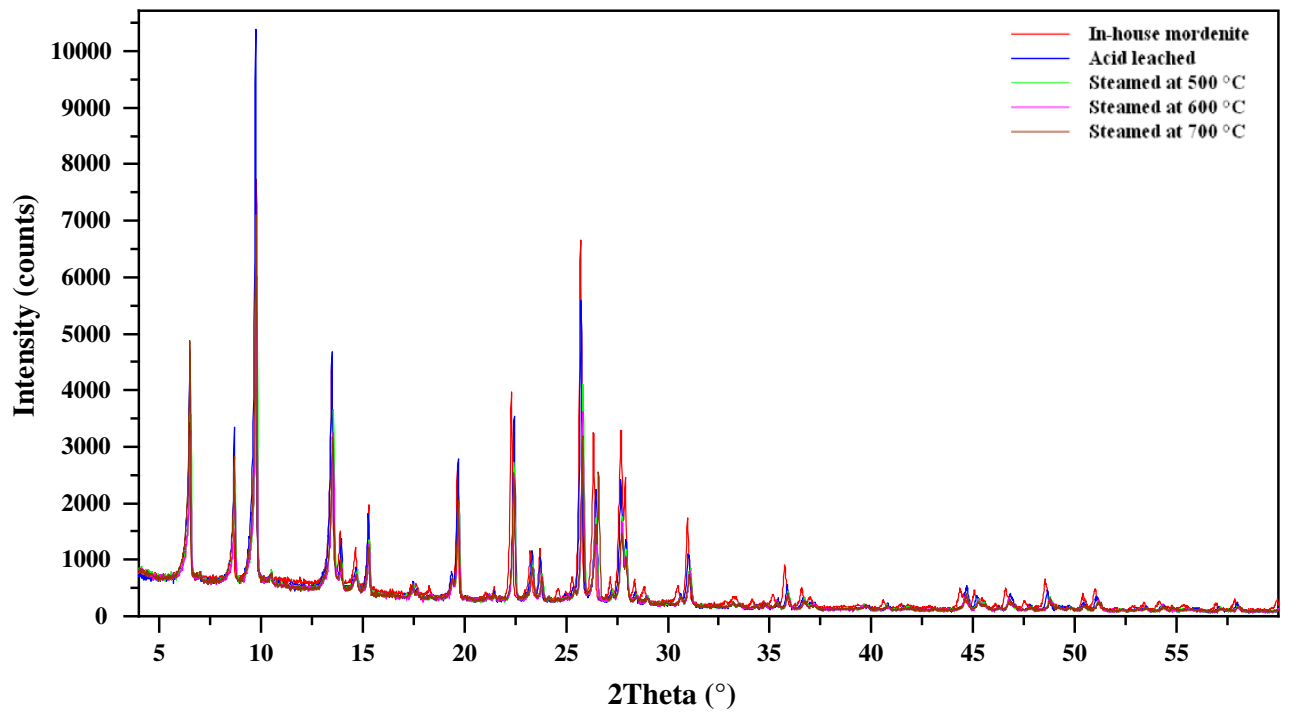

Fig. 26 XRD patterns of acid-leached and steamed mordenites

Deactivation behaviour of two selected commercial mesoporous aluminosilicates and a $\gamma$-alumina-based catalyst

TOS stability during the hydroisomerisation of $\mathrm{n}-\mathrm{C} 7$ under identical reaction conditions was examined using two selected commercial mesoporous aluminosilicatesAl-SBA-15 and Al-MCM-48-and a $\gamma$-alumina catalyst, which were loaded with $1 \mathrm{wt} \%$ platinum by the ionexchange technique and tested using the atmospheric pressure glass fixed-bed flow reactor system. The two mesoporous aluminosilicates, Al-SBA-15 and Al-MCM48 , containing 8 and $3 \mathrm{wt} \%$ aluminium, respectively, were supplied by Claytec (USA) [20] as white powders in their proton form. Their main surface texture features and the methods by which the alumination and protonation were 
Fig. $27{ }^{27} \mathrm{Al}$ NMR of acidleached and steamed samples
Fig. $28{ }^{29}$ Si NMR of acidleached and steamed samples
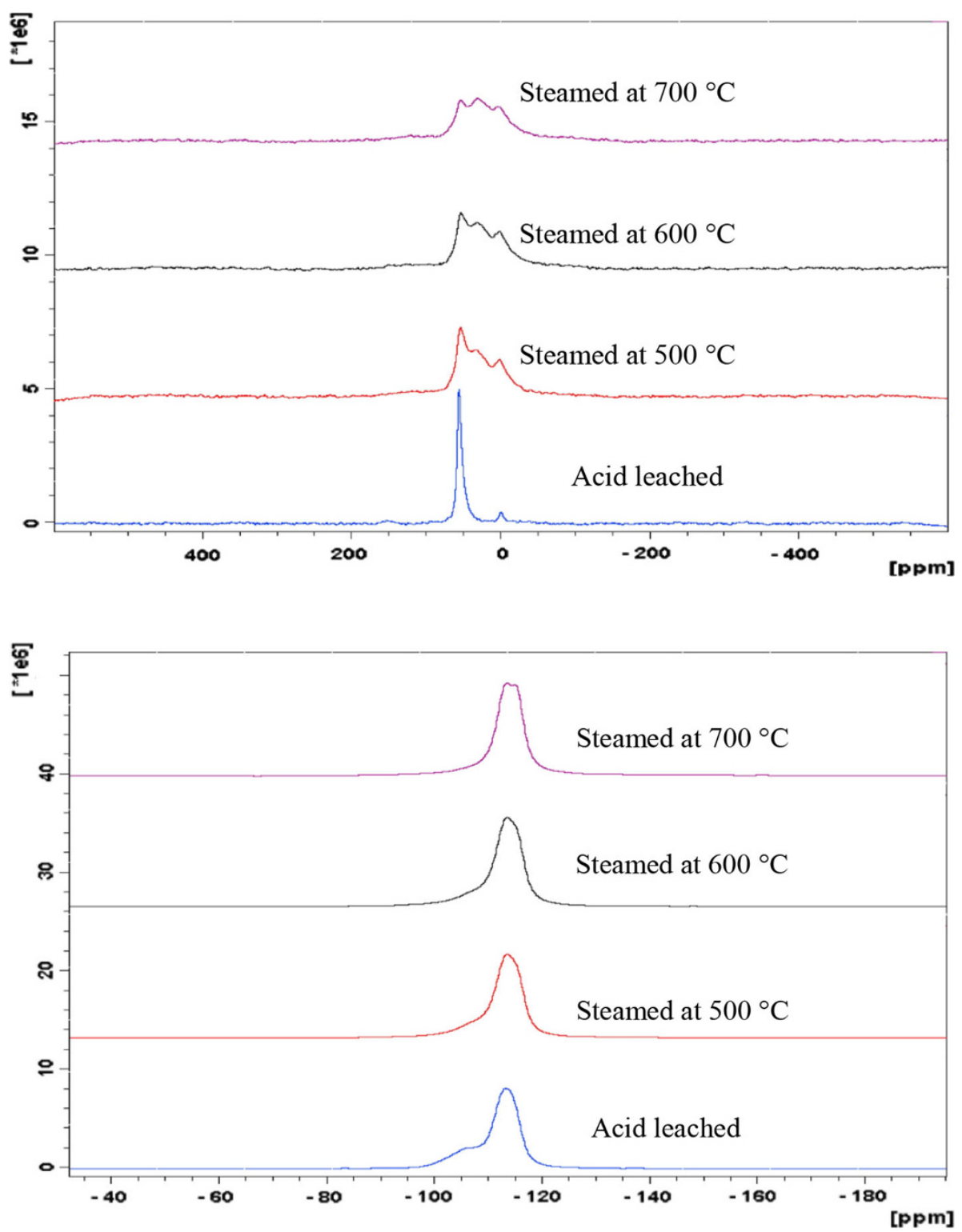

preformed, as specified by the supplier, are shown in Table 14.

Figure 31 shows the SEM image of Al-SBA-15 and AlMCM-48 catalysts. It can be observed that both samples consist of non-uniform and irregular-shaped particles varying in size from 0.5 to $2 \mu \mathrm{m}$. XRD patterns of the AlSBA-15 and Al-MCM-48 catalysts are shown in Fig. 32. The Al-SBA-15 sample shows well-resolved patterns with a prominent diffraction peak (100) and two additional diffraction peaks indexed to (110) and (200) reflections, which match well with the pattern reported for SBA-15 [56], indicating that the Al-SBA-15 product prepared by post-alumination had a well-ordered hexagonal mesostructure, whereas the XRD pattern of the Al-MCM-48 sample was identical to the one reported by Beck et al. [57]. Four diffraction peaks were also clearly observed and indexed to (211), (220), (420) and (332), indicating that the Al-MCM-48 product prepared by post-alumination had a well-ordered cubic mesostructure. Table 15 shows some in-house characterisations of the Al-SBA-15, Al-MCM-48 and $\gamma$-alumina catalysts using various different techniques.

Solid-state MAS NMR spectroscopy of ${ }^{27} \mathrm{Al}$ indicated the presence of tetrahedrally coordinated aluminium atoms in the Al-SBA-15 (A) and Al-MCM-48 lattices. It also revealed extra-framework octahedral and pentahedral $\mathrm{Al}$ in the pores of both molecular sieves, which may have been formed during hydrothermal crystallisation and/or by dealumination during calcination [58], as shown in Fig. 33. Therefore, it can be confirmed that not all $\mathrm{Al}$ atoms were inserted in the frameworks of SBA-15 and MCM-48.

In the ${ }^{29} \mathrm{Si}$ MAS NMR spectra, two peaks at 110 and $102 \mathrm{ppm}$ were assigned to $\mathrm{Si}(0 \mathrm{Al})$ and $\mathrm{Si}(1 \mathrm{Al})$ 

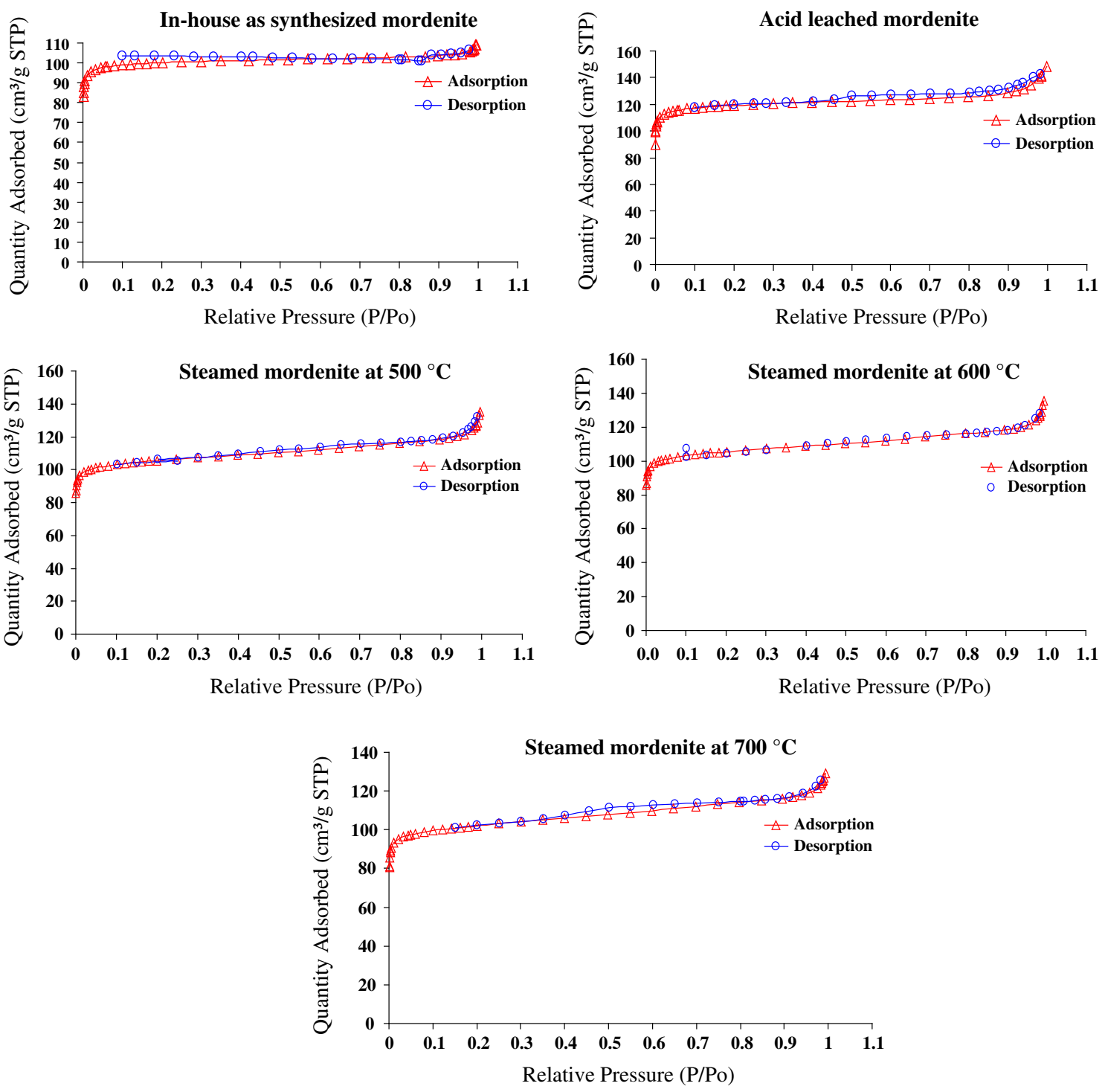

Fig. $29 \mathrm{~N}_{2}$ adsorption and desorption isotherms of acid-leached and steamed samples

configurations respectively for Al-SBA-15, and three peaks at 110,101 , and $92 \mathrm{ppm}$ were assigned to $\mathrm{Si}(0 \mathrm{Al}), \mathrm{Si}(1 \mathrm{Al})$ and $\mathrm{Si}(2 \mathrm{Al})$ configurations respectively for Al-MCM-48, as shown in Fig. 34. This confirmed that some Si atoms were substituted by $\mathrm{Al}$ atoms to generate the mesoporous aluminosilicate structure for both catalysts.

The Al-SBA-15 and Al-MCM-48 catalysts were also characterised using nitrogen adsorption at $-196{ }^{\circ} \mathrm{C}$, as shown in Fig. 35, to confirm that these materials had retained their mesostructures after the post-alumination process to substitute the silicon with aluminium. Figure 35 shows the nitrogen adsorption isotherms for both catalysts, which are type IV according to the IUPAC classification [59]. The isotherm of the mesoporous molecular sieve exhibits a sharp inflection characteristic of capillary condensation within uniform pores, where the $\mathrm{P} / \mathrm{P}_{0}$ position of the inflection point is related to the diameter of the pore. The sharp rise near $0.4 \mathrm{P} / \mathrm{P}_{0}$ corresponds to condensation in the primary mesopores. As the size of the primary mesopores increases, the capillary condensation step shifts to higher relative pressures and hysteresis becomes more pronounced. The existence of a hysteresis loop in the isotherms indicates the presence of mesopores and its shape is related to their shape: roughly, a vertical loop indicates cylindrical mesopores, whereas a horizontal one indicates inkbottle-shaped mesopores [51].

As shown in Tables 14 and 15 alongside Fig. 35, the two commercial catalysts exhibited high pore size and pore volume and retained their mesostructures, even after the post-alumination process. Table 14 shows that Al-SBA-15 had a much lower surface area than expected for mesoporous materials $\left(>1,000 \mathrm{~m}^{2} \mathrm{~g}^{-1}\right)$, which can be explained 

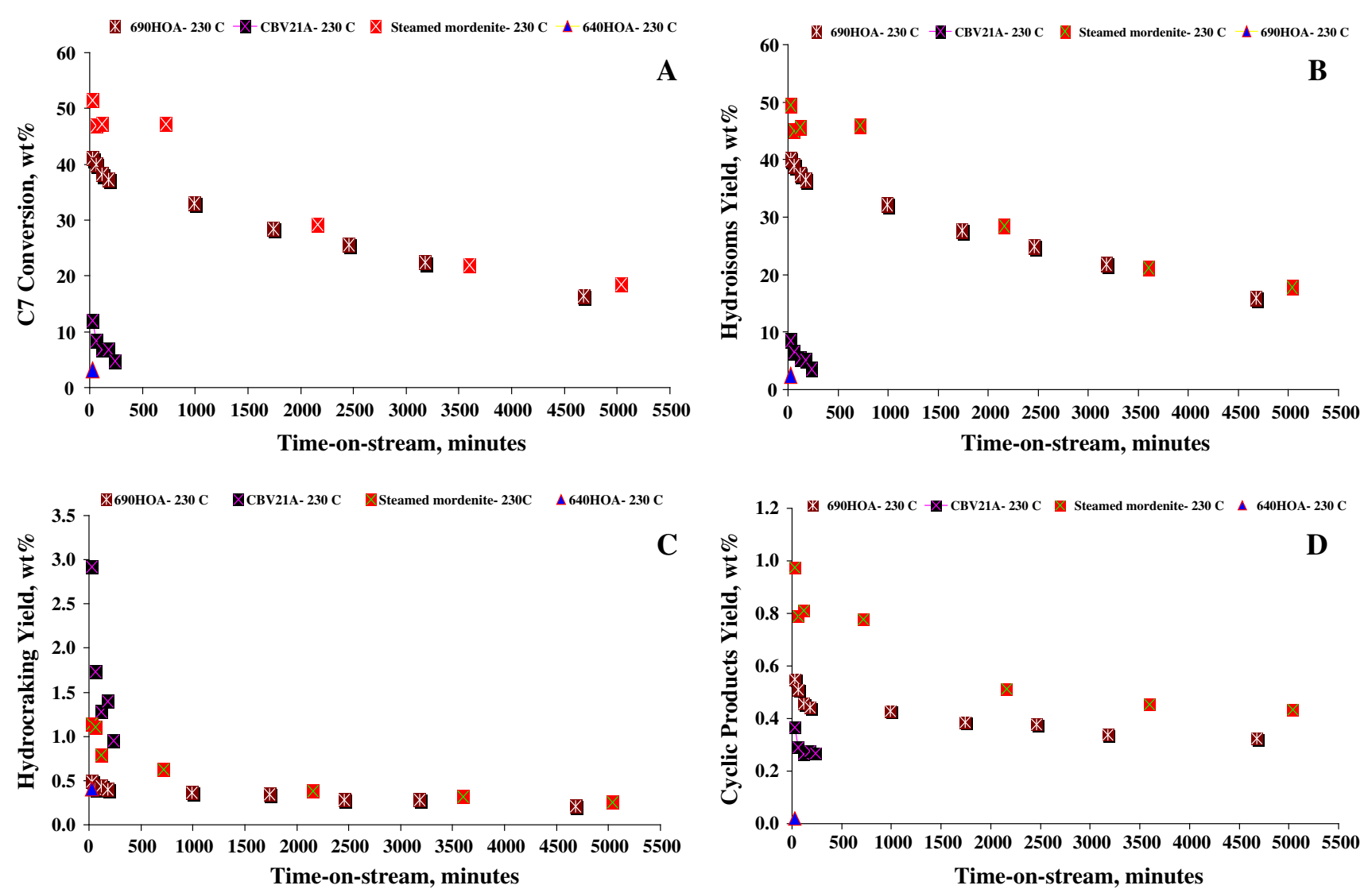

Fig. 30 Overall conversion (a), total yield of C7 isomers (mono $+\mathrm{di}+$ tribranched isomers) $(\mathbf{b})$, total hydrocracking yield (c) and total yield of cyclic products (d) as a function of TOS for

in two ways. First, the presence of EFAL on the mesostructure may partially block the mesopores and subsequently hinder nitrogen adsorption. The existence of EFAL was revealed by NMR, as shown in Fig. 33a. Alternatively, the Al-SBA-15 mesostructure may have partially collapsed, so some residual amorphous material was generated after the post-alumination process. Despite the appearance of the lower surface area, the Al-SBA-15 catalyst retained its general mesostructure, as revealed by the XRD and nitrogen adsorption isotherms shown in Figs. 32 and 35 respectively, while its large pore size and pore volume were comparable with those of Al-MCM-48.

The deactivation behaviour of the $1 \mathrm{wt} \% \mathrm{Pt} / \mathrm{Al}-\mathrm{SBA}-15$ and $1 \mathrm{wt} \% \mathrm{Pt} / \mathrm{Al}-\mathrm{MCM}-48$ catalysts was investigated during the catalytic conversion of $\mathrm{n}-\mathrm{C} 7$ at reaction temperatures of $210,230,250$ and $270{ }^{\circ} \mathrm{C}$ and at atmospheric pressure, using the glass fixed-bed flow reactor system loaded with $1 \mathrm{~g}$ of each catalyst, as described in "Results and discussion" section. The constant mole ratio of hydrogen to $\mathrm{n}-\mathrm{C} 7$ was 9 and WHSV was $5.13 \mathrm{~h}^{-1}$. At temperatures below $300{ }^{\circ} \mathrm{C}$, very low n-C7 conversion was found, and so $370{ }^{\circ} \mathrm{C}$ was chosen as the optimum temperature for studying the activity decay of these catalysts. commercial and in-house steamed mordenite catalysts. WHSV $=5.13 \mathrm{~h}^{-1} ; \mathrm{H}_{2} / \mathrm{C} 7(\mathrm{~mol} / \mathrm{mol})=9 ;$ total pressure $=1 \mathrm{~atm}$; temperature $=230{ }^{\circ} \mathrm{C} ; 1 \mathrm{wt} \% \mathrm{Pt}$ loading

Figure 36a-d illustrates the effects of TOS on the C7 conversion, hydroisomerisation, hydrocracking and cyclic product yields at reaction temperature of $370{ }^{\circ} \mathrm{C}$ for the two catalysts loaded with $1 \mathrm{wt} \% \mathrm{Pt}$ by the ion-exchange method. The $\gamma$-alumina support supplied by Alfa-Aesar (Johnson-Matthey) was also loaded with $1 \mathrm{wt} \% \mathrm{Pt}$ using the wet impregnation method and tested under the same reaction conditions.

Initially, the respective overall conversions for $1 \mathrm{wt} \%$ Pt/Al-SBA-15, $1 \mathrm{wt} \% \mathrm{Pt} / \mathrm{Al}-\mathrm{MCM}-48$ and $1 \mathrm{wt} \% \mathrm{Pt} / \gamma$ $\mathrm{Al}_{2} \mathrm{O}_{3}$ were 51, 39 and $24 \mathrm{wt} \%, 30 \mathrm{~min}$ after the introduction of feed to the reactor at $370{ }^{\circ} \mathrm{C}$. The $1 \mathrm{wt} \% \mathrm{Pt} / \mathrm{Al}-$ SBA-15 catalyst deactivated slightly with TOS, reaching a conversion of $25 \mathrm{wt} \%$ ( $<26 \mathrm{wt} \%$ of the initial catalytic activity) after about 2 days, then remained in a pseudostable state until the reaction terminated after 4 days. The $1 \mathrm{wt} \%$ Pt/Al-MCM-48 started with less activity than the $1 \mathrm{wt} \% \mathrm{Pt} / \mathrm{Al}-\mathrm{SBA}-15$, but with greater TOS stability, deactivating slightly to reach a conversion of $30 \mathrm{wt} \%$ ( $<9 \mathrm{wt} \%$ of the initial catalytic activity) after 2 days, then maintained a pseudo-stable state until the reaction terminated after 3 days. Deactivation was rapid for the $1 \mathrm{wt} \%$ $\mathrm{Pt} / \gamma-\mathrm{Al}_{2} \mathrm{O}_{3}$ catalyst, with high cyclisation activity under the

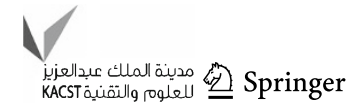


conditions of the investigation, resulting in selectivity towards the cyclic products at $55 \%$, compared with $40 \%$ for the isomer products; thereafter, the catalyst was almost deactivated after $180 \mathrm{~min}$ on stream. The $1 \mathrm{wt} \% \mathrm{Pt} / \mathrm{Al}$ SBA-15 and $1 \mathrm{wt} \%$ Pt/Al-MCM-48 catalysts also exhibited fairly high cyclisation selectivity, of 20 and $27 \mathrm{wt} \%$, respectively, decreasing with TOS to 7 and $9 \mathrm{wt} \%$, respectively, by the end of the reactions. The cracking selectivity of the $1 \mathrm{wt} \% \mathrm{Pt} / \mathrm{Al}-\mathrm{SBA}-15,1 \mathrm{wt} \% \mathrm{Pt} / \mathrm{Al}-$ MCM-48 and $1 \mathrm{wt} \% \mathrm{Pt} / \gamma-\mathrm{Al}_{2} \mathrm{O}_{3}$ catalysts was 1,3 and $10 \mathrm{wt} \%$, respectively. The maximum isomer yields for $1 \mathrm{wt} \%$ Pt/Al-SBA-15, $1 \mathrm{wt} \%$ Pt/Al-MCM-48 and $1 \mathrm{wt} \%$ $\mathrm{Pt} / \gamma-\mathrm{Al}_{2} \mathrm{O}_{3}$ were found to be 40,27 and $10 \mathrm{wt} \%$, respectively, decreasing with TOS in the same way as conversion.

As the major reactions were hydroisomerisation and cyclisation, negligible cracking was observed for the

Table 14 Main surface texture features and the alumination and protonation methods of Al-SBA-15 and Al-MCM-48 as supplied by Claytec (USA) [20]

\begin{tabular}{|c|c|c|c|c|}
\hline Sample & $\begin{array}{l}\text { BET surface } \\
\text { area }\left(\mathrm{m}^{2} \mathrm{~g}^{-1}\right)\end{array}$ & $\begin{array}{l}\text { Total pore volume @ } \\
\mathrm{P} / \mathrm{P}_{0}=0.98\left(\mathrm{~cm}^{3} \mathrm{~g}^{-1}\right)\end{array}$ & $\begin{array}{l}\text { BJH pore } \\
\text { size }(\mathrm{nm})\end{array}$ & Alumination and protonation methods \\
\hline $\begin{array}{l}8 \text { wt } \% \text { Al- } \\
\text { SBA-15 }\end{array}$ & 408 & 0.75 & 8.6 & $\begin{array}{l}\text { Calcination of the as-made pure silica mesophase at } 600{ }^{\circ} \mathrm{C} \text { to remove } \\
\text { surfactant, followed by grafting reaction of the pure silica mesophase with } \\
\text { aluminium i-propoxide to achieve alumination, followed by another } \\
\text { calcination at } 550{ }^{\circ} \mathrm{C} \text { to form the protonated derivative }\end{array}$ \\
\hline $\begin{array}{l}3 \text { wt\% Al- } \\
\text { MCM- } \\
48\end{array}$ & 1,217 & 1.4 & 2.4 & $\begin{array}{l}\text { Sodium aluminate was used for } \mathrm{Al} \text { incorporation during framework } \\
\text { assembly, followed by ammonium ion exchange in the presence of } \\
\text { surfactant, then calcination at } 600{ }^{\circ} \mathrm{C} \text { to form the protonated derivative }\end{array}$ \\
\hline
\end{tabular}
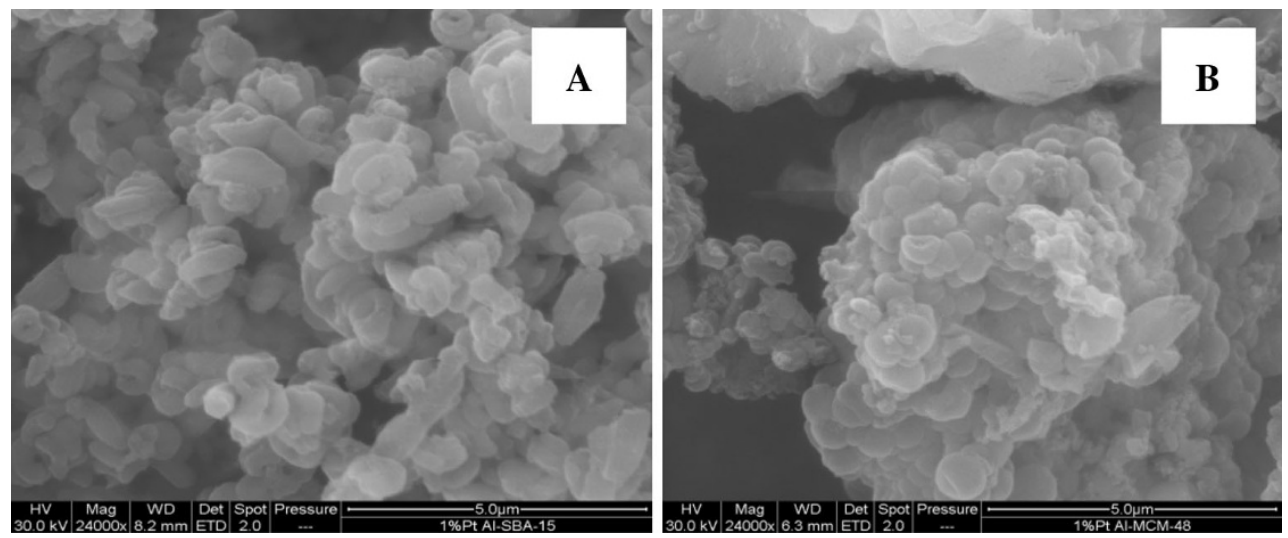

Fig. 31 SEM micrographs of Al-SBA-15 (a) and Al-MCM-48 (b)
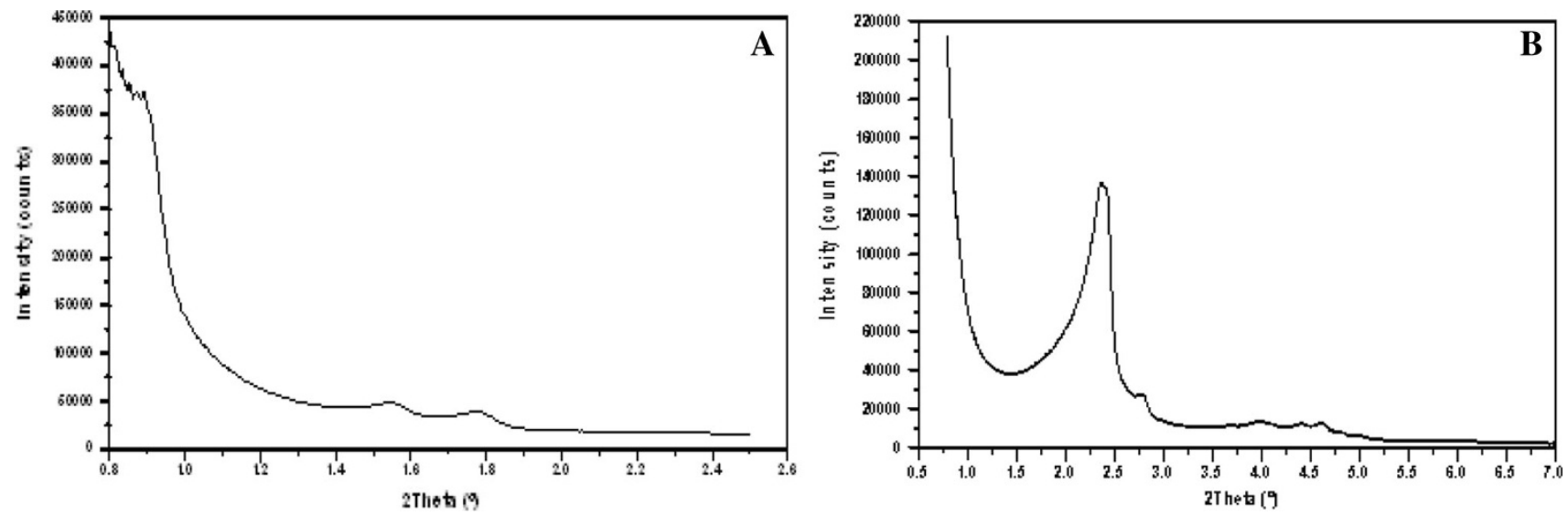

Fig. 32 XRD patterns of Al-SBA-15 (a) and Al-MCM-48 (b) 
Table 15 Some characterisations of Al-SBA-15 and Al-MCM-48 catalysts

\begin{tabular}{|c|c|c|c|c|c|c|c|c|}
\hline $\begin{array}{l}\text { Bulk (Si/Al) } \\
(\mathrm{mol} / \mathrm{mol})\end{array}$ & $\begin{array}{l}\text { Framework (Si/Al) } \\
(\mathrm{mol} / \mathrm{mol})\end{array}$ & $\begin{array}{l}\text { Bulk Pt } \\
\text { (wt\%) }\end{array}$ & $\begin{array}{l}\mathrm{Si} / \mathrm{Al} \text { atomic } \\
\text { conc } \%(\mathrm{XPS})\end{array}$ & $\begin{array}{l}\text { Pt atomic } \\
\text { conc \% (XPS) }\end{array}$ & $\begin{array}{l}\text { Acidity } \\
\left(\mathrm{mmol} \mathrm{g}^{-1}\right)\end{array}$ & $\begin{array}{l}\text { Surface area } \\
\left(\mathrm{m}^{2} \mathrm{~g}^{-1}\right)\end{array}$ & $\begin{array}{l}\text { Pore volume } \\
\left(\mathrm{cm}^{3} \mathrm{~g}^{-1}\right)\end{array}$ & $\begin{array}{l}\text { Pore } \\
\text { size }(\AA)\end{array}$ \\
\hline \multicolumn{9}{|l|}{ Al-SBA-15 } \\
\hline 11.05 & 6.39 & 0.95 & 10.62 & 0.04 & 0.29 & - & - & - \\
\hline \multicolumn{9}{|l|}{ Al-MCM-48 } \\
\hline 32.65 & 9.33 & 0.95 & - & - & - & 1,035 & 1.33 & 34.36 \\
\hline \multicolumn{9}{|l|}{$\gamma$-alumina } \\
\hline - & - & - & - & - & 0.19 & 211 & 0.59 & 90.49 \\
\hline
\end{tabular}
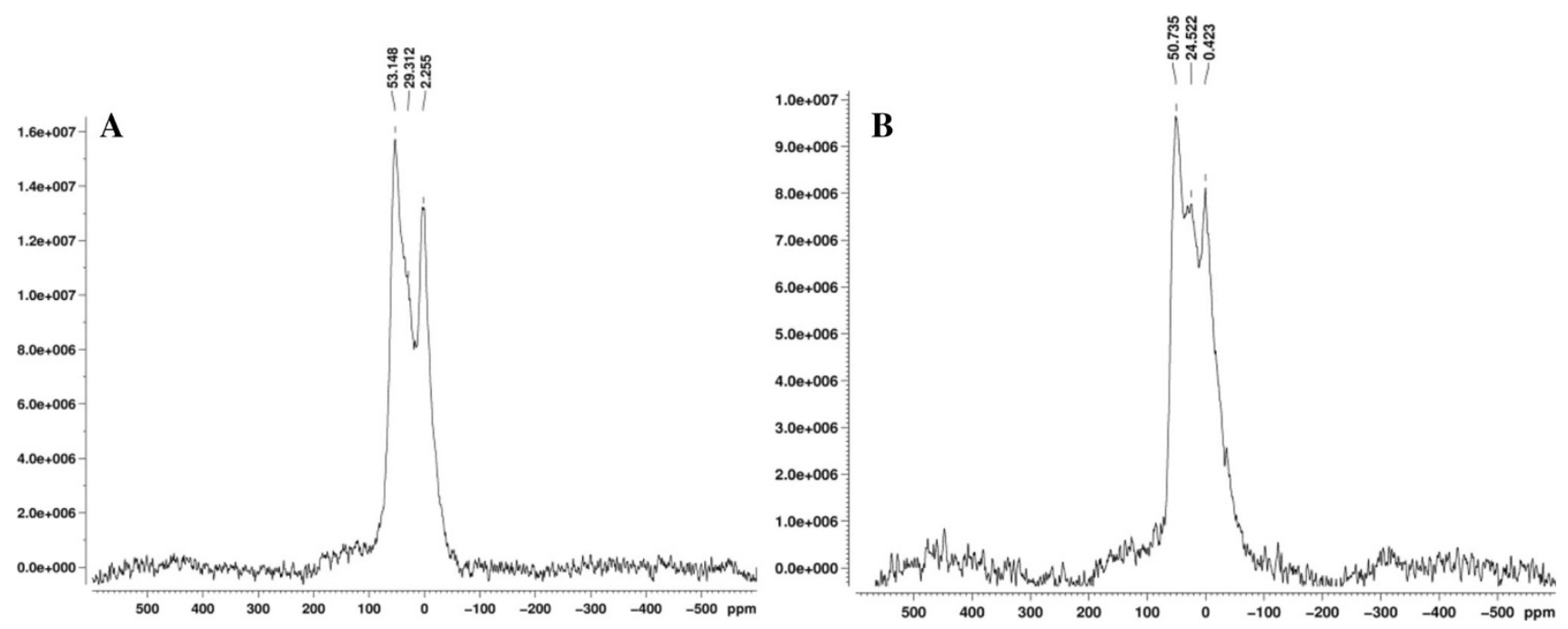

Fig. $33{ }^{27} \mathrm{Al}$ MAS NMR spectra of Al-SBA-15 (a) and Al-MCM-48 (b)

$1 \mathrm{wt} \% \mathrm{Pt} / \mathrm{Al}-\mathrm{SBA}-15$ and $1 \mathrm{wt} \% \mathrm{Pt} / \mathrm{Al}-\mathrm{MCM}-48$. Small amounts of alkenes were also detected in the products. Although the deactivation rate was significant during the first few minutes, the activity of the catalyst became reasonably stable after about 2 days. A certain amount of initial deactivation has been reported by other workers during the isomerisation of $n$-alkanes over $\mathrm{Pt}$ catalysts, which is expected under atmospheric pressure conditions [60]. However, it was shown that a great quantity of oligomers (cyclic products) is produced from propene at low temperatures on MCM-41-type catalysts and that the pore size of the mesoporous material can make a difference when the aim is to oligomerise larger olefins or to produce large lubricant molecules in general [12].

It is reported that the very high surface area of ordered mesoporous materials makes it easier to obtain highly dispersed noble metal catalysts $[12,61]$. However, because these catalysts have fewer acid sites, as shown in Table 15, the turnover frequency (TOF) of $\mathrm{n}-\mathrm{C} 7$ hydroisomerisation at $370{ }^{\circ} \mathrm{C}$ over these sites would be expected to be low, which means in turn that there would be a relatively low level of interaction between the low acid sites in the large pore walls of these catalyst and the iso-heptane molecules generated by dehydrogenation on the platinum sites. Thus, these alkenes will be oligomerated to produce the cyclic products. It can be concluded that the acid and metal sites are not sufficiently well balanced to produce ideal bifunctional catalysts for $\mathrm{n}-\mathrm{C} 7$ conversion. The oligomers formed may be attributed to the formation of carbonaceous species on the catalyst surface, which contribute to the poisoning and/or blocking of the active centres. Thus, it is clear that good isomerisation activity is obtained when the hydrogenation activity of the metal $(\mathrm{Pt})$ and the Brønsted acid activity of the bifunctional catalyst are in balance. In comparison to the $1 \mathrm{wt} \% \mathrm{Pt} / \gamma-\mathrm{Al}_{2} \mathrm{O}_{3}$ catalyst, the $1 \mathrm{wt} \%$ Pt/Al-SBA-15 and $1 \mathrm{wt} \% \mathrm{Pt} / \mathrm{Al}-\mathrm{MCM}-48$ produced smaller quantities of cracked products, probably due to their effectively greater Pt dispersion.

The maximum coke content for the $1 \mathrm{wt} \% \mathrm{Pt} / \mathrm{Al}-\mathrm{SBA}-$ 15 catalyst was found to be $0.49,0.72$, and $0.70 \mathrm{wt} \%$ in the top, middle and bottom reactor zones, respectively, while the minimum coke content for the $1 \mathrm{wt} \% \mathrm{Pt} / \gamma-\mathrm{Al}_{2} \mathrm{O}_{3}$ catalyst was found to be $0.36 \mathrm{wt} \%$, as revealed by TGA analysis. It can be clearly seen that the middle and bottom 


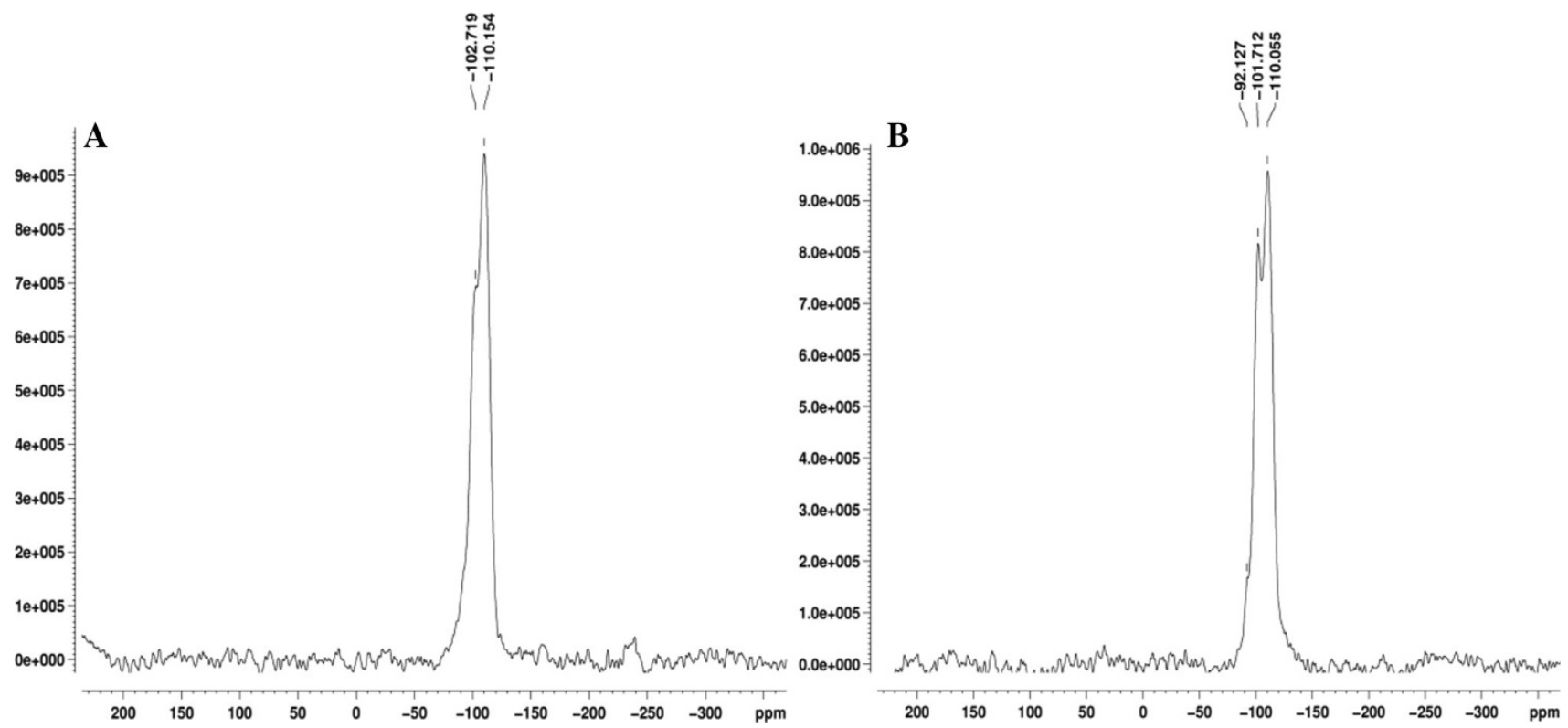

Fig. $34{ }^{29}$ Si MAS NMR spectra of Al-SBA-15 (a) and Al-MCM-48 (b)
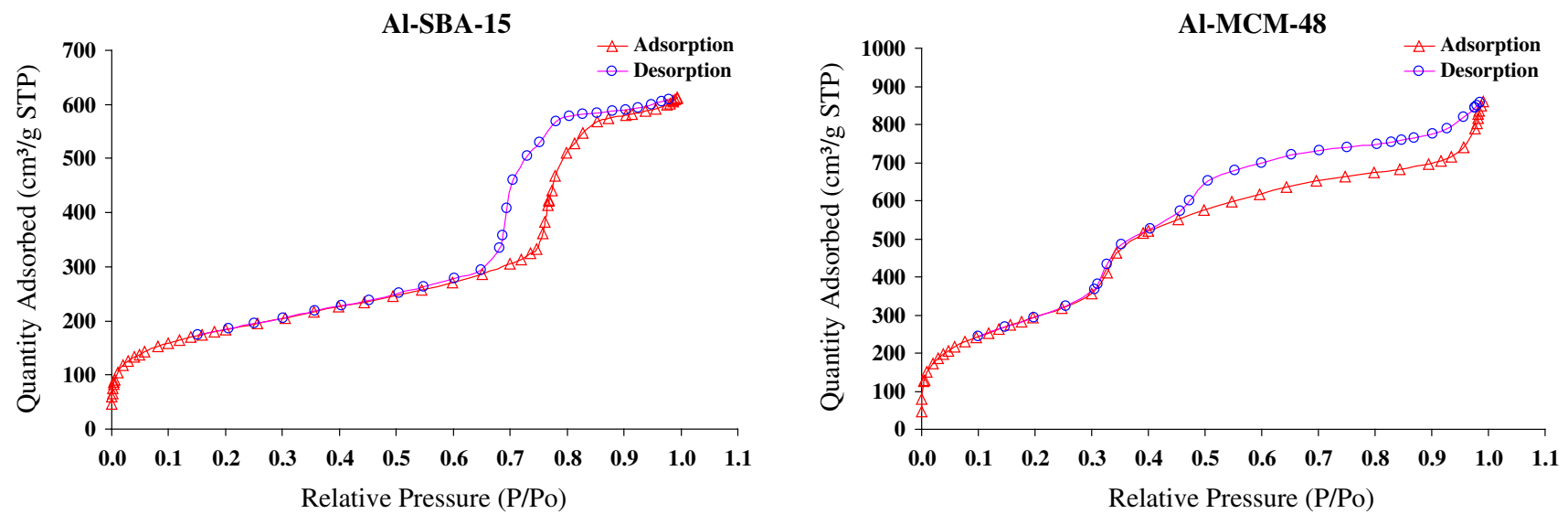

Fig. $35 \mathrm{~N}_{2}$ adsorption and desorption isotherms of Al-SBA-15 and Al-MCM-48

zones of $1 \mathrm{wt} \% \mathrm{Pt} / \mathrm{Al}-\mathrm{SBA}-15$ had the highest hard coke content in the catalyst bed, whereas there was slightly less coke in the top zone. This suggests that the middle and bottom zones of the catalyst bed contributed the most activity, where the reaction took place. In addition, the lower coke content in the top zone is to some extent indicative of the low acidity of this catalyst and the fact that no diffusion limitations were encountered with it, since such limitations would result in coking and would cause the top section of the bed to be coke rich.

\section{Conclusions}

There are many conclusions which can be drawn from this investigation of the deactivation of a range of commercial bifunctional nanoporous-based catalysts during the hydroisomerisation of normal heptane (n-C7) under identical reaction conditions. The main cause of deactivation of acid zeolite catalysts is generally coking, as coke compounds become trapped in the zeolite pores and can poison the acid sites or block their access:

- It has been shown that many different parameters control the stability of USY zeolites in the hydroisomerisation of $\mathrm{n}-\mathrm{C} 7$. Not only reaction conditions but also catalyst characteristics play the crucial roles.

- For most of the catalysts studied, total conversion increased dramatically as reaction temperature increased in the range of $210-270{ }^{\circ} \mathrm{C}$. However, the total selectivity of $\mathrm{C} 7$ isomers at lower temperatures was very high throughout the deactivation reaction at 

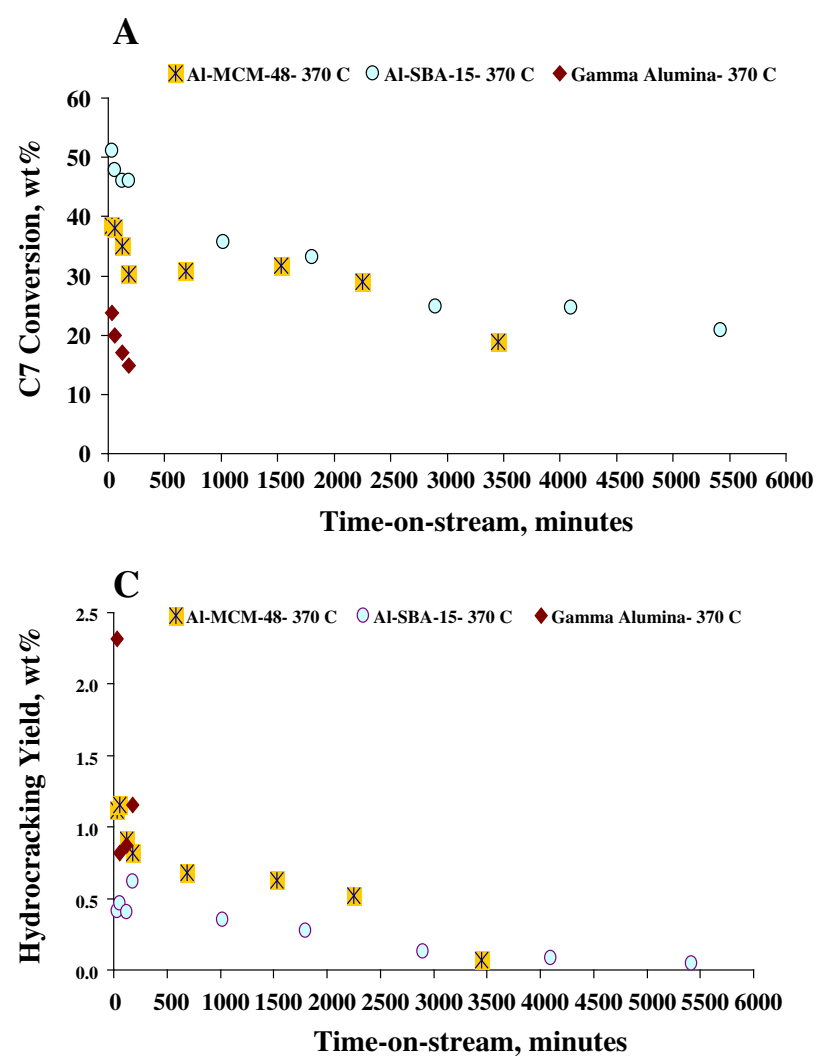

Fig. 36 Overall conversion (a), total yield of C7 isomers (mono $+\mathrm{di}+$ tribranched isomers) $(\mathbf{b})$, total hydrocracking yield (c) and total yield of the cyclic products (d) as a function of TOS for

210 and $230{ }^{\circ} \mathrm{C}$, taking advantage of the thermodynamic equilibrium.

- The selectivity of cracked products increased at the higher temperatures of 250 and $270{ }^{\circ} \mathrm{C}$ during the first few hours of the deactivation reaction and then decreased rapidly throughout the TOS. The selectivity of cyclic products was slightly higher at the lower temperatures of 210 and $230{ }^{\circ} \mathrm{C}$.

- Increasing pressure resulted in decreased overall conversion and slightly decreased selectivity to isomers with noticeable increased selectivity to the cyclic products, particularly at the lower temperatures of 210 and $230{ }^{\circ} \mathrm{C}$.

- There was no obvious cracking activity at the lower temperatures of 210 and $230{ }^{\circ} \mathrm{C}$, and constant WHSV as the reaction pressure changed, and in contrast there was increased selectivity towards the cracked product as the reaction pressure increased at the highest temperature of $270{ }^{\circ} \mathrm{C}$.

- The total conversion increased as the contact time increased at constant temperature and pressure. However, increasing the contact time between the $\mathrm{n}-\mathrm{C} 7$ feed and the catalyst seems to cause an increase in cracking selectivity.
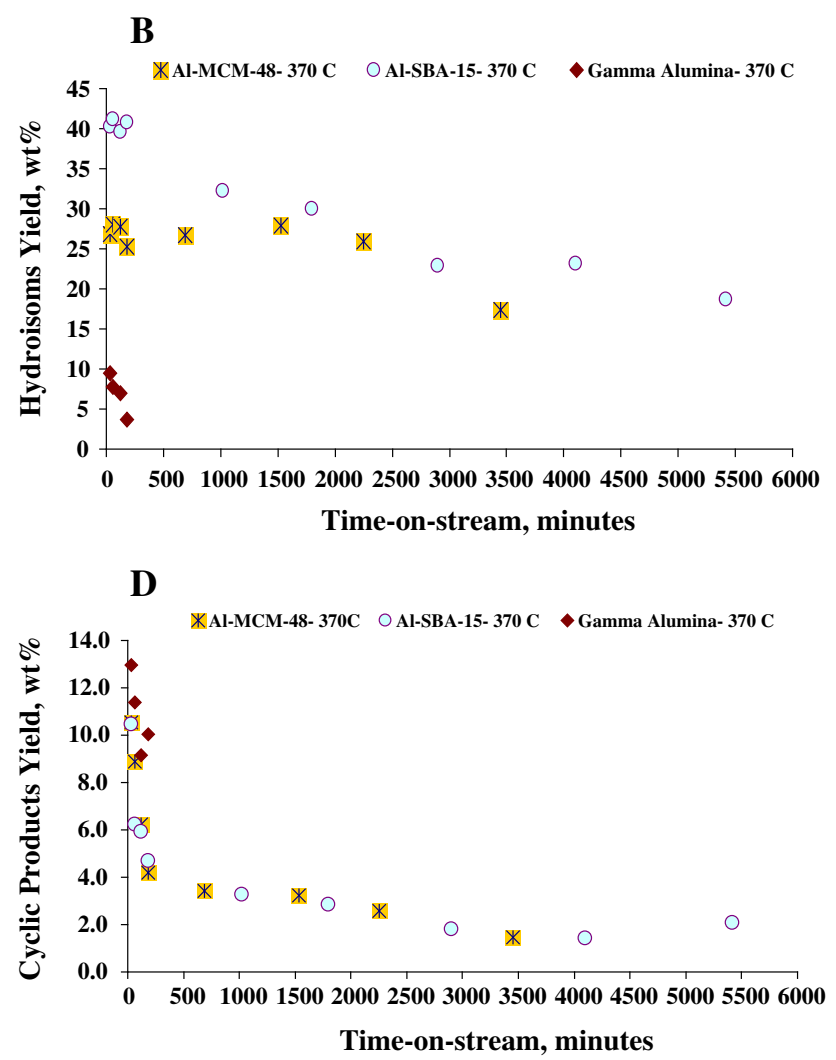

the Al-SBA-15, Al-MCM-48 and $\gamma$-alumina catalysts. $\mathrm{WHSV}=5.13 \mathrm{~h}^{-1} ; \mathrm{H}_{2} / \mathrm{C} 7(\mathrm{~mol} / \mathrm{mol})=9 ;$ total pressure $=1 \mathrm{~atm}$; temperature $=370{ }^{\circ} \mathrm{C} ; 1 \mathrm{wt} \% \mathrm{Pt}$ loading

- Zeolite Y commercial catalysts that were generated by steaming at different levels of severity behaved very differently to each other and to acid-leached commercial catalysts.

- USY zeolite pore structures which can inhibit coke formation in conjunction with careful dealumination to decrease the number of acid sites are necessary for the development of time-stable reforming zeolite-based catalysts.

- There is a clear correlation between the obtained yield of the cracked products, which relates to the existence of the stronger acid sites and to the hard coke. Maximum hard coke values were found at $270{ }^{\circ} \mathrm{C}$.

- The balance between the number of Pt atoms and the number of acid sites plays an important role in determining the activity, selectivity and stability of the bifunctional catalyst. The greater the value of $n_{\mathrm{Pt}} / \mathrm{n}_{\mathrm{A}}$, the slower the coke formation and the higher the catalyst stability.

- Lower platinum dispersion may have resulted in the formation of a considerably greater quantity of coke.

- Lower acidity, hence less cracking activity, resulted in the catalyst being more stable against deactivation by coking, which is the case for zeolites with high $\mathrm{Si} / \mathrm{Al}$ ratios.

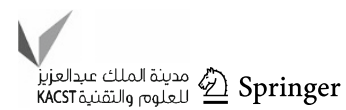


- High surface area and larger pore volume, due to the more severe dealumination process and acid leaching, reduced the hard coke content, thus slowing the deactivation rate.

- The AHFS acid-leached zeolite had a larger pore volume (smaller pore size and larger surface area), due to the alleviation of the obstruction by EFAL of the mesopore system, thus slowing the formation of coke and providing good catalytic stability.

- The higher Pt loading, up to $2 \mathrm{wt} \%$, improved catalytic stability, due to a better balance and closeness of the catalytic functions.

- Pt-Ni bimetallic catalysts were better than monometallic catalysts containing only $\mathrm{Ni}$ because they had higher activity, better selectivity for C7 isomers and more stability. The presence of platinum in the bimetallic catalysts improved the formation of metal particles to a great extent and reduced their sizes, while enhancing the reduction of nickel.

- The best method to introduce the platinum into the beta zeolite pores was found to be the ion-exchange method at $\mathrm{pH}>9$ which achieved a better metal/acid balance, lower cracking activity, and relatively good metal dispersion.

- The metal functions deactivated faster than the acid functions for all the catalysts loaded with platinum, irrespective of the method used. However, this was not sufficiently severe to cause a drop in $\mathrm{n}-\mathrm{C} 7$ conversion due to the unique channel system and pore structure of beta zeolite.

- The TOS behaviour of USY zeolites can be enhanced by forming composite catalysts of USY and beta zeolite, providing a unique pore structure and acidity to improve their TOS stability.

- The metal function deactivated faster than the acid function in all the composite catalysts but did not cause a severe drop in $\mathrm{n}-\mathrm{C} 7$ conversion, indicating that the composite zeolite pore structure plays a very important role in the conversion, and an appropriate combination of the pore structure and acidity showed superior TOS behaviour.

- Although the composite catalyst offers a highest acidity compared to the corresponding individual catalysts; coking is moderate and as such the TOS stability is reasonable.

- Synthesis parameters greatly affect mordenite morphology in terms of the size and aspect ratio of the mordenite crystals, so a range of mordenite morphologies were obtained for a variety of catalysts, both inhouse and commercial. Each catalyst had different diffusion and porosity properties; therefore, performance differed among them.
- The framework aluminium was removed to extraframework positions as a result of steam dealumination as well as giving the final in-framework $\mathrm{Si} / \mathrm{Al}$ ratio. On the other hand, acid leaching resulted in samples that were practically free of EFAL, which in turn led to the formation of aluminium gradients along the zeolite crystallites. A more uniform aluminium distribution was achieved by steam treatment.

- The main factors controlling catalyst stability and selectivity were pore topology, acid strength, acid site density and location of the acid sites. The crucial feature for coke formation was the pore topology of the catalyst.

- The synthesis method of mesoporous materials and the post-alumination process applied significantly affect the number and strength of acid sites and thereby their catalytic activity, selectivity and stability.

- As the mesoporous molecular sieves present very high total surface area and large pore size, this may depress the TOF, causing the olefins (alkenes) produced during the dehydrogenation of alkanes on the metal sites to have less interaction with the acid sites on which they can be hydrogenated to give their relevant isomers. Thus, the alkenes will be oligomerated to produce the cyclic products, which may be attributed to the formation of carbonaceous species on the catalyst surface, contributing to the poisoning and/or blocking of the active centres.

Acknowledgments I would like to thank Dr. Patrick Hill (Manchester University) for his help in carrying out the SEM analysis, Dr. Vladimir Zholobenk (Keele University) who kindly provided the FTIR technique, Dr. Christopher Muryn (Manchester University) for his help in performing the XRD analyses, Professor Michael Anderson and Dr. Barbara Gore (Manchester University), who kindly provided the NMR technique, Mr. Martin Jennings (Manchester University) for his help with the elemental analysis and Mr. David Gordon (Manchester University) for his cooperation in making the glass reactor.

Open Access This article is distributed under the terms of the Creative Commons Attribution License which permits any use, distribution, and reproduction in any medium, provided the original author(s) and the source are credited.

\section{References}

1. Guisnet M, Ribeiro FR (2011) Deactivation and regeneration of zeolite catalysts. Imperial College Press, London

2. Bartholomew CH (2003) Catalyst deactivation and regeneration. In: Kirk-Othmer encyclopedia of chemical technology. Wiley, London

3. Zhang W, Smirniotis PG (1999) On the exceptional time-onstream stability of HZSM-12 zeolite: relation between zeolite pore structure and activity. Catal Lett 60:223-228 
4. Stöcker M (2005) Gas phase catalysis by zeolites. Microporous Mesoporous Mater 82:257-292

5. Gopal S, Smirniotis PG (2004) Factors affecting isomer yield for $n$-heptane hydroisomerization over as-synthesized and dealuminated zeolite catalysts loaded with platinum. J Catal 225:278-287

6. Kuznetsov PN (2003) Study of $n$-octane hydrocracking and hydroisomerization over $\mathrm{Pt} / \mathrm{HY}$ zeolites using the reactors of different configurations. J Catal 218:12-23

7. Villegas JI, Kumar N, Heikkila T, Smieskova A, Hudec P, Salmi T, Murzin DY (2005) A highly stable and selective Pt-modified mordenite catalyst for the skeletal isomerization of $\mathrm{n}$ butane. Appl Catal 284:223-230

8. McDaniel CW, Maher PK (1968) New ultrastable form of faujasite. In: Molecular sieves. London: Soc Chem Ind, pp 86-194

9. Van Laak ANC, Sagala SL, Zečević J, Friedrich H, de Jongh PE, de Jong KP (2010) Mesoporous mordenites obtained by sequential acid and alkaline treatments - catalysts for cumene production with enhanced accessibility. J Catal 276:170-180

10. Moushey DL (2006) Formation of mesoporosity in zeolite and mesoporous molecular sieve structures through use of carbon as a secondary templating agent. Dissertation, University of Cincinnati, USA

11. Logar NZ, Kaucic V (2006) Nanoporous materials: from catalysis and hydrogen storage to wastewater treatment. Acta Chim Slov 53:117-135

12. Corma A (1997) From microporous to mesoporous molecular sieve materials and their use in catalysis. Chem Rev 97:2373-2419

13. Pinnavaia TJ, Liu Y (2002) Aluminosilicate mesostructures with improved acidity and hydrothermal stability. J Mater Chem 12:3179-3190

14. Zeolyst International, http://www.zeolyst.com/our-products/standardzeolite-powders/zeolite-y.aspx. Accessed 29 May 2011

15. Tosoh Corporation, http://www.tosoh.com/Products/tcdzeo.htm\# hzc. Accessed 26 June 2011

16. Rawlence DJ, Earl, GJ (1993) Materials having novel structure factors for catalysis of hydrocarbon transformation and development of selective processes. BRITE-EURAM 4633, 5th Meeting Report, Elf Solaize

17. Abudawood R, Alotaibi F, Garforth A (2011) Hydroisomerization of $n$-heptane over Pt-loaded USY zeolites. Effect of steaming, dealumination and the resulting structure on catalytic properties. Ind Eng Chem Res 50:9918-9924

18. Abudawood R (2010) Hydroisomerization of alkanes over metalloaded zeolite catalysts. Dissertation, University of Manchester

19. Alotaibi F (2011) Comparative study of the time-on-stream stability of bifunctional nanoporous-based catalysts in $n$-heptane hydroisomerisation. Dissertation, University of Manchester

20. Claytec, Inc., http://claytecinc.com/products. Accessed 29 May 2011

21. Robson H, Lillerud KP (2001) Verified Syntheses of zeolitic materials, 2nd edn. Elsevier, Amsterdam

22. Weitkamp J, Puppe L (1999) Catalysis and zeolites. Springer, Berlin

23. Wang QL, Torrealba M, Giannetto G, Guisnet M, Perot G, Cahoreau M, Caisso J (1990) Dealumination of Y zeolite with ammonium hexafluorosilicate: a SIM-XPS study of the aluminium distribution. Zeolites 10:703-706

24. Wang QL, Giannetto G, Torreaaba M, Perot G, Kappenstein C, Guisnet M (1991) Dealumination of zeolites: II. Kinetic study of the dealumination by hydrothermal treatment of a NH4NaY zeolite. J Catal 130:459-470

25. Wang QL, Giannetto G, Guisnet M (1991) Dealumination of zeolites: III. Effect of extra-framework aluminum species on the activity, selectivity, and stability of $\mathrm{Y}$ zeolites in $n$-heptane cracking. J Catal 130:471-482
26. Remy MJ, Stanica D, Poncelet G, Feijen EJP, Grobet PJ, Martens JA, Jacobs PA (1996) Dealuminated H-Y zeolites: relation between physicochemical properties and catalytic activity in heptane and decane isomerization. J Phys Chem 100:12440-12447

27. Van Bekkum H, Flanigen EM, Jacobs PA, Jansen JC (2001) Introduction to zeolite science and practice, 2nd edn. Elsevier, Amsterdam, pp 261-288

28. Roussel ML, emberton J, Guisnet M, Cseri T, Benazzi E (2003) Mechanisms of $n$-decane hydrocracking on a sulfided NiW on silica-alumina catalyst. J Catal 218: 427-437

29. Guerin M, Kappenstein C, Alvarez F, Giannetto G, Guisnet M (1988) Preparation of PtHY catalysts: influence on the catalytic properties of the complexes used as platinum precursors. Appl Catal 45:325-333

30. Martins A, Silva JM, Ribeiro FR, Ribeiro MF (2006) Hydroisomerization of $n$-hexane over Pt-Ni/HBEA using catalysts prepared by different methods. Catal Lett 109(1-2):83-87

31. Alotaibi F, Abudawood R, Al-Megren H, Al-Kinany H, Garforth A (2013) The time-on-stream stability of some selected bifunctional nanoporous-based catalysts in $n$-heptane hydroisomerisation. J Appl Petrochem Res (submitted)

32. Chao K, Lin C, Lin C, Wu H, Tseng C, Chen S (2000) $n$-Heptane hydroconversion on platinum-loaded mordenite and beta zeolites: the effect of reaction pressure. Appl Catal A 203:211-220

33. Tran MT, Gnep NS, Szabo G, Guisnet M (1998) Isomerization of $n$-butane over $\mathrm{H}$-mordenites under nitrogen and hydrogen: influence of the acid site density. J Catal 174:185-190

34. Guisnet M, Fouche V (1991) Isomerization of $n$-hexane on platinum dealuminated mordenite catalysts: I. Influence of the silicon-to-aluminium ratio of the zeolite. Appl Catal 71:283-293

35. Wang ZB, Kamo A, Yoneda T, Komatsu T, Yashima T (1997) Isomerization of $n$-heptane over Pt-loaded zeolite $\beta$ catalysts. Appl Catal 159:119-132

36. Chica A, Corma A (1999) Hydroisomerization of pentane, hexane, and heptane for improving the octane number of gasoline. J Catal 187:167-176

37. Lónyi F, Lunsford JH (1992) The development of strong acidity in hexafluorosilicate-modified Y-type zeolites. J Catal 136:566-577

38. Cruz JM, Corma A, Fornes V (1989) Framework and extraframework aluminum distribution in $\left(\mathrm{NH}_{4}\right)_{2} \mathrm{~F}_{6}$ Si-dealuminated Y-zeolites-relevance to cracking catalysts. Appl Catal 50:287-293

39. Gola A, Rebours B, Milazzo E, Lynch J, Benazzi E, Lacombe S, Delevoye L, Fernandez C (2000) Effect of leaching agent in the dealumination of stabilized Y zeolites. Microporous Mesoporous Mater 40:73-83

40. Jordao MH, Valencia E, Vicemario S, Dilson C (1999) Characterization of Pt/HUSY and Pt-Ni/HUSY catalysts by transmission electron microscopy. Mate Res 2:219-223

41. Karthikeyan D, Lingappan N, Sivasankar B (2008) Hydroisomerization of $n$-octane over bifunctional Ni-Pd/HY zeolite catalysts. Ind Eng Chem Res 47:6538-6546

42. Barsi FV, Cardoso D (2009) Bimetallic Pt-Ni catalysts supported on USY zeolite for $n$-hexane isomerization. Braz J Chem Eng 26-2:353-360

43. Roldán R, Beale AM, Sánchez-Sánchez M, Romero-Salguero FJ, Jiménez-Sanchidrián C, Gómez JP, Sankar G (2008) Effect of the impregnation order on the nature of metal particles of bi-functional Pt/Pd-supported zeolite beta materials and on their catalytic activity for the hydroisomerization of alkanes. J Catal 254:12-26

44. Eswaramoorthi I, Lingappan N (2003) Ni-Pt/H-Y zeolite catalysts for hydroisomerization of $n$-hexane and $n$-heptane. Catal Lett 87(3-4):133-142

45. Kampers FWH, Engelen CWR, van Hoof JHC, Konigsberger DC (1990) Influence of preparation method on the metal cluster size 
of platinum/ZSM-5 catalysts as studied with EXAFS. J Phys Chem 94(23):8574-8578

46. Changlei J, Bo M, Xiwen Z, Fengxiang L, Zhizhi Z, Bo Q (2008) Catalytic performance of $\mathrm{Pt} / \mathrm{HY}-\beta$ in $n$-octane hydroisomerization. Petrol Sci 6:299-305

47. Smirniotis PG, Davydov L, Ruckenstein E (1999) Composite zeolite-based catalysts and sorbents. Catal Rev 41:43-113

48. Hamidi F, Bengueddach A, Di Renzo F, Fajula F (2003) Control of crystal size and morphology of mordenite. Catal Lett 87:149-152

49. Treacy MMJ, Higgins JB (2001) Collection of simulated XRD powder patterns for zeolites. Elsevier, Amsterdam

50. Janssen AH, Koster AJ, de Jong KP (2001) Three-dimensional transmission electron microscopy observations of mesopores in dealuminated zeolite Y. Angew Chem Int Ed 40:1102-1104

51. Van Donk S, Janssen AH, Bitter JH, de Jong KP (2003) Generation, characterization, and impact of mesopores in zeolite catalysts. Catal Rev 45:297-319

52. Janssen AH, Koster AJ, de Jong KP (2002) On the shape of the mesopores in zeolite Y: a three-dimensional transmission electron microscopy study combined with texture analysis. J Phys Chem 106:11905-11909

53. Lee JK, Rhee HK (1997) Characteristics of Pt/H-beta and Pt/Hmordenite catalysts for the isomerization of $n$-hexane. Catal Today 38:235-242
54. Van Donk S (2002) Adsorption, diffusion and reaction studies of hydrocarbons on zeolite catalysts. PhD Dissertation, Utrecht University, Netherlands

55. Chica A, Corma A, Miguel PJ (2001) Isomerization of C5-C7nalkanes on unidirectional large pore zeolites: activity, selectivity and adsorption features. Catal Today 65:101-110

56. Nie C, Huang L, Zhao D, Li Q (2001) Performance of Pt/AlSBA-15 catalysts in hydroisomerization of $n$-dodecane. Catal Lett 71:117-125

57. Beck JS, Vartuli JC, Roth WJ, Leonowicz ME, Kresge CT, Schmitt KD, Chu CTW, Olson DH, Sheppard EW (1992) A new family of mesoporous molecular sieves prepared with liquid crystal templates. J Am Chem Soc 114:10834-10843

58. Eimer GA, Pierella LB, Monti GA, Anunziata OA (2002) Synthesis and characterization of Al-MCM-41 and Al-MCM-48 mesoporous materials. Catal Lett 78:65-75

59. Gregg SJ, Sing KSW (1982) Adsorption, surface area and porosity. Academic Press, London

60. Chaudhari K, Das TK, Chandwadkar AJ, Sivasanker S (1999) Mesoporous aluminosilicate of the MCM-41 type: its catalytic activity in $n$-hexane isomerization. J Catal 186:81-90

61. Chaudhari K (2000) Synthesis, characterization and catalytic properties of mesoporous molecular sieves. $\mathrm{PhD}$ Thesis, Catalysis Division, National Chemical Laboratory, Pune 